\title{
Insights into Theranostic Properties of Titanium Dioxide for Nanomedicine
}

Cite as

Nano-Micro Lett.

(2020) 12:22

Received: 1 October 2019

Accepted: 8 December 2019

Published online: 14 January 2020

(C) The Author(s) 2020

\author{
Morteza Hasanzadeh Kafshgari ${ }^{1 凶}$, Wolfgang H. Goldmann ${ }^{\square}$ \\ $\bowtie$ Morteza Hasanzadeh Kafshgari, morteza.kafshgari@polymtl.ca; Wolfgang H. Goldmann, \\ wgoldmann@biomed.uni-erlangen.de \\ 1 Department of Engineering Physics, Polytechnique Montreál, Montreal, QC H3C3A7, Canada \\ 2 Department of Physics, Biophysics Group, University of Erlangen-Nuremberg, 91052 Erlangen, Germany
}

\section{HIGHLIGHTS}

- Multifunctional $\mathrm{TiO}_{2}$ nanostructures hold promise for advancing a wide range of biomedical applications due to a feasible integration of distinct theranostic features.

- Fabrication and post-fabrication strategies implemented to generate multifunctional $\mathrm{TiO}_{2}$ nanostructures for a broad range of biomedical applications are briefly outlined. The opportunities and challenges of $\mathrm{TiO}_{2}$ nanomaterials are highlighted in order to open the possibility of clinical translation.

\section{ABSTRACT Titanium dioxide $\left(\mathrm{TiO}_{2}\right)$ nanostructures exhibit a broad range of theranostic properties that make them attractive for biomedi- cal applications. $\mathrm{TiO}_{2}$ nanostruc- tures promise to improve current theranostic strategies by leveraging the enhanced quantum confinement, thermal conversion, specific surface area, and surface activity. This review highlights certain important aspects of fabrication strategies, which are employed to generate multifunctional $\mathrm{TiO}_{2}$ nanostructures, while outlining post-fabrication techniques with an}

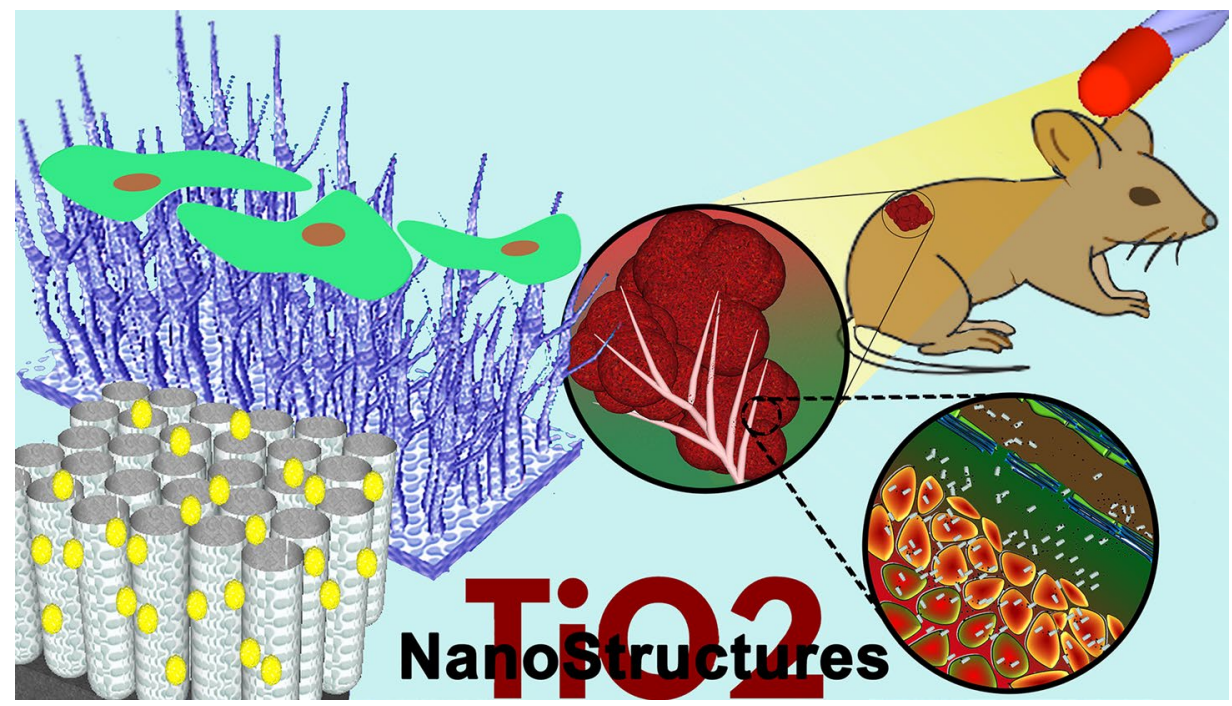
emphasis on their suitability for nanomedicine. The biodistribution, toxicity, biocompatibility, cellular adhesion, and endocytosis of these nanostructures, when exposed to biological microenvironments, are examined in regard to their geometry, size, and surface chemistry. The final section focuses on recent biomedical applications of $\mathrm{TiO}_{2}$ nanostructures, specifically evaluating therapeutic delivery, photodynamic and sonodynamic therapy, bioimaging, biosensing, tissue regeneration, as well as chronic wound healing.

KEYWORDS $\mathrm{TiO}_{2}$ nanostructures; Drug delivery systems; Bioimaging; Biosensing; Tissue regeneration 


\section{Introduction}

Titanium dioxide $\left(\mathrm{TiO}_{2}\right)$ bulk materials are often employed in medical applications and devices, including implants, facial cosmetic surgeries, cardiovascular devices, external prostheses, as well as surgical instruments. When approaching nanoscale dimensions of bulk $\mathrm{TiO}_{2}$, quantum confinement occurs over superfine pieces and introduces new physical, mechanical, optical, and electronic properties [1, 2]. Compared to conventional bulk materials, $\mathrm{TiO}_{2}$ nanostructures (NSs), developed in different morphologies (i.e., sphere, tube, cylinder, fiber, sheet, whisker, wire, and rod) through feasible and reproducible fabrication strategies, have been employed in a wide range of leading-edge biomedical applications [2-6]. These efforts, for example, have resulted in enhancing drug delivery systems through the fabrication of porous $\mathrm{TiO}_{2}$ nanocarriers due to a huge surface-to-volume ratio, which can enlarge the therapeutic loading capacity [7-9]. The performance of $\mathrm{TiO}_{2}$ nanomaterials in biomedical applications can also depend on nanoscale morphologies and their specific properties. Besides their improved surface area, one-dimensional $\mathrm{TiO}_{2}$ nanocarriers designed to adhere more on the vascular endothelium compared to spherical nanoparticles at the tumor microenvironment, have ameliorated the cellular uptake and intracellular therapeutic delivery $[10,11]$. To achieve the best performance, the fabrication of $\mathrm{TiO}_{2}$ nanomaterials with a well-designed composition, morphology, crystalline structure, and integration is an advantage.

Besides their intrinsic properties, an elaborated surface modification, such as a harmless doping, deposition, and biomolecule conjugation, can completely generate unique $\mathrm{TiO}_{2}$ nanomaterials with a specific biomedical applicationoriented feature. The possibility of a thermal hydrogenation generating black $\mathrm{TiO}_{2}$ nanomaterials, a thermal oxidization altering crystalline structure or even a solvothermal method fabricating mesoporous $\mathrm{TiO}_{2}$ popcorn particles, can boost the photocatalyst activity compared to other nanomaterials (i.e., based on carbon or silicon) for photodynamic therapy [12-16]. Compared to other nanomaterials, $\mathrm{TiO}_{2} \mathrm{NSs}$ can also be easily modified to become thermo-, $\mathrm{pH}-, \mathrm{X}$-ray-, and ultraviolet (UV)-responsive nanocarriers to advance drug delivery systems and eliminate such side effects of conventional chemotherapy $[8,10,17-20]$. In addition, accumulation of $\mathrm{TiO}_{2}$ nanomaterials at target tissues in the body can be become improved through a conjugation of biomolecules (i.e., folic acid and antibody) and deposition of iron oxide nanomaterials (i.e., magnetically guided therapeutic delivery) $[8,12,21]$. Biodistribution and accumulation of bare and surface-modified $\mathrm{TiO}_{2}$ nanomaterials in the body can also be visualized and verified using a magnetic resonance imaging (MRI) and fluorescence-based microscopy to accurately detect the target tissue prior to therapy in order to minimize side effects [22-25].

The detection (e.g., of circulating cancer cells and pathogens), as well as small biomolecules in clinical blood samples, has been advanced through the use of $\mathrm{TiO}_{2}$ platforms (i.e., label-free microfluidic immunosensors, photoelectrochemical biosensors, field-effect transistors, and amperometrics) [26-30]. To improve the detection performance, the band gap engineering of $\mathrm{TiO}_{2} \mathrm{NSs}$ using a simple doping or deposition process is highly feasible and efficient compared to other nanoplatforms [31, 32]. Therefore, reusable and high-precision biosensors are highly likely to enter the market with the aid of enhanced cost-effective $\mathrm{TiO}_{2}$ nanomaterials, which possess a wide band gap and high surface activity [2, 29].

$\mathrm{TiO}_{2}$ nanomaterials are biocompatible and less toxic than other nanomaterials (i.e., copper oxide, zinc oxide, and manganese oxide) [33, 34]. The long-term stability of $\mathrm{TiO}_{2}$ nanomaterials in biological conditions is another advantage that can protect the loaded biomolecules from denaturation in comparison to other unstable (degradable) nanomaterials in an aqueous solution (i.e., a fast dissolution of silicon-based nanomaterials can quickly disassociate and release the loaded therapeutics) [19]. Besides their biocompatibility and stability, $\mathrm{TiO}_{2} \mathrm{NSs}$ are also well known for tissue regeneration owing to high tensile strength, flexibility, corrosion resistance, as well as cellular adherence and proliferation [35-38]. Moreover, the photocatalytic activity of $\mathrm{TiO}_{2}$ nanomaterials is another advantage used to fight against antibiotic resistant bacteria in order to accelerate chronic wound healing by enhancing cellular adhesion and proliferation $[39,40]$.

In this review, we re-examine advanced strategies for the formation of $\mathrm{TiO}_{2}$ nanomaterials and present a summary of post-fabrication and surface chemistry approaches developed to generate elaborated $\mathrm{TiO}_{2}$ nanoplatforms for a broad range of biomedical applications. We briefly discuss biological responses following the administration of bare and 
surface-modified $\mathrm{TiO}_{2}$ nanomaterials in vitro and in vivo to highlight possible induced cytotoxicities and inflammations. We further delineate recent research achievements in therapy, diagnostic biosensing, tissue regeneration, and wound healing in vitro and in vivo, and pay attention to the developed $\mathrm{TiO}_{2}$ nanoplatforms for biomedical applications and address opportunities to initiate next-generation technologies and cutting-edge nanoscale devices.

\section{Fabrication of $\mathrm{TiO}_{2} \mathrm{NSs}$}

The fabrication of $\mathrm{TiO}_{2} \mathrm{NSs}$ can be broadly classified as bottom-up (an individual element progresses through homogeneous nucleation and growth) and top-down processes (the successive fragmentation of a bulk material into a series of nanoscale structures) [1-3]. The most common $\mathrm{TiO}_{2} \mathrm{NSs}$ (listed below) can be fabricated by both bottom-up and topdown strategies to introduce a specific theranostic feature for biomedical applications. Strategies are summarized in this section that overviews the development of mono- and multifunctional $\mathrm{TiO}_{2} \mathrm{NSs}$ for nanomedicine.

\subsection{Nanoparticles}

$\mathrm{TiO}_{2}$ nanoparticles are the most common NSs widely employed for nanomedicine. An inexpensive mass production of pharmaceutical $\mathrm{TiO}_{2}$ nanoparticles with a narrow size distribution, adjustable polymorphism, and surface property can feasibly accelerate their use for biomedical applications such as therapeutic delivery and diagnosis [41]. Bottom-up techniques, including sono-chemical strategies, hydrothermal approaches, microwave processes, chemical/physical vapor deposition, microemulsion, and sol-gel techniques, have been mostly applied to generate narrow-sized $\mathrm{TiO}_{2}$ nanoparticles with a flexible surface chemistry in comparison to the top-down processes [1, 41, 42].

For therapeutic delivery, the formation of nanoscale $\mathrm{TiO}_{2}$ with a high surface area (i.e., $587.7 \mathrm{~m}^{2} \mathrm{~g}^{-1}$ for particles $9 \mathrm{~nm}$ in diameter [43]) and porous structure are the compulsory properties [44]. Inducing porosity within the structure of $\mathrm{TiO}_{2}$ nanoparticles can increase the specific surface area. An adjustable pore size from a couple of nanometers to a few nanometers is beneficial for packing a wide range of therapeutic agents [45]. For example, mesoporous $\mathrm{TiO}_{2}$ nanoparticles were prepared through a surfactant-assisted hydrometallurgical procedure of ilmenite concentrate, and the pore size of the porous particles (around 30-60 nm in diameter) could be varied from 2 to $12 \mathrm{~nm}$ [46].

Multifunctional nanoparticles, which are employed in targeted drug delivery systems and photodynamic therapy, are the most common structure developed in this category. Multifunctional $\mathrm{TiO}_{2}$ nanoparticles with a magnetic core are a favorite nanohybrid for implanting a wide range of theranostic features, which include magnetic-guided and triggered therapeutic delivery systems [47, 48]. For example, mesoporous $\mathrm{TiO}_{2}$-coated $\mathrm{Fe}_{3} \mathrm{O}_{4}$ nanoparticles have recently been developed through a combined fabrication strategy, i.e., the solvent thermal method to generate an amino-functional magnetic core and homogeneous precipitation of $\mathrm{TiOSO}_{4}$ to form a porous shell [48]. To generate hollow $\mathrm{TiO}_{2}$ nanoparticles, fabrication of iron oxide $\mathrm{TiO}_{2}$ core-shell nanocomposites is an advantage due to the easy removal of the magnetic core within the process. As shown in Fig. 1a, a homogeneous deposition of anatase $\mathrm{TiO}_{2}$ onto $\alpha-\mathrm{Fe}_{2} \mathrm{O}_{3}$ nanotemplates forms core-shell nanoparticles, and a subsequent etching procedure $\left(\mathrm{HCl} 0.2 \mathrm{M}\right.$ at $100{ }^{\circ} \mathrm{C}$ for 6-24 h) removes the core template, resulting in a hollow structure [49]. A wide range of multifunctional nanoparticles can also be produced through the combination of a couple of approaches, including the template-assisted technique and hydrothermal strategy for providing an individual crystalline phase, polymorphism, size distribution, and porosity in situ [50, 51]. Multifunctional polypyrrole-coated mesoporous $\mathrm{TiO}_{2}$ nanocomposites, for example, can be fabricated through pre-hydrolysis of titanium precursors combined with the solvothermal treatment strategy for photothermal, sonodynamic, and chemotherapeutic treatments and dualmodal ultrasound/photoacoustic imaging of tumors [7, 52].

\subsection{Nanowires and Nanorods}

One-dimensional (1D) $\mathrm{TiO}_{2}$ nanowires and nanorods are one of the powerful platforms that play a critical role in capturing and transmitting the biological responses at the interface required for the development (e.g., of ultrasensitive detection devices) [53,54]. $1 \mathrm{D} \mathrm{TiO}_{2}$ nanowires and nanorods have been synthesized by means of templateassisted methods and solution- or vapor-based approaches. Among these approaches, solution-based fabrication of 

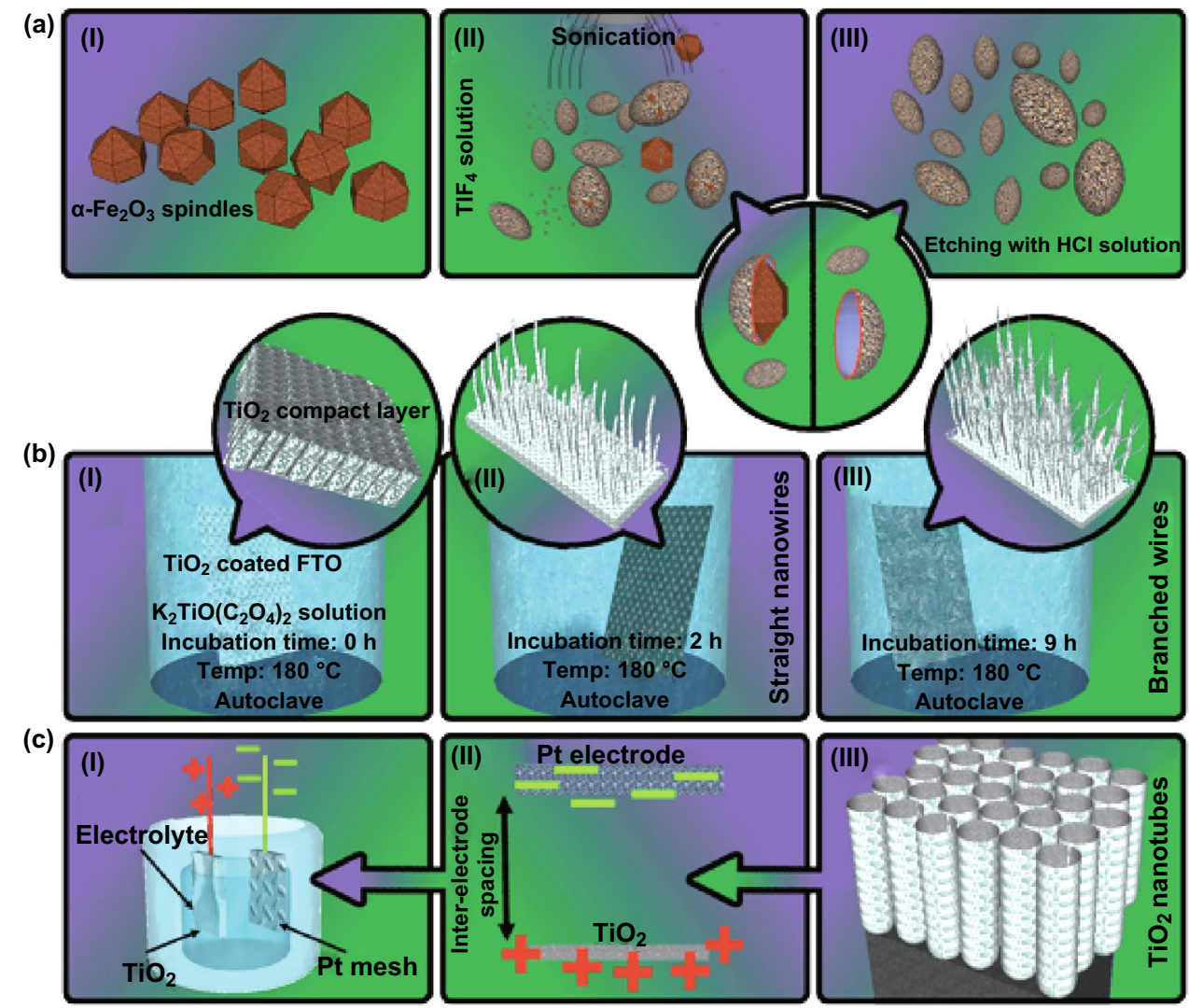

Fig. 1 Simplified schematic representation of fabrication techniques for $\mathrm{TiO}_{2}$ nanomaterials. a Non-spherical, hollow, and magnetically loaded particles fabricated through a template-assisted, bottom-up strategy. Adapted from Ref. [49] with permission from the John Wiley \& Sons. b The hydrothermal approach is one of the bottom-up strategies for the fabrication of a wide range of one-dimensional $\mathrm{TiO}_{2} \mathrm{NSs} \mathrm{The}^{\mathrm{TiO}} \mathrm{P}_{2}$ precursor, temperature, and incubation time determine the final nanostructure. Adapted from Ref. [55] with permission from the Springer Nature. c Wellaligned and ordered $\mathrm{TiO}_{2}$ nanotubes can be fabricated through a top-down strategy based on electrochemical anodization. Adapted from Ref. [74] with permission from the American Chemical Society

$\mathrm{TiO}_{2}$ nanowires and nanorods is well known due to an easy mass production and desirable growth length and properties. Generation of a supercritical fluid at a specific temperature and pressure dissolves almost all solid $\mathrm{TiO}_{2}$ precursors, followed by a precipitation process to form nanowires or nanorods [2]. $\mathrm{TiO}_{2}$ nanowire arrays can be generated using a substrate precoated with $\mathrm{TiO}_{2}$ nanoparticles via the hydrothermal method [55]. To grow long $\mathrm{TiO}_{2}$ nanowire trunks with numerous short nanorod branches by a surfactant-free procedure, a mixed homogeneous solution $\left(\mathrm{K}_{2} \mathrm{TiO}\left(\mathrm{C}_{2} \mathrm{O}_{4}\right)\right.$, diethylene glycol and water) can be initially poured into a Teflon-lined stainless steel autoclave with FTO glass and then heated up to $180{ }^{\circ} \mathrm{C}$ using a hydrothermal method for 1-12 h (Fig. 1b).
The fabrication of branch-type $\mathrm{TiO}_{2}$ nanowires, whether anatase or rutile, can also be created by hydrothermal processes [2]. The mechanisms involved in the fast growth of one-dimensional $\mathrm{TiO}_{2} \mathrm{NSs}$ through the self-assembly, require the crystal structure with superior anisotropic properties [56]. In the case of poor anisotropic $\mathrm{TiO}_{2}$, the self-assembly rate should be accelerated by introducing a precipitation interface, dislocation propagation direction, and higher constructive block concentrations [2]. The strategies and mechanisms involved in the fabrication of nanorods are largely similar to that of nanowires; however, nanorods are shorter while reflecting a smaller aspect ratio and rigid structure $[56,57]$. Rutile $\mathrm{TiO}_{2}$ nanorods can also be precisely fabricated by a hydrothermal method (at 
$180^{\circ} \mathrm{C}$ ) and controlled by adjusting the amount of $\mathrm{HCl}$ and ethanol during the reaction $[2,58]$.

\subsection{Nanofibers}

To fabricate ultrasensitive diagnostic devices (i.e., capturing cancer cells) or tissue regenerations, $\mathrm{TiO}_{2}$ nanofibers are one of the best candidates due to an improved local topographic interaction between the deposited nanofibers and extracellular matrix [59]. To produce long, fibrous nanomaterials, the electrospinning technique has been developed using a precursor, binder, and stabilizer [59]. Compared to the electrospinning strategy, other strategies, including self-assembly and template-assisted approaches, have proven unwieldy for the generation of $\mathrm{TiO}_{2}$ nanofibers [2]. Their diameter can mainly be altered by adjusting the diameter of the spin orifice, the conductivity, and the viscosity of the binding polymers as well as solvents $[60,61]$. Employing a volatile solvent and less of the binder can further facilitate the removal of any residual organic substances from the final nanofiber structures [60]. Fabrication of porous and hollow $\mathrm{TiO}_{2}$ nanofibers is also important for different biomedical applications such as bone regeneration. In this case, a polymeric sol-gel solution composed of $\mathrm{CaCO}_{3}$ and $\mathrm{TiO}_{2}$ precursor that flows through a coaxial nozzle electrospinning into a cross-linker solution, produces $\mathrm{CaCO}_{3} / \mathrm{TiO}_{2}$ nanofiber, and the subsequent etching of $\mathrm{CaCO}_{3}$ on the calcined $\mathrm{TiO}_{2}$ fibers using dilute $\mathrm{HCl}$ fabricates porous and hollow $\mathrm{TiO}_{2}$ nanofibers [9]. Moreover, highly porous $\mathrm{TiO}_{2}$ nanofibers with a surface area of about $128 \mathrm{~m}^{2} \mathrm{~g}^{-1}$ can be generated using an electrospinning under high humid environment without applying a secondary chemical process or removal of the glycerin component [62].

\subsection{Nanowhiskers}

Whiskers are one of crystalline materials with a distinct crystal anisotropy and possess high strength and fracture resistance close to the theoretical ultimate strength of a given material, whereas their size and length are smaller than short fibers. One-dimensional $\mathrm{TiO}_{2}$ nanowhiskers exhibit the highest photocatalytic efficiency due to a unique morphology and monocrystalline defect-free lattice structure in comparison to nanoparticles [5]. To produce $\mathrm{TiO}_{2}$ nanowhiskers, a reactant containing $\mathrm{TiO}_{2} / \mathrm{K}_{2} \mathrm{O}$ needs to be sintered at $810{ }^{\circ} \mathrm{C}$, and then, the interim product should undergo a wet grounding. The potassium-rich nanophase gradually forms during a long incubation of the interim product in water ( 7 days), and further $\mathrm{HCl}$ treatment and calcination generate a tetragonal crystal structure (anatase) $[4,5]$. Rutile $\mathrm{TiO}_{2}$ nanowhiskers with diameters of $\sim 10-50 \mathrm{~nm}$ and lengths of several micrometers can also be synthesized by annealing a precursor powder, in which $\mathrm{NaCl}$ and $\mathrm{Ti}(\mathrm{OH})_{4}$ particles (through an adjusted molar ratio) are homogeneously mixed [63].

\subsection{Nanotubes}

One-dimensional $\mathrm{TiO}_{2} \mathrm{NSs}$ offer specific properties, including quantum confinement effects, electron tunneling, as well as a high surface area, draw exclusive attention to biomedical applications (i.e., drug delivery systems and biosensors) [64]. A vast number of strategies, including electrochemical anodization and hydrothermal, sol-gel, and electrospinning methods, have been exploited to fabricate $\mathrm{TiO}_{2}$ nanotubes.

While the fabrication of $\mathrm{TiO}_{2}$ nanotubes through bottom-up processes may be complex, variable, and lowyield, a cylindrical structure accompanied by a pure crystalline phase can be achieved $[65,66]$. The self-organization of nanotubes through an alkaline treatment of $\mathrm{TiO}_{2}$ or titanium alkoxide powder can generate an anisotropic and open-end structure $[67,68]$. Conversely, the mechanism involved in the hydrothermal method initially forms nanosheets, and a subsequent neutralization step triggers a rolling procedure to generate $\mathrm{TiO}_{2}$ nanotubes. The hydrothermal method is cost-effective due to the unprocessed metallic titanium source; however, the high concentration of the alkaline solution can often lead to excessive intercalation, thus assembling disordered nanotubes [67].

To fabricate uniform and ordered $\mathrm{TiO}_{2}$ nanotubes, template-assisted methods as an interesting alternative can be employed by depositing titanium oxide components on the outer or inner wall of nanoporous templates; the former is called a positive template, and the latter a negative template [69]. In both cases, a uniform, cylindrical structure made of either soft or hard anisotropic templates, including anodic aluminum oxide membranes (consisting of an array of monodisperse pores), multi-walled carbon nanotubes, soft polymeric templates and well-ordered zinc 
oxide nanorod arrays, can be employed to fabricate wellordered $\mathrm{TiO}_{2}$ nanotubes [69-71]. The outer diameter and length of templates primarily determine the inner diameter and length of the final tubular structures, which can be open- or closed-ended [64]. Mesoporous $\mathrm{TiO}_{2}$ nanotubes can also be fabricated using a template-assisted method mediated with a sol-gel, followed by the calcination and template removal procedures $[2,45]$. Although the magnitude of the specific surface area generally depends on the tubes' length and diameter, features offered by mesoporous $\mathrm{TiO}_{2}$ nanotubes can be adjusted to the requirements of the specific biomedical application [45, 64]. Although template-assisted strategies certainly offer a wide variety of tubular structures and properties, their intractability restricts fine-tuning the final diameter, length, and order of $\mathrm{TiO}_{2}$ nanotubes.

To achieve well-ordered and well-aligned $\mathrm{TiO}_{2}$ nanotubes with a high aspect ratio, the electrochemical anodization of titanium foils in the presence of fluoride-rich electrolytes has proven practical $[72,73]$. As depicted in Fig. 1c, electrochemical anodization offers systematic control over the morphology of $\mathrm{TiO}_{2}$ nanotubes by adjusting certain parameters, including viscosity, $\mathrm{pH}$, fluoride concentration, stirring effect, temperature, water content of the electrolyte, anode-cathode working distance, potential applied, and processing time $[74,75]$. To generate highly smooth nanotube arrays, for instance, an electrolyte composed of glycerol and fluoride ions can be employed in a longer period of processing time $[10,21,76]$. The fabrication of freestanding tubular membranes, contrarily, is possible through sonication and post-treatments (i.e., diluted hydrofluoric acid, hydrogen peroxide, and oxalic acid) [75]. Recently, we have expanded the electrochemical anodization to fabricate individual anodic $\mathrm{TiO}_{2}$ nanotubes and nanocylinders through a controlled time-varying protocol. By assembling a two-electrode anodization Teflon cell (a mesh-type platinum counter electrode placed above the titanium surface) and adding the electrolyte composed of ammonium fluoride (a)
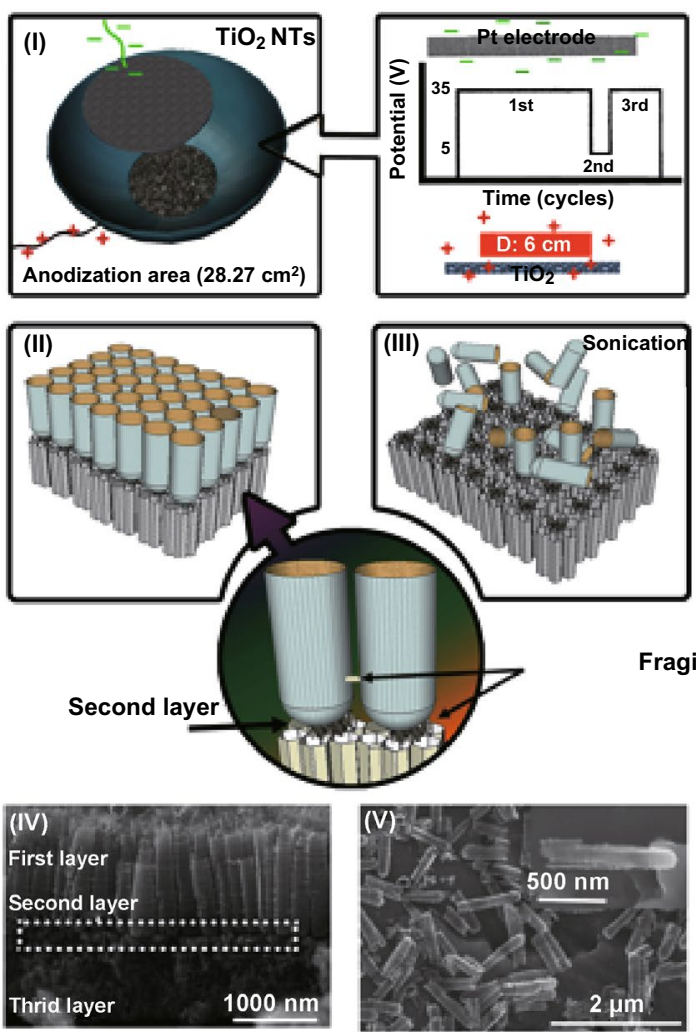

(b)
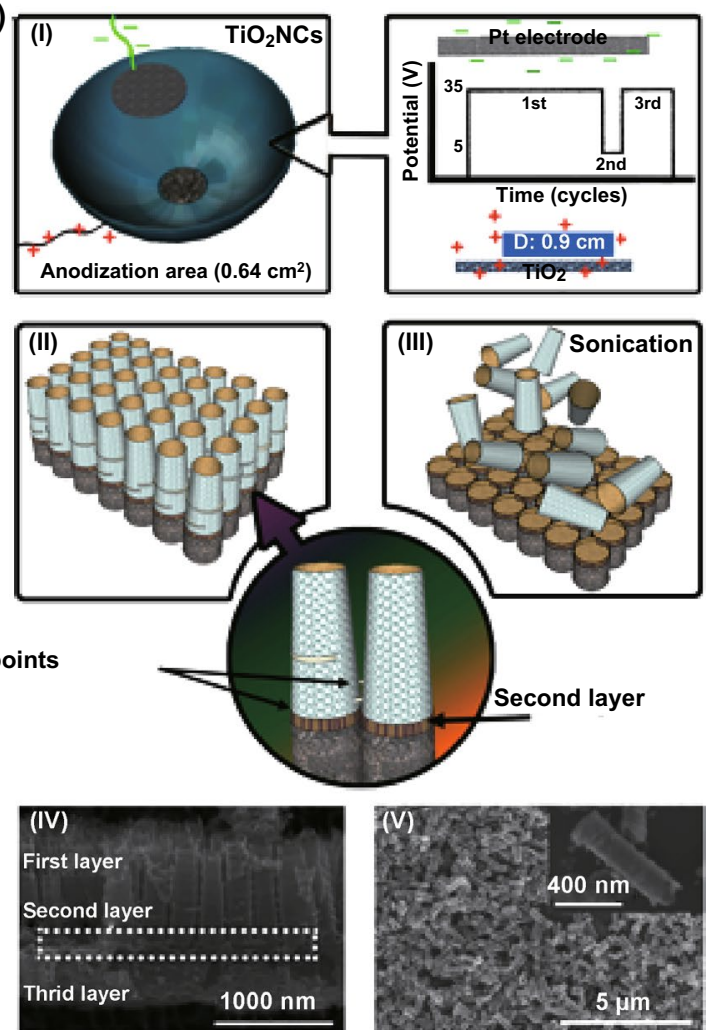

Fig. 2 Schemes and representative SEM images of separated anodic $\mathrm{TiO}_{2}$ a nanotubes and b nanocylinders fabricated by using electrochemi$\mathrm{cal}$ anodization. The fabrication processes of the nanotubes and nanocylinders depend on the size of anodization cell (the area exposed to the electrolyte) and quick voltage changes (first cycle: $35 \mathrm{~V}$ and $240 \mathrm{~min}$, second cycle: $5 \mathrm{~V}$ and $10 \mathrm{~min}$, and third cycle: $35 \mathrm{~V}$ and $60 \mathrm{~min}$ ). Adapted from Ref. [10] with permission from the American Chemical Society 
$(0.27 \mathrm{M})$ in glycerol/water $(60 / 40, \mathrm{v} / \mathrm{v})$ solution, a controlled three-step anodization (consisted of (i) $35 \mathrm{~V}$ for $240 \mathrm{~min}$, (ii) $5 \mathrm{~V}$ for $10 \mathrm{~min}$, and (iii) $35 \mathrm{~V}$ for $60 \mathrm{~min}$ ) can precisely generate weak points at the multilayer tubular array, which can break into individual tubes by using mild sonication (Fig. 2). The adjustment of the physiochemical features, such as the electrolyte composition and voltage applied, is also required to trigger the generation of individually separated $\mathrm{TiO}_{2}$ nanotubes or nanocylinders on arrays by means of mild sonication. Moreover, the size of the area exposed to the electrolyte is critical for the formation of either $\mathrm{TiO}_{2}$ nanotubes (open on one end) or nanocylinders (open on both ends). For example, the use of the bigger exposed area $\left(28.27 \mathrm{~cm}^{2}\right)$ to the electrolyte fabricates $\mathrm{TiO}_{2}$ nanotubes, whereas the small area $\left(0.67 \mathrm{~cm}^{2}\right)$ produces nanocylinders at the same anodization conditions [10]. In another study, an indirect fabrication based on a bamboo-splitting mechanism (electrochemical anodization) has also been introduced for forming nanowires on the array, using a long-term anodization of titanium foils in the presence of a viscous electrolyte containing fluoride ions [77]. However, the fabrication of well-ordered and -aligned nanowires, nanorods, and nanoribbons has yet to be developed by means of electrochemical anodization.

\subsection{Nanosheets}

Quasi-two-dimensional nanomaterials can play a critical role in biomedical applications as a result of their interfacial and mechanical properties [78-81]. $\mathrm{TiO}_{2}$ nanosheets can be fabricated through bottom-up strategies, including the hydrothermal approach, liquid-phase exfoliation, and self-assembly [79, 82]. In most cases, $\mathrm{TiO}_{2}$ nanosheets have been fabricated using the hydrothermal strategy based on the starting materials (i.e., tetrabutyl titanate) and high concentration of hydrofluoric acid as a capping agent in an autoclave at $200{ }^{\circ} \mathrm{C}$ for $24 \mathrm{~h}$. Zhang and co-workers fabricated $\mathrm{TiO}_{2}$ nanosheets with the hydrothermal approach by adding $48 \%$ hydrofluoric acid dropwise into the titanate isopropoxide kept in a heated Teflon-lined autoclave chamber $\left(180^{\circ} \mathrm{C}\right)$ for $24 \mathrm{~h}$ [6]. Similarly, hexagonal titanate nanosheets with a tunable thickness and length can be generated by adding lactic acid $[79,83]$. During the last few years, $\mathrm{TiO}_{2}$ nanosheets with different methods (i.e., the bacteria-assisted synthesis of nanosheet-assembled $\mathrm{TiO}_{2}$ hierarchical architectures [84]) have been fabricated, but these developed nanosheets have not been verified for biomedical applications.

\section{Post-fabrication of $\mathrm{TiO}_{2} \mathrm{NSs}$}

\subsection{Crystalline Structure}

In most cases, fabricated $\mathrm{TiO}_{2} \mathrm{NSs}$ are amorphous and require additional thermal treatments to achieve a single or polymorphic crystalline structure. The crystalline structure of $\mathrm{TiO}_{2} \mathrm{NSs}$ directly influences the photocatalytic activity upon UV irradiation. For example, $\mathrm{TiO}_{2}$ films with crystalline phases (anatase and a mixture of anatase and rutile) can generate higher amounts of reactive oxygen species (ROS) compared to the rutile phase [39]. A wide range of annealing temperatures can form different crystalline structures including anatase, brookite, rutile, and polymorph. Brookite crystals are always within crystalline $\mathrm{TiO}_{2} \mathrm{NSs}$, and pure brookite crystalline structures can be generated using the hydrothermal strategy $[31,32,57,85]$. Annealing temperatures between 280 and $800{ }^{\circ} \mathrm{C}$ first create a polymorphic structure, and raising the annealing temperature toward $900{ }^{\circ} \mathrm{C}$ then increases rutile crystals within the polymorphic structure $[74,86]$. Note that the annealing process in a vacuum or gaseous atmosphere, including nitrogen, argon, and nitrogen/hydrogen, also generates different polymorphic structures [74]. Interestingly, bottom-up strategies are able to directly synthesize crystalline structures consisting of different proportions of polymorphism compared to the top-down strategies [67]. On the other hand, the annealing process can be a major drawback with mesoporous $\mathrm{TiO}_{2} \mathrm{NSs}$ due to the pores potentially collapsing, their specific surface area being reduced or other properties changed (i.e., hydrophobicity). These changes may directly impact a number of biological responses, including cellular adsorption, interaction, and adhesion [87].

\subsection{Doping}

The insertion of electronically active atoms into the lattice of $\mathrm{TiO}_{2} \mathrm{NSs}$ is an astounding strategy to engineer the original band gap (between 1.8 and $4.1 \mathrm{eV}$ ) for generating ultrasensitive biosensors and elaborated optical devices [31, 32]. Both transition-metallic (i.e., gold, platinum, iron, silver, 
lithium, and copper) and nonmetallic ions (i.e., nitrogen, carbon, fluoride, and sulfur) can be incorporated into $\mathrm{TiO}_{2}$ NSs to improve the valence and energy bands [88]. The doping can be performed through: (i) fabrication process into a solution composed of doping elements, (ii) thermal treatment in the presence of gaseous doping elements, (iii) ion implantation, (iv) anodic formation of alloys containing the transition-metallic elements, and (v) electrochemical doping approaches [32]. These doping strategies incorporate elements into the substitutional and interstitial sites of the lattice [89]. The most well-known doping elements (i.e., nitrogen, carbon, and sulfur) narrow the optical band gap by improving the valence band. The calcination of $\mathrm{TiO}_{2} \mathrm{NSs}$ fabricated through wet approaches (precursors composed of glucose and tetrabutylammonium hydroxide) also generates a well-incorporated carbon doping within the structure [31, 90]. The other doping elements such as silicon, chrome, vanadium, and nickel incorporated into $\mathrm{TiO}_{2} \mathrm{NSs}$ using an ion implantation can also improve the optical band gap. Although doping of $\mathrm{TiO}_{2}$ NSs can be performed through both wet and dry strategies, resulted properties are different. For example, nitrogen wet doping of $\mathrm{TiO}_{2} \mathrm{NSs}$ quenches visible photocurrent and photocatalytic activities; however, these activities remain untouched by doping at the nitrogen/ argon or ammonia atmosphere [31].

\subsection{Deposition}

Another alternative strategy to lower the original band gap (e.g., n-type $\mathrm{TiO}_{2}$ semiconductor, $\sim 3.2 \mathrm{eV}$ ) is the incorporation of metallic nanomaterials with a desired band gap into $\mathrm{TiO}_{2} \mathrm{NSs}$, to significantly improve optical, electronic, and catalytic properties. A wide range of strategies have been developed to deposit and coat (core-shell nanomaterials) different metals (i.e., platinum, gold, or silver) as well as quantum dots onto the $\mathrm{TiO}_{2} \mathrm{NSs}$. In addition, deposition of the nanostructured materials can remarkably affect cellular behaviors and responses, recognition of biomolecules, and ions at the interface [91]. For example, a simple deposition of gold nanoparticles on the surface of $\mathrm{TiO}_{2}$ nanotubes can significantly improve the glucose detection [92]. Deposition strategies, ranging from electrodeposition, chemical bath deposition, and the hydrolysis of precursors, have been developed to randomly decorate or fill
$\mathrm{TiO}_{2}$ nanomaterials $[93,94]$. Porous gold nanoparticles, for example, can be incorporated into $\mathrm{TiO}_{2}$ nanotubes by using combined approaches, including sputtering, dewetting, and etching [95]. To generate one-dimensional magnetic $\mathrm{TiO}_{2}$ nanomaterials, anodic $\mathrm{TiO}_{2}$ nanotubes can be soaked into a magnetic solution (i.e., ferrofluids) and the magnetic nanoparticles from the solution can be deposited on the tubes through an external magnetic field placed at the bottom of the tubular array. The fabricated magnetic anodic $\mathrm{TiO}_{2}$ nanotubes have a potential for being loaded with different therapeutics and guided with a magnetic field (i.e., a permanent magnet and magnetic tweezer device) to a target tissue [21]. In the case of nanofibers, $\mathrm{TiO}_{2}$-based precursors can be mixed with metallic nanoparticles in order to be easily incorporated into $\mathrm{TiO}_{2}$ nanofibers through the electrospinning technique [2].

\subsection{Self-Assembled Monolayers and Carbonization}

A self-assembled functional monolayer on the surface of $\mathrm{TiO}_{2}$ NSs can lead to a selective conjugation of biomolecules, including proteins, ligands and antibodies, as well as the adhesion of mammalian cells. The formation of selfassembled monolayers on the surface of $\mathrm{TiO}_{2} \mathrm{NSs}$ is more or less limited to carbonyldiimidazole, phosphonic acid, and organosilane-based reactive components [96]. Salonen and co-workers have also introduced a functional combination of carbon into the lattice and onto their surface to improve bioactivities [97, 98]. Hydrocarbonization process, an indirect short incubation of $\mathrm{TiO}_{2}$ nanomaterials in the presence of acetylene gas at high temperature (i.e., $850{ }^{\circ} \mathrm{C}$ ), creates a graphitic monolayer on the surface to improve the mechanical stability [98]. The structure of the carbon monolayer in titanium oxycarbide depends on the incubation time and temperature. A hydrothermal reduction in graphene oxide can also warp the carbon monolayer on the surface of $\mathrm{TiO}_{2}$ nanoparticles [99]. A thermal annealing of the surfactant-coated nanomaterials (i.e., nanosheets) is an interesting alternative for the carbonization [100].

\subsection{Polymer and Biomolecule Conjugation}

Bioconjugation strategies are an essential step for clinical translation of $\mathrm{TiO}_{2}$ nanomaterials in order to detect, track, 
visualize, target, and treat a wide range of diseases. To generate smart and flexible nanocarriers, polymeric coverage can impart a broad spectrum of new properties to $\mathrm{TiO}_{2}$ NSs. A thermo-, pH- and enzyme-responsive coverage can create smart, multistage theranostic nanoplatforms. A wide range of synthesized or natural polymers, including chitosan, polyethylene glycol, and polydopamine, have been employed for the conjugation, coating, and capping of $\mathrm{TiO}_{2}$ NSs [101-103]. Certain biochemical linkers, developed to temporary conjugate therapeutic agents, can be cleaved in a specific physiochemical condition by enzymes, irradiation, and the physiological environment (i.e., acidic $\mathrm{pH}$ of the endocytic compartments) [17]. In addition, the conjugation of biomolecules such as proteins, enzymes, and antibodies on the surface of nanomaterials plays a critical role in facilitating the detection of specific cells and therapeutic delivery to intracellular compartments, while reducing the risk of macrophages [104]. The biomolecules can be conjugated on the surface of $\mathrm{TiO}_{2} \mathrm{NSs}$ through various functional chemical linkers that can provide a rapid conjugation strategy to limit any bioactivity losses [96, 102]. Polymers, antibodies, and therapeutics can be conjugated through one of the following strategies (see Bioconjugate Techniques [105]):

- Carbodiimide chemistry A specific and practical conjugation strategy binds the primary amines of biomolecules and polymers to the surface of carboxyl-reactive $\mathrm{TiO}_{2} \mathrm{NSs}$ by means of the water-soluble 1-ethyl-3-(-3-dimethylaminopropyl) carbodiimide hydrochloride (EDC for an aqueous synthesis) and water-insoluble dicyclohexyl carbodiimide (DCC for an organic reaction). The carbodiimide coupling reaction at the physiological $\mathrm{pH}$ is less effective compared to the most efficient coupling condition at the acidic $\mathrm{pH}(\sim 4.5)$, a simultaneous use of $N$-hydroxysuccinimide (NHS) or water-soluble Sulfo-NHS, and EDC is therefore recommended to provide the highest coupling efficiency at the physiological $\mathrm{pH}$ [106].

- Click chemistry A highly selective, high yield, and fast coupling reaction occurs between copper-catalyzed Huisgen cycloadditions of azides and alkynes to conjugate biomolecules, fluorophores, therapeutics, as well as polymers on the surface of $\mathrm{TiO}_{2}$ nanomaterials [107]. The surface of biomolecules and $\mathrm{TiO}_{2}$ nanomaterials can be modified by either the azide- or the alkyne-reactive moieties for the click coupling chemistry. However, a copperfree click chemistry is a point in order to eliminate the cytotoxic effects of the copper catalysts in biomedical applications. The activated biomolecules by means of a cyclooctyne (i.e., dibenzocyclooctyne $=\mathrm{DBCO}$ ) $\mathrm{can}$ also bind to azide-labeled $\mathrm{TiO}_{2}$ nanomaterials.

- Maleimide chemistry Sulfhydryl-reactive chemical groups (-SH, thiols) are the most common cross-linker moieties for the conjugation of biomolecules on the surface of nanomaterials. In most cases, maleimide groups can specifically react with sulfhydryl groups at $\mathrm{pH}$ between $\sim 6.5$ and 7.5 to form a stable and irreversible thioether linkage. The coupling by the sulfhydryl groups is more selective and precise due to their limited available number on the biomolecules [108]. However, sulfhydryl-reactive chemical groups can be easily added through a reaction with available primary amines using the Traut's reagent. Interestingly, plasmonic-deposited or -coated $\mathrm{TiO}_{2} \mathrm{NSs}$ can also be directly conjugated through a reaction with sulfhydryl-reactive chemical groups of the biomolecules to generate a bio-monolayer on the surface [109]. Moreover, the reduction in antibodies (i.e., using Tris(2-carboxyethyl)phosphine hydrochloride to cleave disulfide bonds) can expose their free sulfhydrylreactive chemical groups to plasmonic- or maleimidemodified surfaces and create a direct conjugation [110].

- Hydrazide-reactive chemistry Targeted drug delivery based on antibody (an affinity-based binding) for the detection of exposed antigens, e.g., of cancer cell population, requires a precise conjugation strategy to less disrupt the Fab region of the antibodies. The oxidation of the carbohydrate at the Fc region of the antibody by using sodium periodate generates aldehyde groups, which can bind to the hydrazide moieties at the surface of nanomaterials [111]. The use of the hydrazone linkage can also create $\mathrm{pH}$-cleavable linkers for certain biomedical applications (i.e., intracellular therapeutic delivery systems) in order to target specific subcellular compartments. Through a reaction between a carbonyl-reactive group (i.e., anticancer doxorubicin drug) and hydrazide moiety (i.e., on the surface of $\mathrm{TiO}_{2} \mathrm{NTs}$ ) a $\mathrm{pH}$-cleavable linkage can therefore be generated [10].

\section{Biological Responses to $\mathrm{TiO}_{2} \mathrm{NSs}$}

\subsection{In vitro Cytotoxicity Assessments}

The fundamental evaluation of potential health hazards caused by exposure to nanomaterials is now a crucial step. At the nanoscale, the size reduction in nanomaterials can trigger an excessive cellular uptake and subcellular 
accumulation and may disrupt activities of organelles [44, 97]. Transporting nanomaterials across the plasma membrane and accessing subcellular compartments rely on a multitude of factors, spanning surface properties and bioconjugation to size and morphology [112]. Internalization is initially affected by the cellular interactions between receptors located on the membrane and the surface of nanomaterials. Therefore, the communication between the cell receptors and nanostructure activates multiple endocytosis pathways, including clathrin-mediated endocytosis, caveolae, micropinocytosis, and phagocytosis [113]. Both aggregated and agglomerated $\mathrm{TiO}_{2}$ nanoparticles can be internalized into cells by phagocytosis, and monodispersed $\mathrm{TiO}_{2}$ nanoparticles can mainly be internalized through an energy-dependent endocytosis [114, 115]. Although the energy-dependent mechanisms are highly active for the endocytosis (e.g., of nanowires), the internalization efficiency depends on the aspect ratio of one-dimensional nanomaterials [116]. The rate of cellular uptake can be boosted through post-fabrications and surface modifications. A common size-dependent intracellular mechanism and localization roughly show an intracellular trafficking pathway, mostly ending up in endosomes and lysosomes [117, 118].

The incubation of $\mathrm{TiO}_{2}$ nanomaterials can induce both cytotoxic and genotoxic effects on mammalian cells by disrupting mitochondrial membranes [119, 120]. The toxicity can become exacerbated by increasing the dosage of $\mathrm{TiO}_{2}$ nanomaterials [121]. $\mathrm{TiO}_{2} \mathrm{NSs}$ can primarily cause the production of ROS, DNA fragmentation, and oxidative stress and lesions (i.e., rendering nucleotides and inactivating base excision repair pathways) $[122,123]$. The production of ROS, DNA damages, and chromosomal aberrations can arrest the cell cycle and subsequently trigger apoptosis [124, 125]. $\mathrm{TiO}_{2}$ nanoparticles can also cause a structural damage (i.e., mitochondrial damage and downregulation of ERKpathway-related factor proteins), reduce the cell activity, and disturb the testosterone generation or secretion in the treated Leydig cells [126].

Bioactivity of nanomaterials is shape- and length-dependent. Cylindrical $\mathrm{TiO}_{2}$ nanomaterials, for instance, can induce significant apoptosis compared to spherical NSs [69, 127]. It was also observed that one-dimensional $\mathrm{TiO}_{2}$ nanomaterials can accelerate the formation of autophagosome-like vacuoles and the reduction in the mitochondrial calcium concentration [128]. Correspondingly, long $\mathrm{TiO}_{2}$ nanofibers can also disturb the transepithelial electrical resistance and perturbation, and generate a significant hemolysis and macrophage activation [127]. Anodic freestanding $\mathrm{TiO}_{2}$ nanotubes, for example, can also induce genotoxic cellular responses, including ROS production, without a significant cell death, while the non-anodic tubes are less toxic [125, 129].

The cellular responses to $\mathrm{TiO}_{2}$ nanomaterials can also be manipulated according to crystalline structures and surface chemistries in order to maximize cell viability and cellular uptake [130-132]. The super reactive crystalline structures induce a wide variety of toxicities related to the defect sites and distinctive crystal orientations [85, 133]. Both brookite and anatase $\mathrm{TiO}_{2}$ nanorods, for example, can reduce cell viability through the ROS production and expression of autophagosome proteins. However, an extensive distribution of lysosome and expression of endoplasmic reticulum proteins can be induced by anatase $\mathrm{TiO}_{2}$ nanorods [128]. On the other hand, polymeric surface modifications can reduce or diminish hazard risks caused by the administration of $\mathrm{TiO}_{2}$ nanomaterials [134-137]. The surface modifications may suppress the reactivity of crystals and minimize cellular and subcellular obstructive interactions [44, 125, 138]. However, polymeric surface modifications must be conscientiously optimized, because a hydrophilic and positively charged polymeric layer on the surface of nanomaterials may cause severe obstructive interactions within the subcellular compartments and consequently produce greater ROS and cytotoxicity [139].

The cellular responses are different toward one-dimensional arrays, such as implants and scaffolds with varying morphologies and structures [140-142]. The morphology, including pore size (or top-side diameter) and length of the tubular $\mathrm{TiO}_{2}$ arrays, mainly determines cell viability and proliferation through the modulation of the focal adhesion kinase and Ras homolog family member A (RhoA) pathways $[35,143,144]$. The macrophage inflammatory effect of tubular arrays is also controllable through the inhibition of mitogen-activated protein kinases and nuclear factor- $\mathrm{\kappa B}$ pathways [145]. In addition, the change of the crystalline phase of tubular arrays can be another influencing factor in the adhesion and activation (e.g., platelets). The anatase nanotubes (annealed at $450^{\circ} \mathrm{C}$ ) can trigger the adhesion and activation behavior (i.e., spreading tendency and filopodia connections) of the platelets compared to as-formed amorphous nanotubes [66]. However, an elaborated surface modification including biomolecule conjugations alternatively improves cell viability, adhesion, and proliferation [144]. 


\subsection{In Vivo Inflammatory Responses}

Partitioning of nanomaterials into organs and tissues occurs after entering into the cardiovascular system and may induce inflammation. The translocation of $\mathrm{TiO}_{2}$ nanoparticles depends on the injection site. Intravenous injection, for example, exhibits a high number of nanoparticles in the liver and a relatively smaller number in the spleen, lung, and kidneys [146-148]. Inhaled $\mathrm{TiO}_{2}$ nanoparticles that have quickly transferred into the circulatory system may randomly affect gene expression in the heart and lung [149]. $\mathrm{TiO}_{2}$ nanoparticles can then cause pulmonary inflammation through ROS production and the expression of inflammatory cytokines [150]. A recent study on the zebrafish exposed to $\mathrm{TiO}_{2}$ nanoparticles reveals no side effects on the hatching rate of zebrafish embryos and deformity; however, a longterm incubation of the nanoparticles with the adult zebrafish can cause an oxidative damage to the liver and gill (high expression of three antioxidant enzymes: superoxide dismutase, catalase, and glutathione $\mathrm{S}$ transferase) [151]. $\mathrm{TiO}_{2}$ nanoparticles can injure the liver through DNA breaks and chromosomal damages [147]. $\mathrm{TiO}_{2}$ nanoparticles localized in the spleen may cause apoptosis through the splenocyte dysfunction and proliferation of lymph nodules [152]. Moreover, $\mathrm{TiO}_{2}$ nanomaterials accumulating in the kidney can primarily cause severe dysfunction due to nephric inflammation and necrosis [147]. The translocation of $\mathrm{TiO}_{2}$ nanoparticles (5 $\mathrm{nm}$ in diameter, anatase) injected daily into the abdominal cavity for 2 weeks indicated the harmful results by triggering a consecutive series of intramolecular interactions, including a lipid peroxidation and a reduction in the capacities and functionalities of antioxidative enzymes in the brain [153]. Administering two-dimensional $\mathrm{TiO}_{2}$ NSs can also induce significant liver toxicity when changing the level of malondialdehyde, superoxide dismutase, and oxidative stress responses [6, 154, 155]. However, an elaborated surface modification may alter the partitioning or toxicity of $\mathrm{TiO}_{2} \mathrm{NSs}$, thereby eliminating or reducing potential inflammation after their administration. Both freestanding anatase and brookite $\mathrm{TiO}_{2}$ nanorods, for instance, trigger immune responses and proinflammatory cytokines, but anatase nanorods cause fewer lesions compared to the brookite structure $[128,156]$. In addition, normal spleen and thymus indexes without triggering immune responses after the administration of PEGylated $\mathrm{TiO}_{2}$ nanosheets, were reported [6]. The surface modification should also facilitate the clearance of the nanomaterials used for therapies. For example, after an intravenous injection, $\mathrm{TiO}_{2}$ nanoparticles (agglomerated with 73.3-95\% of agglomerates with a peak size around 1400-1800 $\mathrm{nm}$ ), which were quickly eliminated from blood and relocated in liver, spleen, and lungs, were interestingly cleared from the body with a half-life of 12.7 days [157].

\section{Biomedical Applications}

\section{$5.1 \mathrm{TiO}_{2} \mathrm{NSs}_{\text {for Therapy }}$}

\subsubsection{Therapeutic Delivery}

Therapeutic vehicles based on $\mathrm{TiO}_{2}$ nanomaterials have been developed to deliver small molecules, proteins, and genes to target tissues and organs in the body. Increasing the surface area by generating pores within the nanomaterials maximizes therapeutic loading compared to their nonporous counterparts. As previously reported, the charge interactions between the therapeutic agents and nanomaterials mainly facilitate physical adsorption [158, 159]. In certain cases, the loading capacity can be alternatively increased by means of an external driving force such as voltage [160]. Apart from that, controlled release kinetics are also favorable for drug delivery systems. The release rate can be tuned using different strategies including polymeric capping or coatings on the surface of $\mathrm{TiO}_{2} \mathrm{NSs}[161,162]$. The controlled filling of nanotubes with drug-loaded polymeric micelles can generally slow down the release rate [163]. Drug reservoirs composed of $\mathrm{TiO}_{2}$ nanorods, nanofibers, and nanotubes also exhibit a sustained drug release for dermal drug delivery applications [164-166].

A stimuli-responsive drug release for a precise chemotherapy in order to minimize side effects is achievable through the conjugation of $\mathrm{pH}-$, thermo-, and enzymeresponsive polymers on the surface [44]. Multifunctional mesoporous $\mathrm{TiO}_{2}$ nanocarriers that had been conjugated with polyethyleneimine (PEI) and folic acid, for instance, were prepared for a drug delivery system based on the NIR laser-controlled drug release system [8]. X-ray illumination of $\mathrm{TiO}_{2}$ nanomaterials can create electron-hole pairs within the structure (degrading organic linkers) and generate a triggered release [18]. A combined strategy for a stimuli-responsive drug release, for example, has also been 
(a)
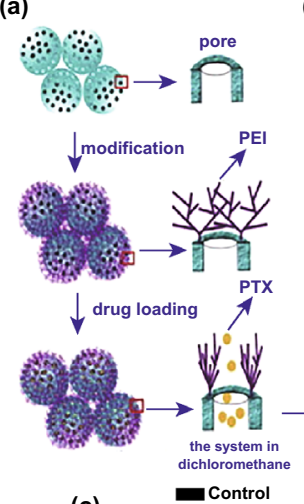

(c)

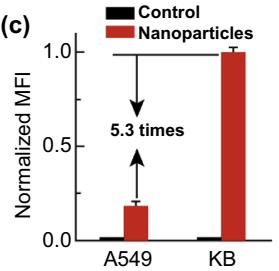

(b)

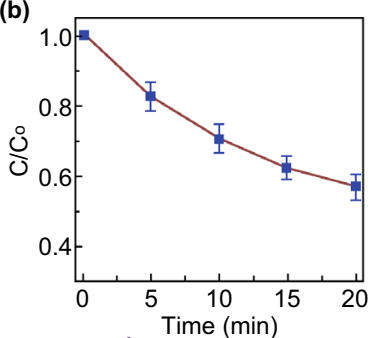

(e)

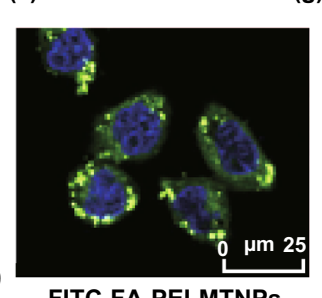

(f)

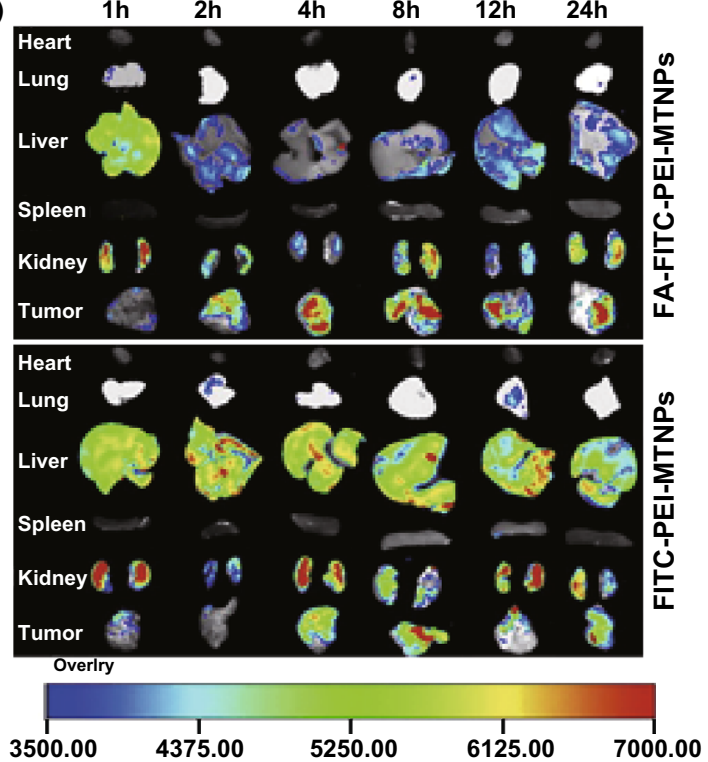

Fig. 3 a Illustration of drug loading and the release process in multifunctional mesoporous $\mathrm{TiO}_{2}$ nanocarriers conjugated with PEI and folic acid. $\mathbf{b}$ The photocatalytic degradation of folic acid-PEI on the surface of mesoporous $\mathrm{TiO}_{2}$ nanocarriers through the use of UV light irradiation. c The improved cellular internalization of the nanocarriers into KB and A549 cells after $5 \mathrm{~h}$ (I) and the number of internalized nanocarriers with and without folic acid conjugation (II). FCM: Flow cytometry measurements. d Fluorescence images of treated KB cells after incubation (I) with and (II) without folic acid-conjugated nanocarriers. The punctuated green colors indicate the nanocarriers and blue (color) shows the cell nuclei. e In vivo fluorescence images of tissue collected at different times (post-injection). Adapted from Ref. [8] with permission from the Elsevier. (Color figure online)

reported by allocating a hydrophobic cap for amphiphilic $\mathrm{TiO}_{2}$ tubular arrays sensitive to the UV light irradiation [17]. The multifunctional porous $\mathrm{TiO}_{2}$ nanoparticles, conjugated with PEI and folic acid, have also been developed for UV-responsive drug release as well as targeted drug delivery (Fig. 3a). The burst release of loaded anticancer drug paclitaxel from $\mathrm{TiO}_{2}$-based nanocarriers was controlled by the PEI capping, and the exposure to UV light irradiation, which accelerated the degradation of PEI on the surface by the generation of free-radicals, released the entrapped anticancer drugs (Fig. 3b). The improved cellular internalization of the folic-conjugated nanocarriers into KB cells (7.4 times higher than nonfunctionalized carriers) was obtained after $5 \mathrm{~h}$ of incubation (Fig. 3c). Compared to the treated KB cells (i.e., higher cellular uptake and cell death), the folic-conjugated nanocarriers induced less cytotoxicity in A549 cells due to the small cellular uptake (5.3 times less than that of KB cells) and demonstrated the selective cancer killing feature (Fig. 3d). In vivo fluorescence images of tissue, including the heart, liver, spleen, lung, kidney, and tumor, collected at different times (post-injection), also confirmed the improved cellular internalization and accumulation of the folic-conjugated nanocarriers into the target tumor after $4 \mathrm{~h}$ postinjection (Fig. 3e) [8]. In addition, PEI on the surface of the nanocarriers is also able to be swollen at the acidic $\mathrm{pH}$ of the intracellular compartments to cause a protonsponge effect, which allows the cargo to be delivered to the cytoplasm $[8,19]$.

Targeted therapeutic delivery system is a key approach to accumulating therapeutics into the site of action in order to boost the therapeutic efficacy. The post-fabrication of nanocarriers by using biomolecules and ligands (i.e., folic acid, hyaluronic acid, and antibody) is a promising strategy, which can precisely accumulate nanomaterials at a specific tissue $[8,167,168]$. For example, the conjugation of CD133 monoclonal antibodies on black $\mathrm{TiO}_{2}$ nanoparticles to target the transmembrane glycoprotein highly expressed at pancreatic cancer stem cells has been developed to guide the nanoparticles for a site-specific cancer therapy [12]. Moreover, folic acid immobilization on the surface of anticancerloaded nanocarriers can effectively promote the cellular 
uptake through a receptor-mediated endocytosis [8]. The penetration of therapeutic agents and nanomaterials is limited in solid malignant tumors [44]. However, the enhanced permeability and retention (EPR) effects, which occur in solid tumors, permit the nanomaterials to gain access to the restricted microenvironments [44, 97]. Correspondingly, a successful delivery of DOX to the orthotopic breast tumor has been achieved by the administration of polyethylene glycol-coated $\mathrm{TiO}_{2}$ nanoparticles based on the EPR effects [169]. After a long circulation time, an intracellular drug release is also an advantage for provision of a sufficient therapeutic effect. Intercellular drug delivery systems can be obtained by using different cleavable linkers ( $\mathrm{pH}-$, thermo-, and UV light irradiation), which temporary bind therapeutics on the surface of nanocarriers. The NIR light has also been employed to trigger an intracellular DOX release from zwitterionic polymer-gated $\mathrm{Au} @ \mathrm{TiO}_{2}$ core-shell nanoparticles. The NIR light irradiation (at $635 \mathrm{~nm}$ ) to the internalized nanocarriers caused an efficient cell death via the accelerated DOX release into the cytoplasm and nucleus in comparison to the treatment without the laser irradiation [170]. (a)

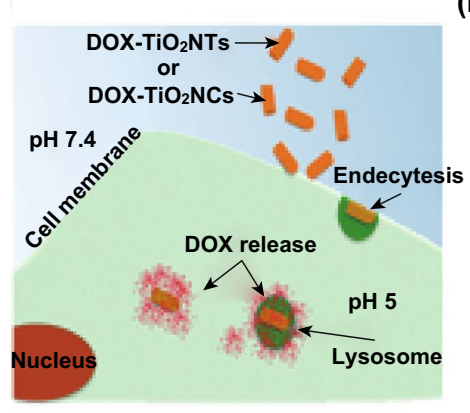

(c)

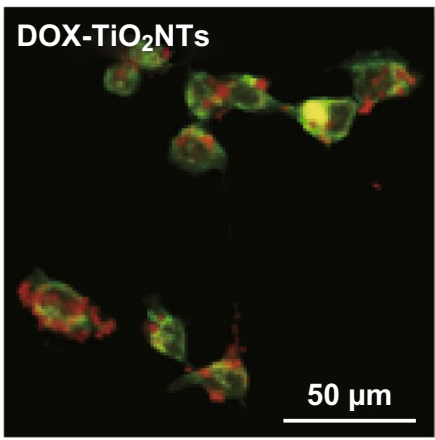

(e)

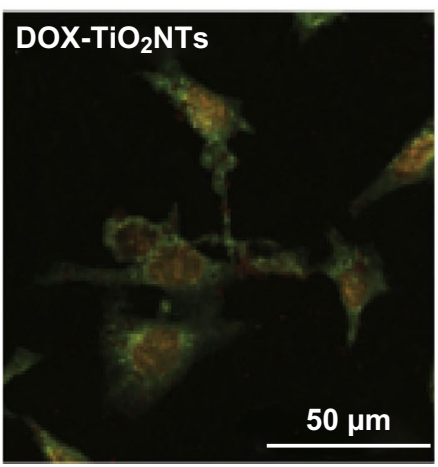

(b)

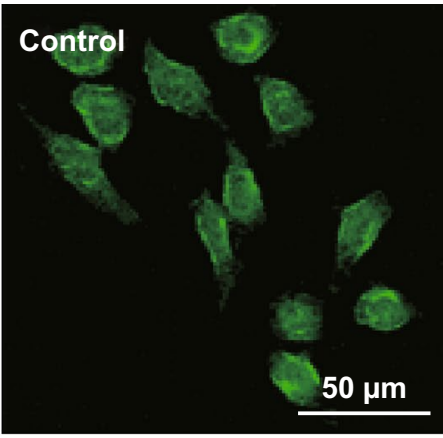

(d)

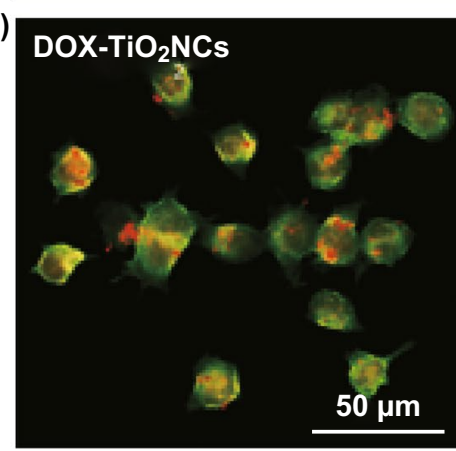

(f) DOX-TiO 2 NCs

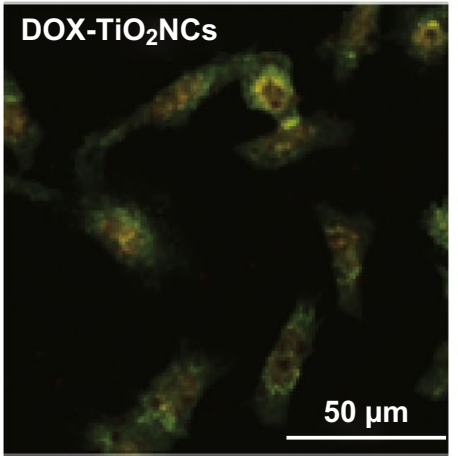

(g)

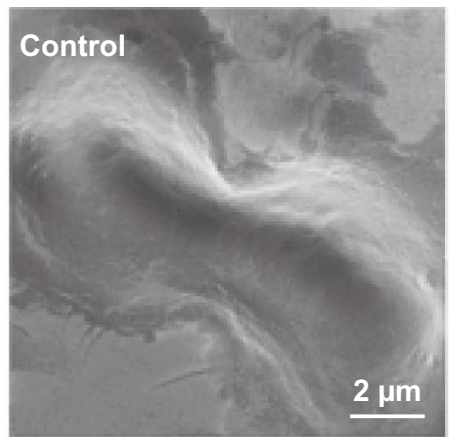

(h)

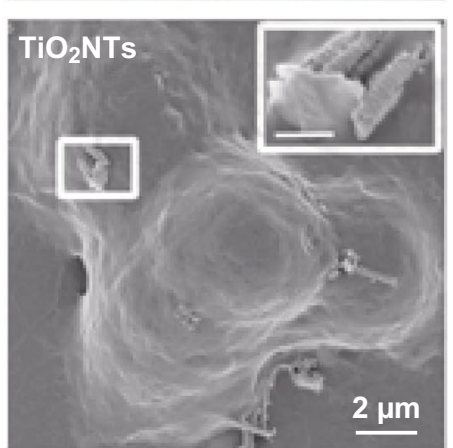

(i)

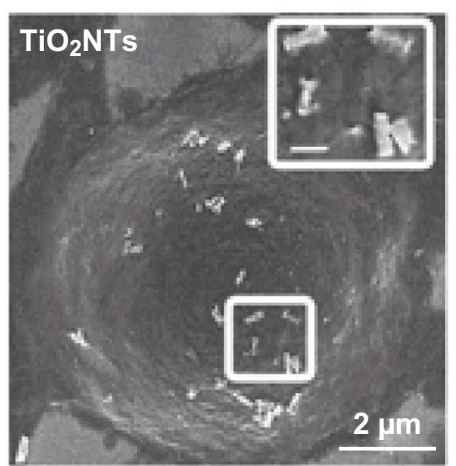

Fig. 4 Internalization of DOX-loaded $\mathrm{TiO}_{2}$ nanotubes and nanocylinders into HeLa cells. (I) The cellular uptake and intracellular DOX release from $\mathrm{TiO}_{2} \mathrm{NSs}$ confirmed by scanning electron microscopy (SEM) and confocal microscopy images of control (-I-control) HeLa cells without the nanocarriers, DOX-conjugated $\mathrm{TiO}_{2} \mathrm{NTs}\left(-\mathrm{I}-\mathrm{DOX}-\mathrm{TiO}_{2} \mathrm{NTs}\right.$, red demarcation) and DOX-conjugated TiO $\mathrm{NCs}\left(-\mathrm{I}-\mathrm{DOX}-\mathrm{TiO} \mathrm{NCs}_{2}\right.$ red demarcation) after $1 \mathrm{~h}$ and $24 \mathrm{~h}$ of incubation. Cells were stained with fluorescein diacetate (green). Insets indicate the magnified images of internalizing $\mathrm{TiO}_{2}$ nanotubes and nanocylinders. Scale bars of the inset frames are $500 \mathrm{~nm}$. Adapted from Ref. [10] with permission from the American Chemical Society 
Freestanding, one-dimensional $\mathrm{TiO}_{2} \mathrm{NSs}$ have been demonstrated to be remarkable platforms for drug delivery systems and cancer therapy. The shape of nanocarriers is a key parameter directly affecting circulation time, biodistribution, and cellular uptake in drug delivery systems. One-dimensional nanocarriers tend to adhere more to vascular endothelium compared to spherical nanocarriers, and improve endothelial targeting, e.g., of a solid tumor and intracellular localization [11, 44]. Recently, an intracellular DOX delivery has been developed by using individual anodic $\mathrm{TiO}_{2}$ nanotubes and nanocyliners to take advantage of a cleavable release based on a hydrazone linker in endolysosomes (Fig. 4). When the conjugated DOX molecules on the surface of freestanding $\mathrm{TiO}_{2}$ nanotubes and nanocylinders were exposed to the acidic environment $(\mathrm{pH}$ 5), the punctate red dots (related to DOX-loaded nanocarriers) were diminished and spread into the entire cell body. The endosomes with the acidic environment triggered the cellular death by cleaving covalently-bound DOX molecules from the nanocarriers. A short incubation (30 $\mathrm{min}$ ) of nanocarriers (DOX-conjugated and DOX-loaded) with HeLa cells and the subsequent replacement of the culture medium (i.e., to eliminate all unbound nanocarriers and released cargo) indicated higher toxicity for the cells treated with $\mathrm{pH}$-cleavable nanocarriers after $72 \mathrm{~h}$, compared to the treatment with DOX-loaded nanocarriers [10].

Magnetically guided drug delivery systems possessing $\mathrm{TiO}_{2}$ nanocarriers functionalized with magnetic responsive materials can alternatively deliver therapeutics into the site of action. It might seem an impractical effort to employ an external magnetic force to target deep tissues under the skin (more than $5 \mathrm{~cm}$ ) owing to a rapid reduction in the magnetic strength. However, it can be partially solved by implanting magnets in the body near the target site [171]. $\mathrm{TiO}_{2}$ nanomaterials are not susceptible to an external magnetic force, and in order to achieve this, the magnetic nanoparticles (i.e., iron oxide) can be embedded into the structure of the nanocarriers [159, 172]. For example, ferrofluid, a magnetic solution (composed of 3-15\% iron oxide (magnetite) and 6-30\% oilsoluble dispersant in 55-91\% distillates (petroleum), viscosity of $6 \mathrm{mPa}$ s, saturation magnetization $44 \mathrm{mT}$ ), can be incubated with $\mathrm{TiO}_{2}$ tubular arrays in order to deposit magnetic nanoparticles $(\sim 10 \mathrm{~nm})$ and generate magnetic $\mathrm{TiO}_{2}$ tubular arrays. In comparison to relatively large magnetically guided $\mathrm{TiO}_{2}$ tubular arrays, their limited displacement at the target tissue, and the necessity for surgery to insert them into the body, freestanding magnetic $\mathrm{TiO}_{2}$ nanomaterials as an alternative can be potentially guided and accumulated into the site of action (Fig. 5). Moreover, magnetic nanotubes, which are sensitive to an external magnetic force (i.e., magnetic tweezer), can undergo displacements up to one micrometer (depends on the amount of deposited ferrofluid and position of nanotubes) after the attachment to the cells. A short exposure to the magnetic field can also improve the cellular binding, e.g., of the magnetic $\mathrm{TiO}_{2}$ nanotubes ( $\sim 6$ nanotubes per cell on average) and cause an enhanced delivery of anticancer camptothecin into the target cells ( $90 \%$ killing efficiency) compared to the control groups without the magnetic force in vitro ( 2 nanotubes per cell on average) [21, 173]. An increased deposition of magnetic nanoparticles into nanotubes might raise and improve the obtained small force $(\sim 2 \mathrm{pN})$ compared to commercially available magnetic beads (i.e., Dynabeads M- 450 with $\sim 54 \mathrm{pN}$ force); however, a balance between the magnetic deposition and drug loading needs to be considered, without affecting the therapeutic efficiency.

Gene therapy as an efficient means of therapeutically delivering oligonucleotides can lead to curing and preventing a broad range of diseases. The short interfering RNA (siRNA) can be transferred to the intracellular compartments of targeted organs in order to silence specific messenger RNA [174, 175]. $\mathrm{TiO}_{2}$ nanoparticles have also been developed to deliver nucleic acid derivatives into the nuclei of target cells. Nanocomposite-based $\mathrm{TiO}_{2}$ nanoparticles and polylysine have been recently fabricated to deliver oligonucleotides as antiviral agents into nucleus of the MadinDarby Canine Kidney cells. Oligonucleotide delivery to nuclei, found to be a cell division phase-dependent process, can happen during the interphase activity of cells, and the prophase condition mostly inhibits the internalization [176]. A sustained release of viral vector encoding proteins from the $\mathrm{TiO}_{2}$ tubular implants can diminish disadvantages of local delivery systems (i.e., short effective time, large dose requirement, repetitive administration, and poor distribution) [177]. To overcome these disadvantages, lentiviral vectors encoding BMP-2 loaded into the nanotubes by the lyophilization were released over 8 days and promoted osteogenic differentiation. This delivery system (lyophilization of the loaded vectors) has shown an advantage because of maintaining the stability of the vectors over the therapeutic period. Moreover, the sustained release of the lentiviral vector encoding BMP-2 improved the local cell accumulation 

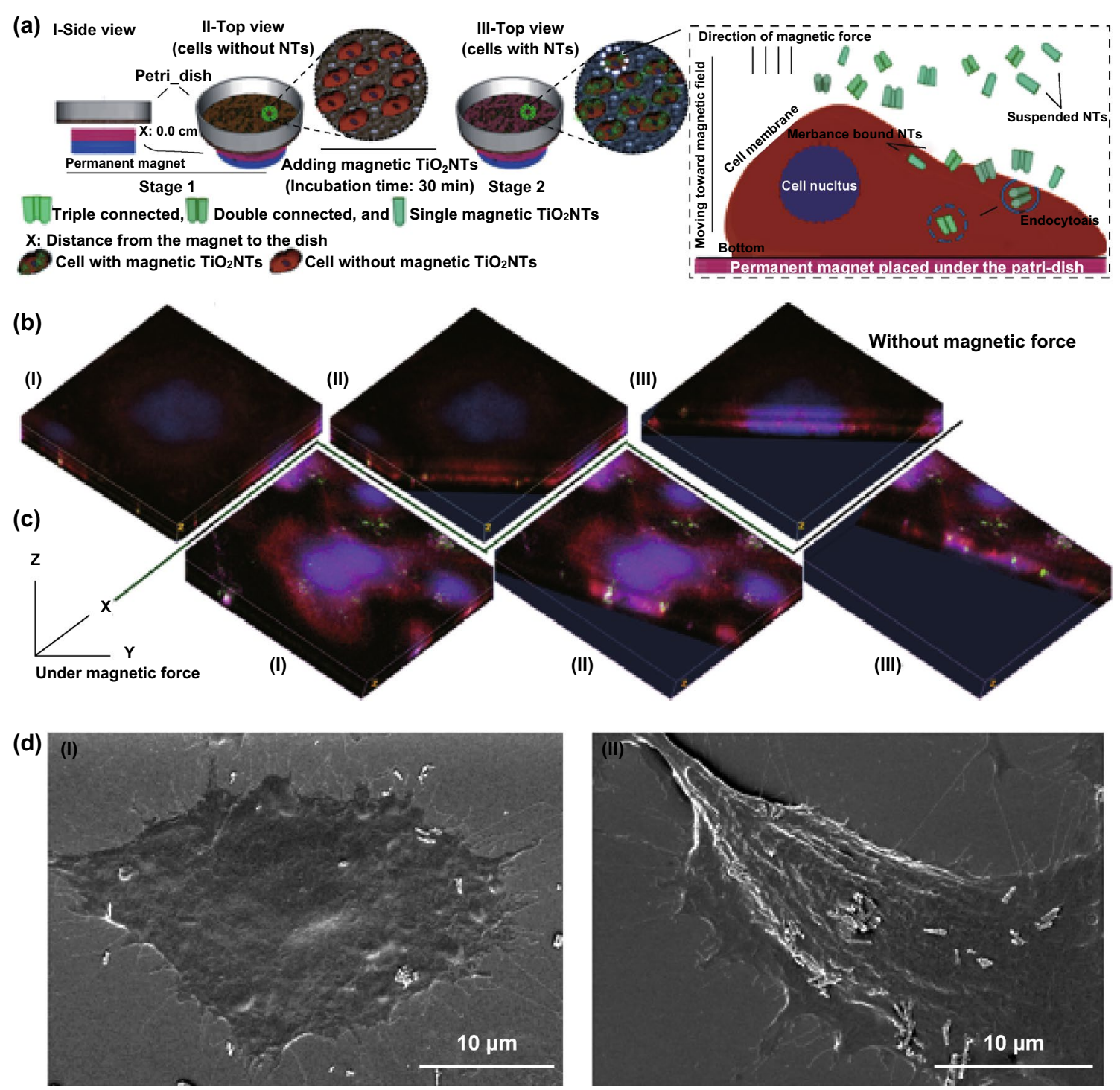

Fig. 5 a Illustration of the improved delivery of anticancer drug camptothecin-loaded magnetic $\mathrm{TiO}_{2}$ nanotubes under a magnetic force. Representative confocal microscopy images (3D) and SEM images of enhanced cellular uptake b without and $\mathbf{c}$ with a magnetic field. The confocal images show magnetic $\mathrm{TiO}_{2} \mathrm{NTs}$ (green), actin filament (red) and nucleus (blue). d Representative SEM micrographs of internalizing magnetic $\mathrm{TiO}_{2} \mathrm{NTs}$ without (I) and with (II) magnetic force. Adapted from Ref. [21] with permission from the Springer Nature. (Color figure online)

by recruiting circulating bone marrow stromal cells around the $\mathrm{TiO}_{2}$ nanotubes and facilitated the differentiation into osteoblasts [177].

A combined strategy for cancer therapy has been exhibited through the administration of $\mathrm{TiO}_{2}$-coated $\mathrm{Fe}_{3} \mathrm{O}_{4}$ core-shell nanocarriers loaded with doxorubicin (DOX) and $\beta$-catenin siRNA (Fig. 6). When mice treated with magnetic $\mathrm{TiO}_{2}$ core-shell nanoparticles were exposed to a magnetic force, a strong signal $\left(\mathrm{T}_{2}\right.$-weighted $\mathrm{MRI}$ and fluorescence) was detected in the tumor site compared to the liver and other normal tissues within a fairly short period of time. The maximum accumulation of magnetic $\mathrm{TiO}_{2}$ core-shell nanoparticles in the tumors was reached at $3 \mathrm{~h}$ post-injection (based on $\mathrm{T}_{2}$-weighted MRI). The developed multifunctional carriers effectively silenced the $\beta$-catenin gene and caused remarkable apoptosis while suppressing proliferation. Exposure to NIR laser irradiation can also generate ROS and triggers tumor cell apoptosis in vitro and in vivo. The intracellular ROS and glutathione $\mathrm{S}$-transferase level in treated cells by $\beta$-catenin 
(a) Control

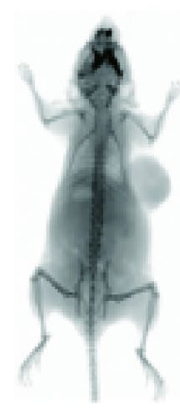

(b)

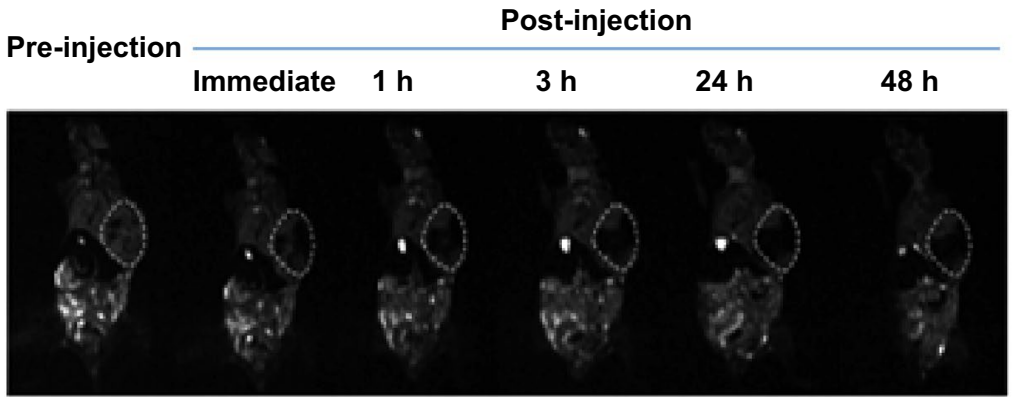

M-DOX-siRNA Mag+M-DOX-siRNA
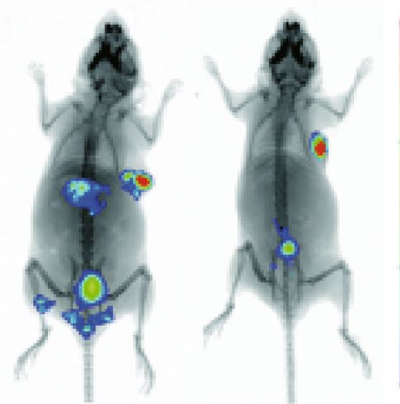

40000

30000

20000

10000

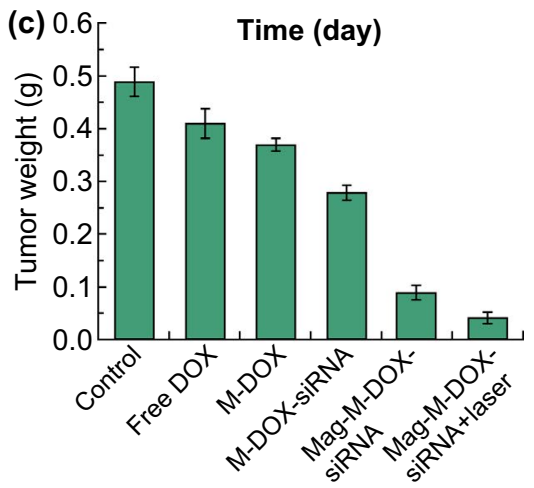

(d)

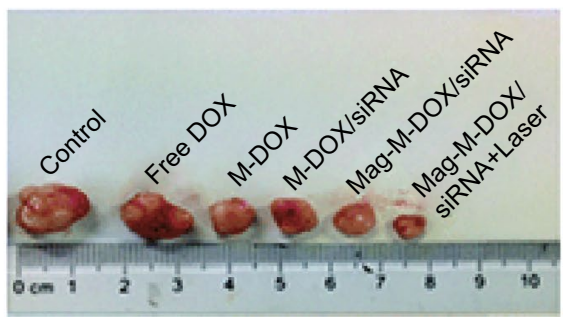

Fig. 6 a Magnetic biodistribution of DOX/siRNA-loaded magnetic mesoporous $\mathrm{TiO}_{2}$ nanocarriers $12 \mathrm{~h}$ after administration in both control and tumor-bearing mice. $\mathbf{b}$ Captured $\mathrm{T}_{2}$-weighted MRI images during pre-injection and post-injection of the core-shell nanocarriers. Tumor regions are shown with the white, dashed circles. $\mathbf{c}$ The measured weight of the tumors of the treated and control mice. $\mathbf{d}$ Images of the tumors from the treated and control mice after the last injection (Abbreviation; $\mathrm{M}: \mathrm{Fe}_{3} \mathrm{O}_{4} @ \mathrm{TiO}_{2} @$ mesoporous $\mathrm{TiO}_{2}$ and $\mathrm{Mag}$ : under a magnetic force). Adapted from Ref. [175] with permission from the Royal Society of Chemistry

siRNA- and DOX-co-loaded core-shell nanocarriers were intensively raised in a time- and laser-dependent manner

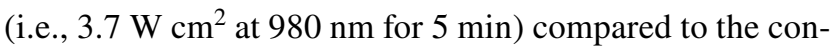
trol groups in vitro. Moreover, the NIR irradiation showed higher ROS generation (3.74-fold) than that of the irradiated cells at $365 \mathrm{~nm}$ (UV region). The tumor volume of the mice treated with siRNA and DOX-loaded magnetic $\mathrm{TiO}_{2}$ core-shell nanoparticles (the effective co-delivery system) was dramatically reduced to $255 \pm 32.2 \mathrm{~mm}^{3}$ compared to the control group (mean volume of $1914 \pm 122.8 \mathrm{~mm}^{3}$ ), and the combined therapy exhibited $92.4 \%$ of tumor growth inhibition without inducing acute toxicity to the vital organs [175].

Alternatively, laser irradiation of gold-decorated $\mathrm{TiO}_{2}$ nanomaterials might be effective for the optoporation process. By using an ultrafast continuous or pulsed NIR laser irradiation of the nanomaterials bound on the cell membrane, optoporation can gently perforate the membrane lipid bilayer of target cells and internalize transgenes into the cytoplasm [178]. Compared to the nanocarriers, which are internalized based on the endocytosis mechanisms and need to trigger an endosomal escape pathway for releasing the transgenes into the cytoplasm, optoporation strategy can directly internalize the transgenes (i.e., mRNA and siRNA delivery) into the cytoplasm and accelerate either an expression or suppression of target proteins $[19,178]$. For example, gold nanomaterials have been frequently used for the optoporation and subsequent delivery of siRNAs into the eye; however, this optoporation process is limited for the internalization of transgenes in deep tissues [179]. Therefore, a combined strategy based on laser and other treatments (i.e., ultrasound) may provide an adequate non-toxic energy and trigger plasmonic-modified $\mathrm{TiO}_{2}$ nanomaterials to perforate the cellular membrane in deep tissues for gene therapy.

\subsubsection{Photo- and Sonodynamic Therapy}

$\mathrm{TiO}_{2}$ nanomaterials that are sensitive to two-photon irradiation generate remarkable amounts of the oxidative stress (ROS affects mitochondrial depolarization and caspase protein up-regulation) and induce hyperthermia that in turn initiates tumor cell apoptosis and necrosis [180]. For example, the hyperthermia effects appearing at temperatures higher 

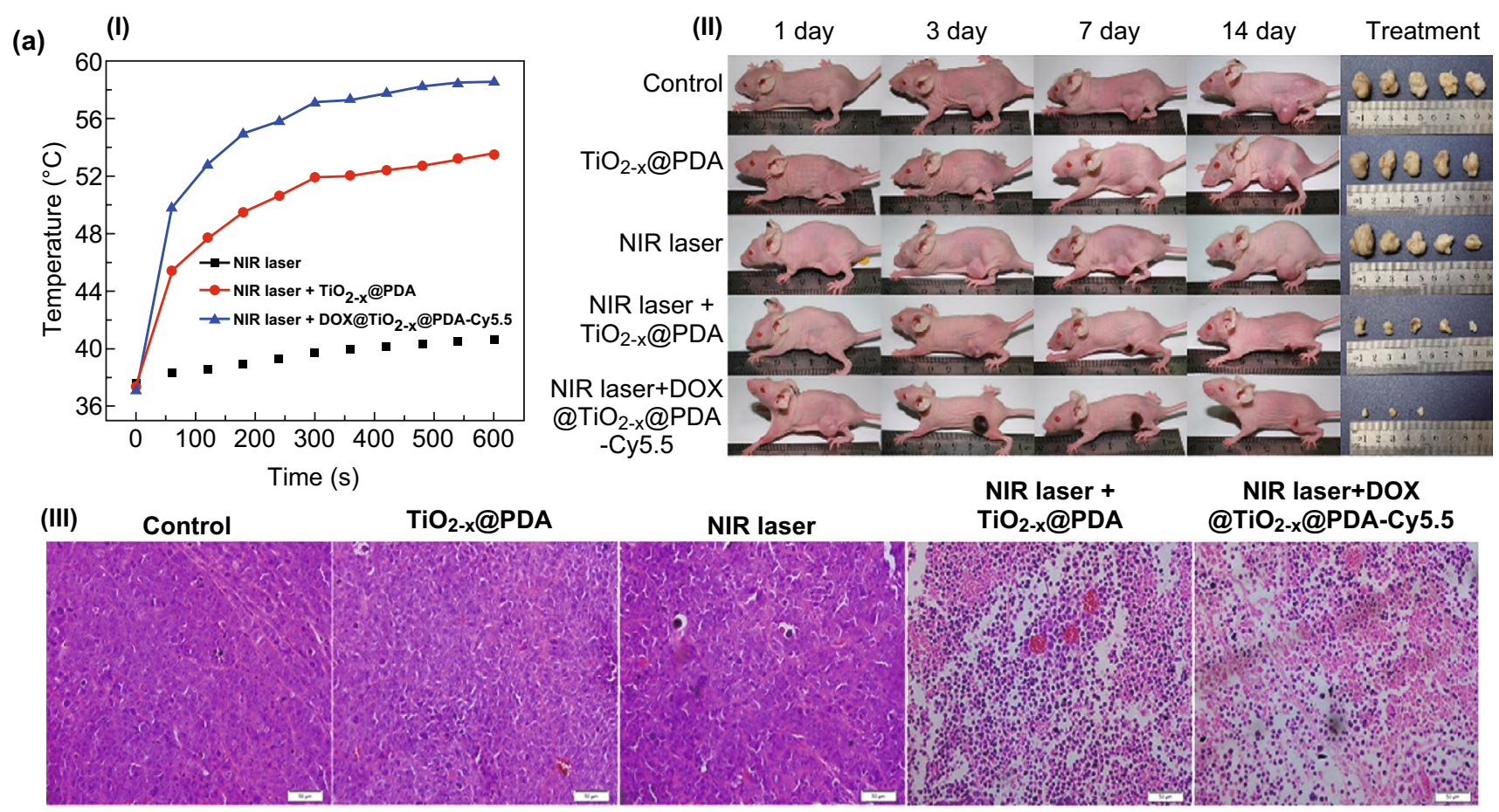

(b)

(III) Control $\mathrm{TiO}_{2-\mathrm{x}} @ \mathrm{PDA}$

Control
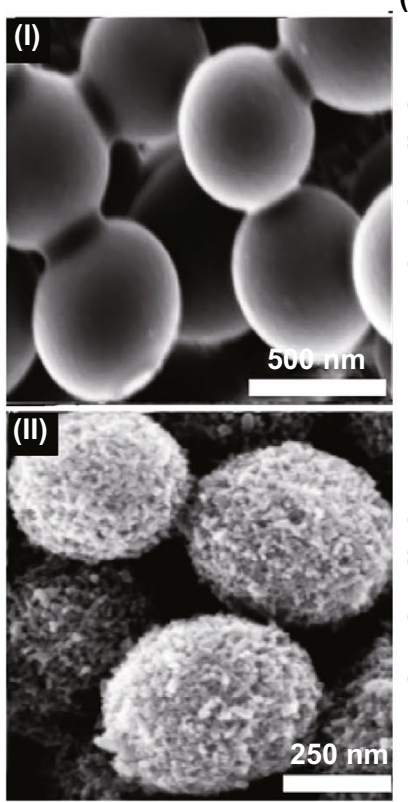

(III)
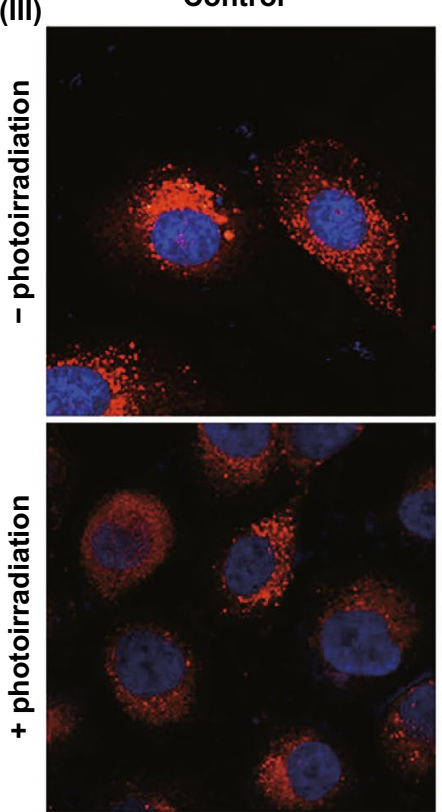

Pops
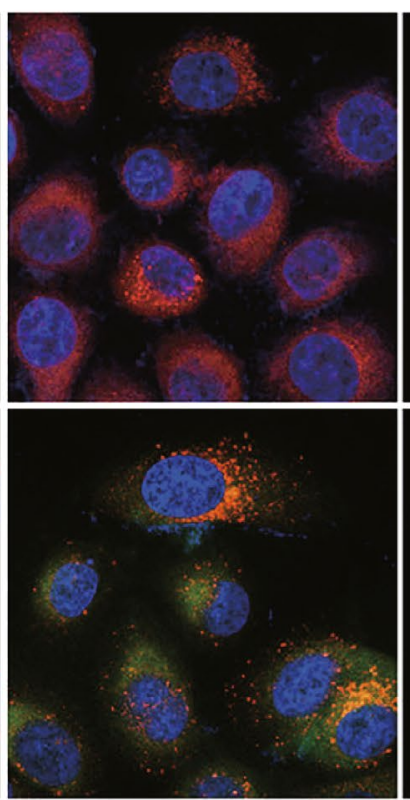

Nanoparticles

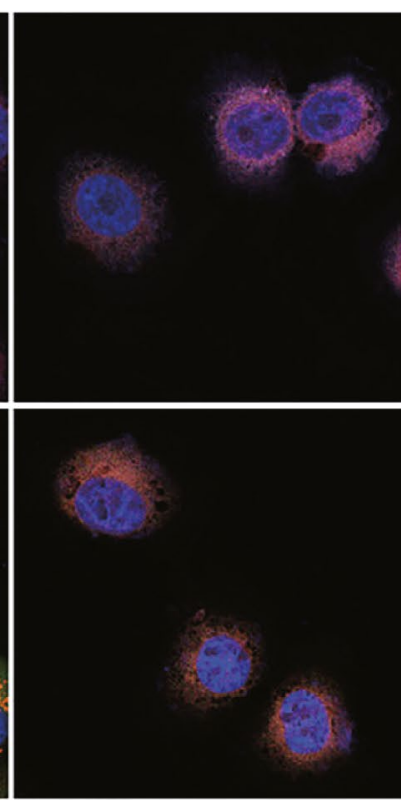

Fig. 7 a Black $\mathrm{TiO}_{2}$ nanocarriers employed for a chemo/photodynamic/photothermal therapy in vivo. The efficient temperature raise (a-I) caused by black $\mathrm{TiO}_{2}$ nanocarriers (DOX@ $\left.\mathrm{TiO}_{2-\mathrm{x}} @ \mathrm{PDA}-\mathrm{Cy} 5.5\right)$ under NIR irradiation $\left(808 \mathrm{~nm}, 1.0 \mathrm{~W} \mathrm{~cm}^{-2}\right.$ ) triggers (a-II) a tumor growth inhibition. (a-III) Histological sections of the treated tumors indicate a noticeable cellular necrosis and apoptosis. Adapted from Ref. [47] with permission from the American Chemical Society. b Upon on/off-switchable photoactivation, $\mathrm{TiO}_{2}$ pops generate high-turnover, flash intracellular ROS. SEM images of mesoporous $\mathrm{TiO}_{2}$ Pops (b-I) before and (b-II) after solvothermal treatment. (b-III) The intracellular ROS generation using pops and smooth nanoparticles in the presence $(+)$ and absence $(-)$ of the irradiation. The green, red, and blue colors represent the intracellular ROS, mitochondria, and nucleus, respectively. Adapted from Ref. [15] with permission from the Springer Nature. (Color figure online) 
than $46^{\circ} \mathrm{C}$ can be generated by exposing the treated cells to NIR laser irradiation. Nevertheless, hyperthermia and ROS generation depend on the concentration, structure, geometry, and crystallinity of $\mathrm{TiO}_{2}$ nanomaterials employed [14-16]. Regardless of the photocatalytic efficiency and photostability of $\mathrm{TiO}_{2} \mathrm{NSs}$, their low quantum yield is a significant drawback. Therefore, a lattice modification of $\mathrm{TiO}_{2}$ (i.e., conversion to the magnéli-phase $\mathrm{Ti}_{8} \mathrm{O}_{15}$ ) can significantly improve the originally low quantum yield and weak photodynamic properties [181]. Alternatively, a thermal hydrogenation of $\mathrm{TiO}_{2} \mathrm{NSs}$ can generate black nanomaterials, with the presence of $\mathrm{Ti}_{3}{ }^{+}$ions, oxygen vacancies, structural disorder/defects in the surface, Ti-OH groups, Ti-H groups, or modified valence band edge, which can improve photocatalytic activities $[12,13]$. A short exposure of black $\mathrm{TiO}_{2}$ nanoparticles to a NIR laser irradiation can kill almost all treated cancer cells and significantly reduced tumor volume compared to the control groups in vivo [13]. The NIR irradiation-responsive drug release system based on black $\mathrm{TiO}_{2}$ nanoplatforms (DOX@ $\left.\mathrm{TiO}_{2-\mathrm{x}} @ \mathrm{PDA}-\mathrm{Cy} 5.5\right)$ has also been employed as a powerful strategy (a combined chemo/photodynamic/photothermal therapy) to inhibit the growth of breast cancer tumor in vivo (Fig. 7a). The DOX-loaded black $\mathrm{TiO}_{2}$ nanoparticles capped by polydopamine $\left(1 \mathrm{mg} \mathrm{mL}^{-1}\right)$ under NIR irradiation $\left(808 \mathrm{~nm}, 1.0 \mathrm{~W} \mathrm{~cm}^{-2}\right)$ were able to generate a temperature raise ( $\Delta \mathrm{T}$ up to $\sim 24^{\circ} \mathrm{C}$ ) and caused a significant intracellular ROS generation and cell death ( 95\%) compared to each strategy carried out separately in vitro. Although the release of DOX from the nanocarriers is $\mathrm{pH}$ dependent, the use of NIR laser irradiation has additionally brought a switchable (on/off) release for the encapsulated DOX from the nanocarriers at both acidic and natural environments. The black $\mathrm{TiO}_{2}$ nanoparticles taking advantage of the combined chemo/photodynamic/photothermal therapies have also indicated a tumor growth inhibition feature in vivo, because those control groups receiving only photodynamic or photothermal therapy have met a poor therapeutic effect, and the irradiated tumors began growing 10 days after the treatment. The evaluation of histological sections of the irradiated tumor (treated animal models with DOX@ $\mathrm{TiO}_{2-\mathrm{x}} @ \mathrm{PDA}-\mathrm{Cy} 5.5$ ) also pointed out a massive cell necrosis and apoptosis compared to the control groups [47]. The biocompatible, mesoporous, $\mathrm{TiO}_{2}$ popcorn nanoarchitectures also offer a super-photocatalytic activity, which generates high-turnover, flash intracellular ROS (on/ off-switchable photon-triggered ROS production) compared to smooth $\mathrm{TiO}_{2}$ particles (Fig. 7b). A solvothermal treatment $\left(\mathrm{TiO}_{2}\right.$ beads mixed with ethanol/DI water $(2: 1 \mathrm{v} / \mathrm{v})$ and $0.55 \mathrm{M}$ ammonia solution and kept at $170{ }^{\circ} \mathrm{C}$ for $18 \mathrm{~h}$ ) generates non-toxic $\mathrm{TiO}_{2}$ Pops $(500 \pm 50 \mathrm{~nm}$ in diameter and surface area up to $100 \mathrm{~m}^{2} \mathrm{~g}^{-1}$ ) with the anatase crystallinity and interacts much better with the complexity of the cellular membrane (i.e., lipid bilayer leakage) in comparison to the rutile structure. The intracellular ROS can be generated in prostate cancer cells (2.5-fold higher) by the photon excitation $\left(3.5 \mathrm{~mW} \mathrm{~cm}^{-2}\right.$ at $\left.365 \mathrm{~nm}\right)$ of non-toxic $\mathrm{TiO}_{2}$ popcorn nanoarchitectures compared to the control groups without photoinduction [15].

A simple incorporation of noble metals into the surface of $\mathrm{TiO}_{2} \mathrm{NSs}$ alternatively improves quantum properties required for the generation of functional anticancer ROS [14]. For example, cobalt and nitrogen-doped $\mathrm{TiO}_{2}$ nanocrystals and $\mathrm{TiO}_{2}$-coated gold nanoparticles can enhance the photoactivation in the visible/NIR region [182]. An electrochemical deposition, e.g., of silver on the surface and a nitrogen doping of $\mathrm{TiO}_{2}$ nanoparticles can also change the treated cell morphology and increase ROS generation in human keratinocytes $(\mathrm{HaCaT})$ and human lung epithelial cells (A549) and cause cell death via a late apoptosis/necrosis [183]. Due to a fast growth of new blood vessels for supplying oxygen and nutrients in tumors, antiangiogenesis is an advantage preventing the vascular growth and causes a significant tumor necrosis. Exposing tumors with internalized $\mathrm{TiO}_{2}$ nanomaterials to the second NIR irradiation (NIR-II) region (1000-1350 $\mathrm{nm}$ ) can create efficient photoreactive effects against malignant tumors. $\mathrm{TiO}_{2}$-coated Au nanobipyramids, for example, have shown a high photothermal conversion efficiency up to $\sim 93 \%\left(\Delta \mathrm{T}: \sim 27^{\circ} \mathrm{C}\right)$ under NIR-II irradiation (at $1064 \mathrm{~nm}$ ). The incorporation of anticancer combretastatin A-4 phosphate drug into the $\mathrm{TiO}_{2}$-coated $\mathrm{Au}$ nanobipyramids combined anticancer and antiangiogenesis activities has inhibited a lung tumor growth (0.4-fold smaller compared to the initial tumor size) in vivo [184].

Alternatively, ROS generation through the use of $\mathrm{TiO}_{2}$ nanomaterials sensitive to ultrasound has been recently improved as a means to kill cancer cells in deep tissues [185]. Au nanocrystals grown on the edge of the $\mathrm{TiO}_{2}$ nanosheets (band gap $2.90 \mathrm{eV}$ ) can induce an effective ROS generation through an ultrasound irradiation compared to pure $\mathrm{TiO}_{2}$ nanosheets (band gap $3.2 \mathrm{eV}$ ), and the engineered band gap prevents the fast recombination of excited electrons and holes that can improve the quantum yield of the ROS 
generation in vitro and in vivo [186]. The hydrophilized $\mathrm{TiO}_{2}$ nanoparticles activated by ultrasound can also generate ROS in the superficial tumors (i.e., intense vascular damage and proinflammatory cytokines) and suppress the growth of deep liver tumors ( 15-fold) far more extensively than in the tumor-bearing mice without the ultrasound treatment [185]. In fact, sonodynamic therapy is limited to generating sufficient ROS against multidrug-resistant cancer due to the efflux of photosensitizer molecules from the P-glycoprotein [187]. Conjugating the trans-activator of transcription peptides on the surface of $\mathrm{TiO}_{2} \mathrm{NSs}$ can therefore overwhelm the effects of the P-glycoprotein and generate sufficient amounts of ROS, which directly breaks double-stranded DNA [187,
188]. Due to the nature of $\mathrm{TiO}_{2}$ nanomaterials sensitive to photo- and sono-dynamic therapy, a combined strategy may significantly improve the ROS generation and therapeutic efficacy.

\subsection{Medical Diagnosis}

\subsubsection{Bioimaging}

Early-stage diagnosis and comprehensive understanding of diseases for employing an efficient therapy can be established through using ultrasensitive bioprobes [189]. A nontoxic surface modification by using a fluorescent molecule

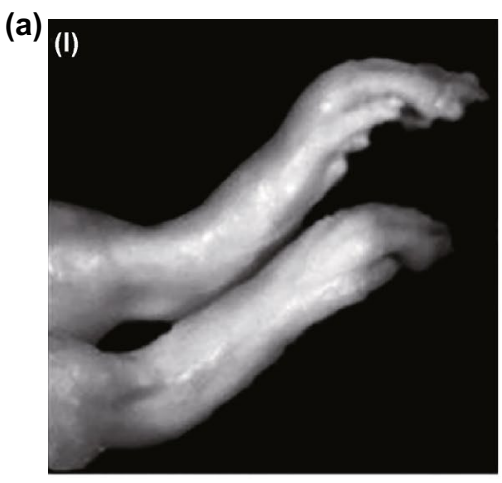

(b)

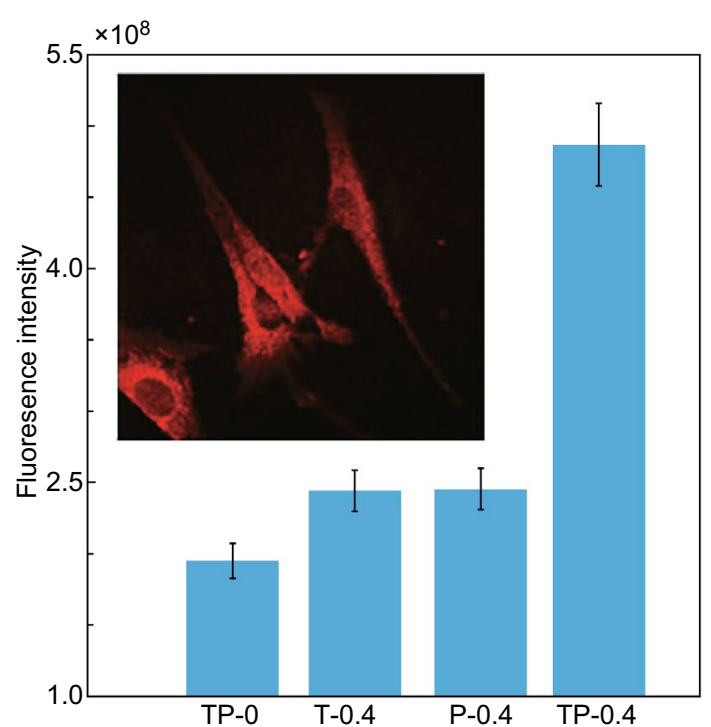

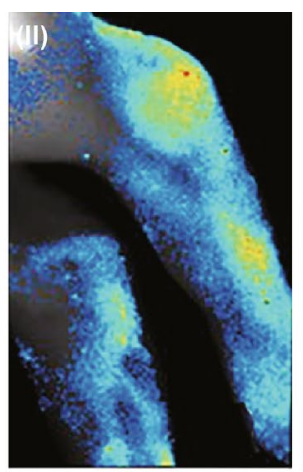

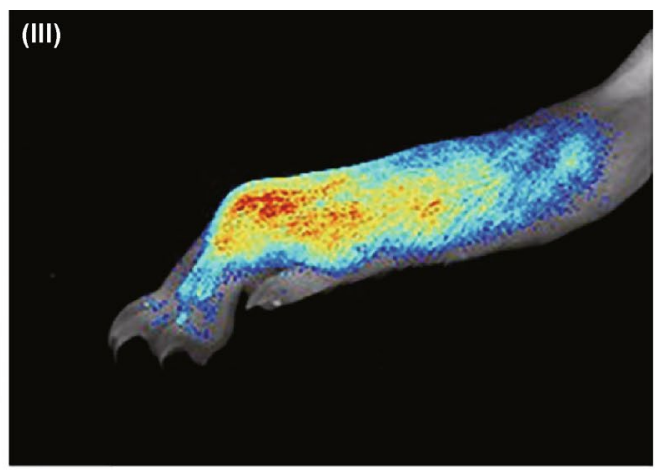

(c)

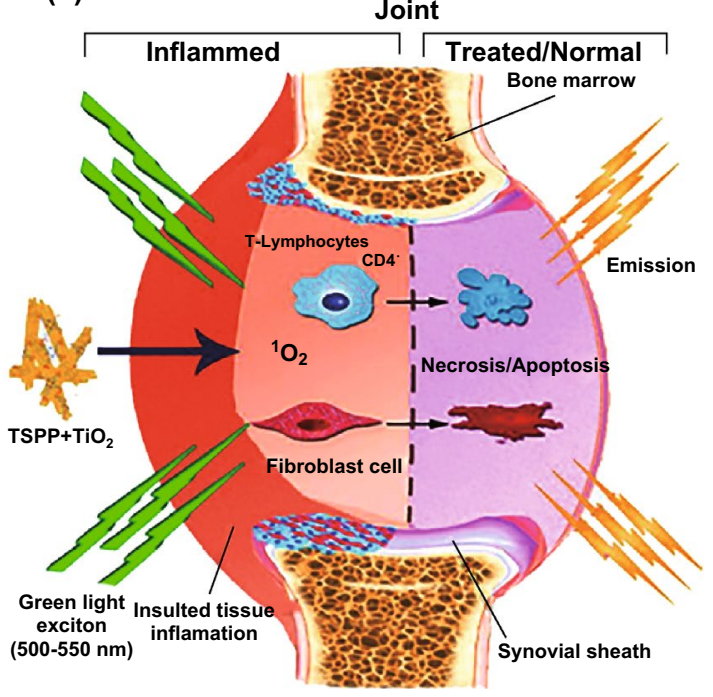

Fig. 8 a Detection of rheumatoid arthritis using TSPP-modified $\mathrm{TiO}_{2}$ nanowhiskers; control sample (I), TP-0, shows no fluorescence; however, TP-0.4 (II) shows fluorescence at tibia-tarsal joint, and (III) in the infected foot. b The fluorescence intensities of different treatment groups illustrate the highest intensity for the group treated with TP-0.4. The inset shows fibroblasts from the rats' RA joint with a bright red intracellular fluorescence. c Bioimaging and PDT properties of the TSPP and $\mathrm{TiO}_{2}$ nanowhiskers in the rheumatoid arthritis joint. The injection of $0.4 \mathrm{~mL}$ of TSPP-conjugated $\mathrm{TiO}_{2}$ nanowhiskers (TP-0.4), $0.4 \mathrm{~mL}$ of TSPP (P-0.4), $0.4 \mathrm{~mL}$ of $\mathrm{TiO}_{2}$ nanowhiskers (T-0.4), and control group without the injection (TP-0). Adapted from Ref. [23] with permission from the Springer Nature 
such as rhodamine $\mathrm{B}$ on the surface of anatase $\mathrm{TiO}_{2}$ nanoparticles can be the easiest option for the bioimaging of the target cells [190]. The sandwich-type electrochemiluminescence based on the tetragonal rutile $\mathrm{TiO}_{2}$ mesocrystals has also been developed to detect zearalenone, which is a mycotoxin secreted by Fusarium (human food contaminants). In most cases, a solution probe containing $\mathrm{Ru}(\mathrm{bpy})_{3}^{2+}$ is incubated with an electrochemiluminescence setup to detect the target molecules; however, their immobilization on the surface of the $\mathrm{TiO}_{2}$ mesocrystals can amplify the emitted signal from the detected zearalenone [22]. However, long-term and real-time imaging, which is limited to conventional organic dyes and fluorescent proteins due to their short emission lifetimes, requires elaborated, stable bioprobes [44]. Recent studies also show that an extra doping procedure with gaseous nitrogen and other metallic elements generates photoluminescent $\mathrm{TiO}_{2}$ nanomaterials by changing the electron movement within the lattice and energy levels [191, 192].

Noninvasive detective and tracking strategies have been developed based on $\mathrm{TiO}_{2}$ nanomaterials in vivo. Tetera sulfonatophenyl porphyrin (TSPP)-conjugated $\mathrm{TiO}_{2}$ nanowhiskers, for example, have been developed as an effective fluorescence bioimaging and photodynamic agent for rheumatoid arthritis (RA) theranostics in vivo (Fig. 8). Fluorescence images can illustrate the tissue localization and cellular internalization of nanowhiskers in the RA synovium due to the excitation between 500 and $550 \mathrm{~nm}$. An overview image of the infected feet and tibia-tarsal joint with the arthritis revealed a very strong fluorescence on day 16 , and the exact location of the arthritis in the infected foot has been determined through imaging of the sagittal sections of the infected joints, which only emitted the fluorescence signal. These nanocomposites $\left(\mathrm{TSPP}_{-} \mathrm{TiO}_{2}\right.$ ) can also produce singlet oxygens upon the green light excitation to necrotize the local cells (i.e., fibroblasts, and lymphocytes) due to an interference with the cellular pathways of adjacent cells. Although ${ }^{1} \mathrm{O}_{2}$ lifespan of singlet oxygens generated within the tissue is short $(\sim 3 \mu \mathrm{s})$, the ROS resides for a longer period of time $(\sim 18 \mathrm{~h})$ in the target tissue, efficiently causing apoptosis to the cells [23]. A simple surface modification (e.g., of gold grown on the edge of $\mathrm{TiO}_{2}$ nanosheets by using mitochondria-targeted triphenylphosphine and AS1411 aptamer) can enhance the computed tomography imaging of intracellular compartments due to the high atomic number of the grown gold nanomaterials [186].
Nuclear medicine imaging strategies, such as the positron emission tomography, are an alternative tool for a noninvasive detection and tracking in vivo due to their relatively long-time stability. For example, the incorporation of $\alpha$ and $\beta$ emitters with $\mathrm{TiO}_{2}$ nanomaterials (i.e., ${ }^{48} \mathrm{~V}$ radionuclides) has been developed to generate supersensitive theranostic nanoprobes. The study on an animal model indicated a quantitative ${ }^{48} \mathrm{~V} \mathrm{TiO}_{2}$ nanoparticles balancing of all organs (largely accumulated in the liver) without an interfering chemical background, and following the clearance process from $1 \mathrm{~h}$ to 4 weeks after the administration [193].

A magnetic resonance imaging (MRI) is a noninvasive clinical imaging technology, which has often been employed for disease diagnosis. In certain cases, MRI requires a contract agent, such as gadolinium (Gd), manganese, and iron oxide nanoparticles to enhance the visibility of tissues [194]. The development of MRI contrast agents based on Gd-enriched nanoprobes (i.e., enhance $\mathrm{T}_{1} \mathrm{MRI}$ contrast) and superparamagnetic $\mathrm{Fe}_{3} \mathrm{O}_{4}$ and $\mathrm{CoFe}_{2} \mathrm{O}_{4}$ nanoparticles (i.e., improve $\mathrm{T}_{2} \mathrm{MRI}$ contrast) is an advantage due to the adjustable conjugation of biomolecules on the surface, biodistribution, and magnetic property. A noninvasive tracing MRI agent, such as $\mathrm{Gd}$-modified $\mathrm{TiO}_{2}$ nanoparticles, can visualize and verify the desired accumulation at the target tissue before triggering the release of cargo from stimuli-responsive nanocarriers and minimizing the side effects [24]. The biodistribution and accumulation of $\mathrm{Gd}$ - or $\mathrm{Fe}_{3} \mathrm{O}_{4}$-modified black $\mathrm{TiO}_{2}$ nanoparticles (high photothermal conversion efficiency) in the tumor can be precisely monitored for an effective photothermal therapy $[12,13]$. Interestingly, the non-modified $\mathrm{TiO}_{2}$ nanoparticles (without adding magnetic or other contrast agents) can also improve MRI $\mathrm{T}_{2}$ proton relaxation time-weighted sequences as a contrast agent with the high concentration [25].

\subsubsection{Biosensors}

Diagnosing and monitoring diseases rely on the precise detection of biomolecules (proteins, genes, and cells, etc.) and can easily indicate a possible abnormality in the body. Both passive and active detection strategies must offer the ability to perform rapid in situ monitoring for health maintenance [195, 196]. Label-free $\mathrm{TiO}_{2}$ biosensors have been employed for the rapid detection of biological interactions converted to optical, electrical, and thermal signals. 
Amperometric biosensors, which consist of an oxidase and peroxidase, have proven critical in preventing issues related to enzyme instability and degradation [197, 198]. Enzymatic biosensors composed of an immobilized Prussian blue and an enzyme glucose oxidase on the surface of gold/TiO ${ }_{2}$ tubular nanocomposites have exhibited a rapid responsiveness, wide linear range, and stability [92]. Conversely, optical interferometric and surface-plasmon-based biosensors have been successfully used to design label-free $\mathrm{TiO}_{2}$ biosensors. For example, stable $\mathrm{TiO}_{2}$ nanotubes fabricated to sense rabbit immunoglobulin $\mathrm{G}(\mathrm{IgG})$ with optical interferometry (reflective interferometric Fourier-transform spectroscopy) exhibited super-sensitivity as well as real-time detection [30]. In fact, the porous structure of $\mathrm{TiO}_{2}$ nanotubes has a strong impact on the sensitivity of biosensors due to higher surface activity and greater electron transfer rates. The mesoporous nanostructures (glucose oxidase electrode), easily coordinate amine and carboxyl groups on the surface, behave as an electron mediator and improve the electron transfer between the redox centers of the enzymes and the electrode surface [199].

Photoelectrochemical biosensors are the alternative detection device based on the charge separation and transfer upon illumination and are highly dependent on substrates as a photoactive material. Modified $\mathrm{TiO}_{2}$ tubular arrays, absorb and respond to the visible light and can also play a critical role in the generation of cost-effective ultrasensitive biosensors [200, 201]. The surface modification of $\mathrm{TiO}_{2}$ nanotube arrays by means of polydopamine can facilitate the horseradish peroxidase decoration for a quantitative $\mathrm{H}_{2} \mathrm{O}_{2}$ detection (range from $1 \mathrm{nM}$ to $5 \mu \mathrm{M}$ ) combined with an enzymeinduced biocatalytic precipitation amplification [200]. The copper-doped $\mathrm{TiO}_{2}$-grafted $\mathrm{C}_{3} \mathrm{~N}_{4}$ as a photosensitizer, for example, has improved the detection of the emitted signal from the alkaline phosphatase and catalyzed the ascorbic acid 2-phosphate to ascorbic acid as a direct electron donor (reduced background signal interference) [202].

An ultrasensitive photoelectrochemical cytosensing platform has been developed through an electrochemical reduction in graphene (EG)/ZnIn $\mathrm{S}_{4}$-co-sensitized $\mathrm{TiO}_{2}$ and immobilization of phosphatidylserine-binding peptides to capture apoptotic cells. Compared to other assays, a stable and nontoxic photoelectrochemical cytosensing platform based on the reduction in the photocurrent signal can exactly detect and capture apoptotic cells (a linear range from $1 \times 10^{3}$ to $5 \times 10^{7}$ cells $\mathrm{mL}^{-1}$ ). This platform can also retain the normal cell growth and proliferation for further precise assessments of therapeutic effects [201]. A label-free microfluidic immunosensor with high sensitivity (a range from $1 \times 10^{-15}$ to $0.1 \times 10^{-6} \mathrm{M}$ ) and selectivity has also been developed for an early detection of epidermal growth factor receptor 2 (quantify breast cancer biomarkers) based on an immunoelectrode made of porous hierarchical graphene foam modified with electrospun carbon-doped titanium dioxide nanofibers (as an electrochemical working electrode). This porous hierarchical graphene foam composition with functional carbon-doped $\mathrm{TiO}_{2}$ nanofibers has shown an increased charge transfer resistance, surface area, as well as improved porous access to the sensor surface by the analyte [27].

The post-fabrication of $\mathrm{TiO}_{2}$ electrodes with receptors associated with targeted molecules makes field-effect transistor (FET) biosensors a versatile probing device. A real-time, selective, and sensitive FET biosensor accompanied by an electrode composed of $\mathrm{TiO}_{2}$ nanowires has been furthered for targeting IgG proteins at the nanogram level [203]. As a matter of fact, a contamination of biosensors in the non-labeled area can reduce the sensitivity of functional substrates. Biosensors also face the obstacle of remaining analytes making FET biosensors non-reusable after detection. However, a reusable FET biosensor based on $\mathrm{TiO}_{2}$ composites encapsulated in graphene oxide has been recently introduced for a protein detection without sensitivity losses [29]. The immobilization of monoclonal antibodies on the surface of $\mathrm{TiO}_{2}$ nanowire bundles can also create a microelectrode-based FET sensor for a rapid and sensitive detection of Listeria monocytogenes without interfering with other foodborne pathogens [204].

$\mathrm{TiO}_{2}$ nanofibers outfitted with cell-capture agents exhibit a remarkable ability to capture circulating colorectal and gastric tumor cells [108]. Moreover, gold-coated $\mathrm{TiO}_{2}$ butterfly-like three-dimensional membranes decorated by lectin molecules have demonstrated a selective recognition between highly invasive (T47D) and less invasive (MCF7) cancer cell lines [26]. Capturing the cancer cells in order to culture them for further investigations is an advantage that has been obtained by using gelatin film-coated $\mathrm{TiO}_{2}$ nanopillar arrays. Due to the high surface area and the interaction with the cell membrane's antigens, the capture efficiency was achieved up to $94.98 \%$, and a rapid digestion of the gelatin layer provided a nondestructive release of the captured cells for future proliferation [205]. Replacing the antibodies and other biomolecules with aptamers can be an alternative strategy for amplifying the detection sensitivity beyond that of conventional biosensors. Mesoporous 

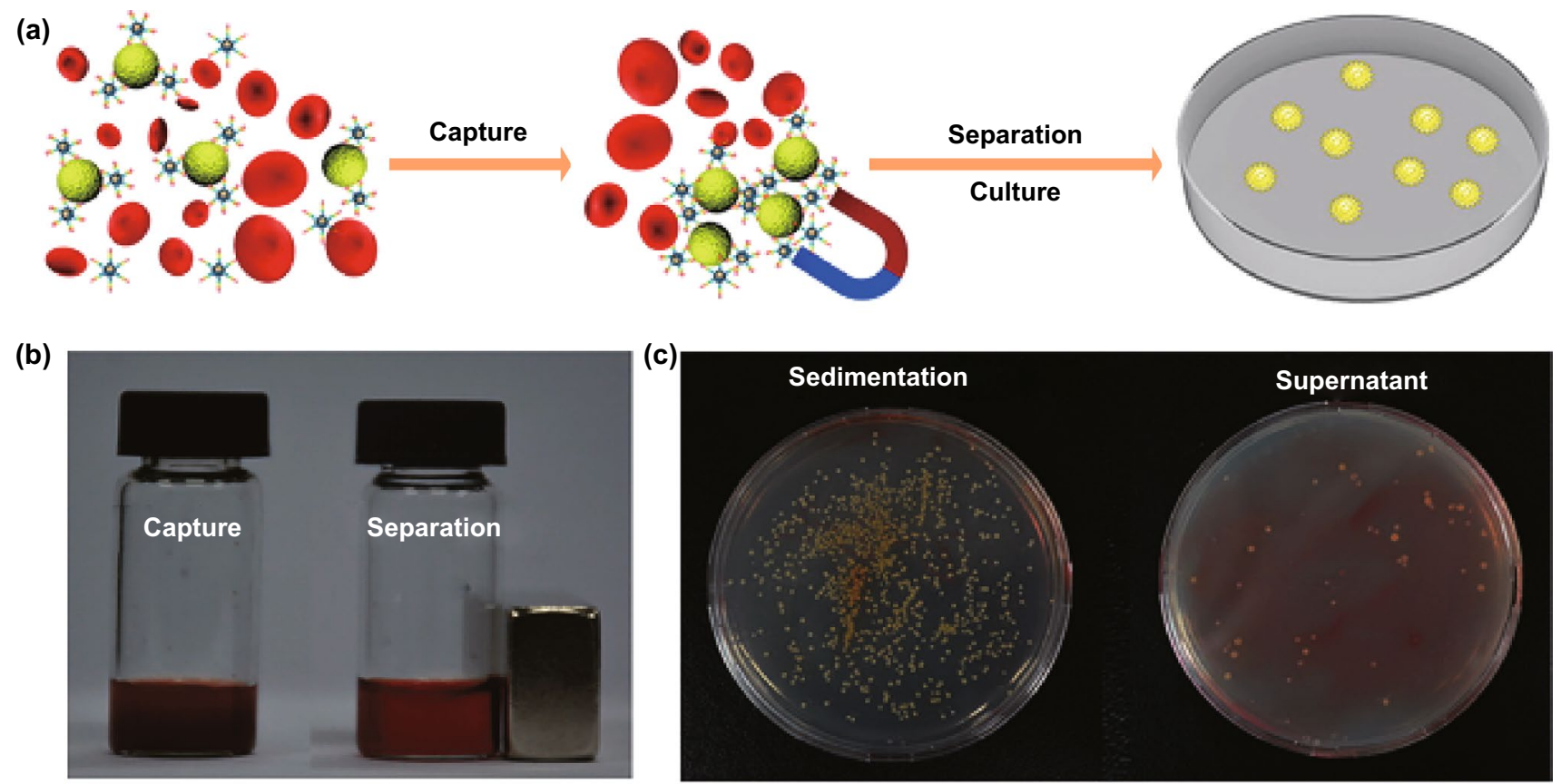

(b)

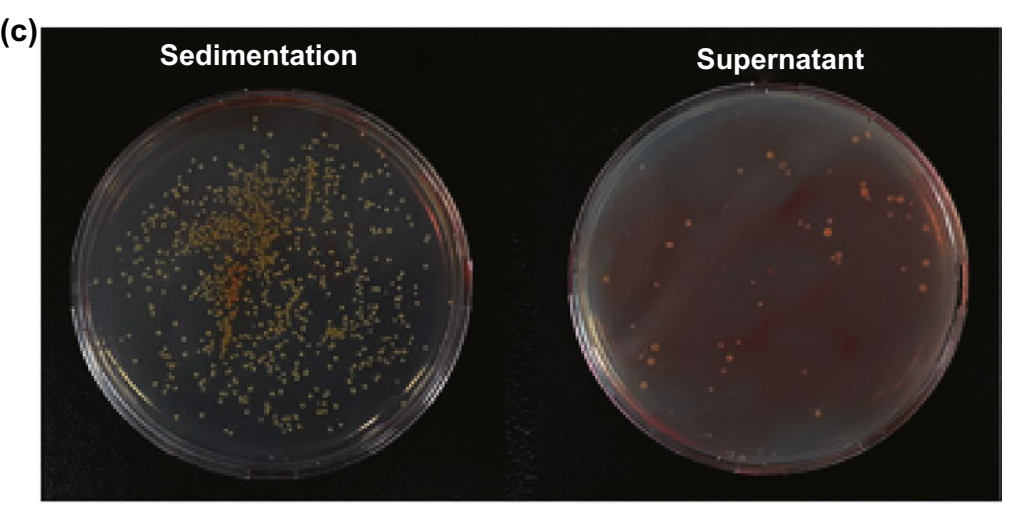

(d)

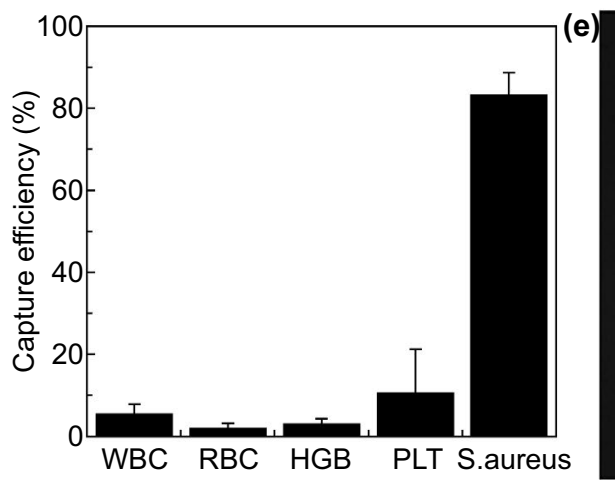

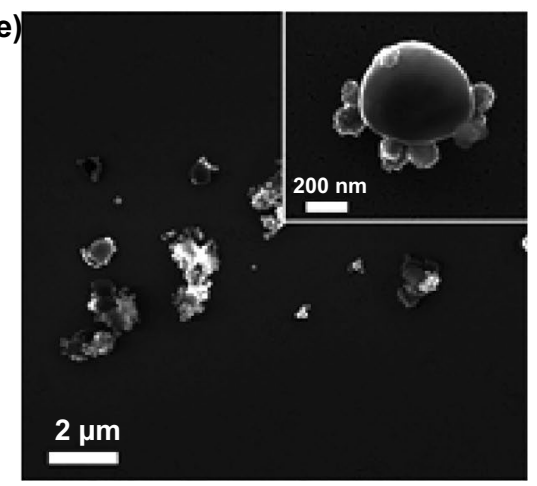

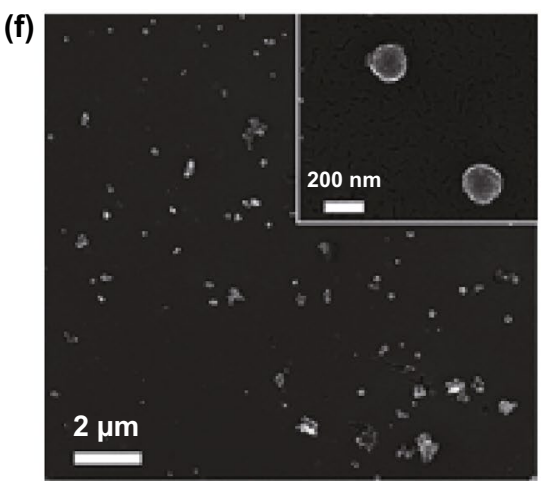

Fig. 9 a The illustration represents the strategy for the identification and capture of pathogenic bacteria (S. aureus). b The photograph exhibits the capture (left) and separation (right) of bacteria with $\mathrm{Fe}_{3} \mathrm{O}_{4} / \mathrm{TiO}_{2}$ core-shell nanoparticles from an infected blood. c The number of colonyforming units in the re-cultured $S$. aureus from sediment and supernatant in agar plates after the separation. d Capture efficiency of different compounds in blood after being treated with $\mathrm{Apt}_{\text {S.aureus }}-\mathrm{Fe}_{3} \mathrm{O}_{4} @ \mathrm{mTiO}_{2}$. SEM images of the captured S. aureus (e) and non-captured E. coli (f) with the aptamer decorated nanoparticles. Adapted from Ref. [28] with permission from the American Chemical Society

$\mathrm{TiO}_{2}$-coated magnetic nanoparticles have been decorated with a sensitive aptamer to fabricate a pathogen capture platform in the blood stream (Fig. 9). The presence of aptamers and iron nanoparticles (core) facilitates the identification, capture, and separation of the bacteria. The conjugation of aptamer on the nanoparticles to detect $S$. aureus cells indicated that the capture efficiency of the platform was about $83 \%$. Current strategy in clinics uses a continuous blood culture system, which is incubated with the blood sample collected from the patient, and the production of metabolite in the culture indicates possible bacterial infections in a time-consuming manner (up to several days). However, aptamer-functionalized nanoplatforms can precisely capture and then separate the target bacteria from the blood sample (using a magnetic force) with a negligible capture of other cells (i.e., white and red blood cells, hemoglobin, and platelets) (Fig. 9d). In addition, an efficient capture of $S$. aureus by the aptamer-modified nanoparticles was found, and highlighted this selectivity mechanism based on the creation of a sequence-defined unique structure (Fig. 9e, f). The inoculated bacteria on solid medium can be further used for different examinations such as colony counting, owing to quick enrichment within $2 \mathrm{~h}$. The bacterial enrichment of clinical blood 
samples due to the high selectivity and strong affinity of the aptamers might be an elaborate strategy to regulate administration of an effective antibiotic therapy at an early stage [28].

\subsection{Tissue Regeneration and Chronic Wound Healing}

The human body's self-healing process is slow when the injury is severe. However, the body indeed accepts external aids from implanted biological tissues and organs grown in the laboratory as a means to accelerate the healing process. It is crucial that scaffolds or implants in the body communicate with the surrounding microenvironment since the recipient's immune system may very likely cause rejection. Biocompatible $\mathrm{TiO}_{2}$ nanomaterials are one of the greatest implantable materials for tissue regeneration owing to their properties of high tensile strength, flexibility, and corrosion resistance. The morphology of $\mathrm{TiO}_{2}$ nanomaterials (i.e., nanotubes) is, nevertheless, the most important factor in improving cell adhesion, proliferation, and differentiation [35, 36]. A scaffold composed of polylactic-co-glycolic acid (PLGA) and $\mathrm{TiO}_{2}$ nanoparticles as well as decorated glass with $\mathrm{TiO}_{2}$ nanoparticles can improve the amount of precipitated calcium for bone regeneration compared to the scaffold without $\mathrm{TiO}_{2}$ nanoparticles [206, 207]. The adhesion and spreading of osteoblast cells with a complete integration can also be attained with composites made of polylactic acid (PLA),

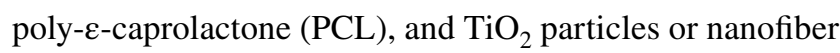
meshes mimicking the bone regeneration properties [37, 38]. Compared to functionalized nanomaterials, it was observed that mesenchymal stem cells prefer to migrate without the interfering features of bare $\mathrm{TiO}_{2}$ nanoparticles. It was shown that bare $\mathrm{TiO}_{2}$ nanoparticles with different sizes can induce negative impacts on viability, adhesion, migration, proliferation, and differentiation of mesenchymal stem cells in a size- and dose-dependent manner in vitro; however, small bare $\mathrm{TiO}_{2}$ nanoparticles can activate the migration of mesenchymal stem cells compared to larger bare nanoparticles (Fig. 10a). The alkaline phosphatase activity, which determines an early mineralization-related protein marker for osteogenesis of osteoblasts, was also increased in the mesenchymal stem cells treated with $\mathrm{TiO}_{2}$ nanoparticles (14 nm in diameter) after 2 weeks compared to those treated with bigger nanoparticles (108 and $196 \mathrm{~nm}$ in diameter) [208]. Biomolecule- $\mathrm{TiO}_{2}$ nanohybrids can be an advantage due to improving antibacterial and -inflammatory features and biocompatibility without increasing the content of $\mathrm{TiO}_{2}$ in vital organs.

In the case of $\mathrm{TiO}_{2}$ tubular arrays, for example, the diameter, porosity, and curved surface regions of the tube directly affect cell viability and proliferation $[35,36]$. Slight changes in the microenvironment can alternatively regulate osteoblast responses during integration of implants with host bones. Iron-doped $\mathrm{TiO}_{2}$ nanotubes $(4.25 \mathrm{wt} \% \mathrm{Fe}$ ), for example, can alter the microenvironment and enhance the proliferation, gene expression of osteogenesis-related proteins, collagen secretion, and extracellular matrix mineralization of osteoblasts compared to as-formed tubular implants [209]. Icariin, a traditional Chinese medicine with a strong antiapoptotic ability in osteocytes and osteogenic function, can also be loaded into $\mathrm{TiO}_{2}$ nanotubular implant to obtain a slow release of the cargo (over 2 weeks) and promote osteoblast cell adhesion, proliferation, and differentiation in vivo [210]. Among other things, biomolecule coverage, which uses bone morphogenetic protein 2 and a peptide fragment of bone sialoprotein on the surface (e.g., $\mathrm{TiO}_{2}$ nanotubes and nanofibers), alternatively exhibits significant proliferation and osseointegration [211, 212]. Recently, a conjugation of sclerostin antibody on the surface of nanotubes, which stimulated Wnt signaling pathway by the reduction in the sclerostin secretion from MLO-Y4 cells (murine osteocytelike cell line), also promoted the differentiation of osteoblasts in a co-culture [213].

The use of $\mathrm{TiO}_{2}$ nanoparticles can also effectively accelerate the wound-healing procedure in vivo for both seconddegree and fourth-degree burns. Triggering factor XII (FXII) and contact system-triggered pathways can cause blood coagulation and clot formation for wound healing. Therefore, $\mathrm{TiO}_{2}$ sol sprayed on the burn wounds in rats adapted to a second-degree burn (groups 1 and 2, untreated and treated, respectively), and a fourth-degree burn (groups 3 and 4 , untreated and treated, respectively) showed a boosted reduction in the exposed wound area (Fig. 10b). The treated wounds with nanoparticles (group 2) have revealed a healing outcome comparable to the normal skin conditions without showing a skin structure alteration, whereas the group 1 without the treatment was subjected to the thickened fibers lying tightly in the papillary layer with a reduced population of glands and flattened sweat epithelium. The activation of fibroblasts and overproduction of the basic substance were also observed at the reticular layer of these rats (group 1). Severe abnormalities (i.e., damaged epithelium and 


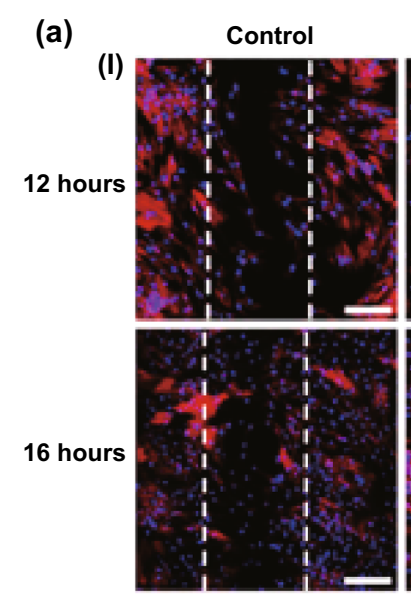

(b) (I)

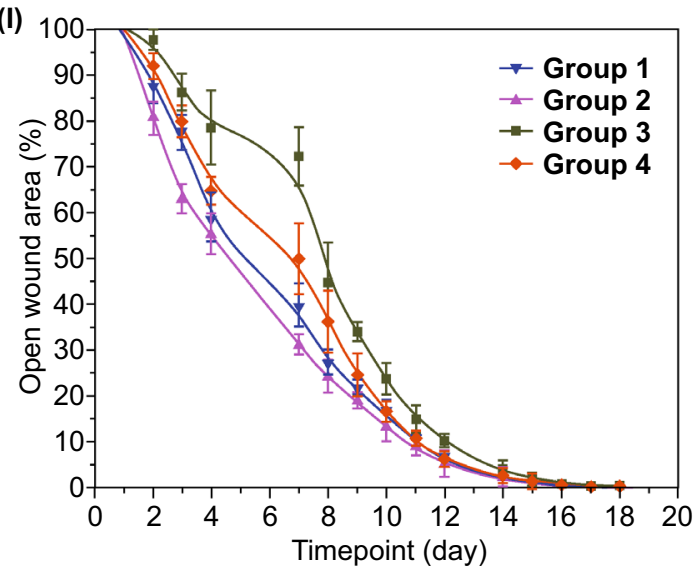

(II)
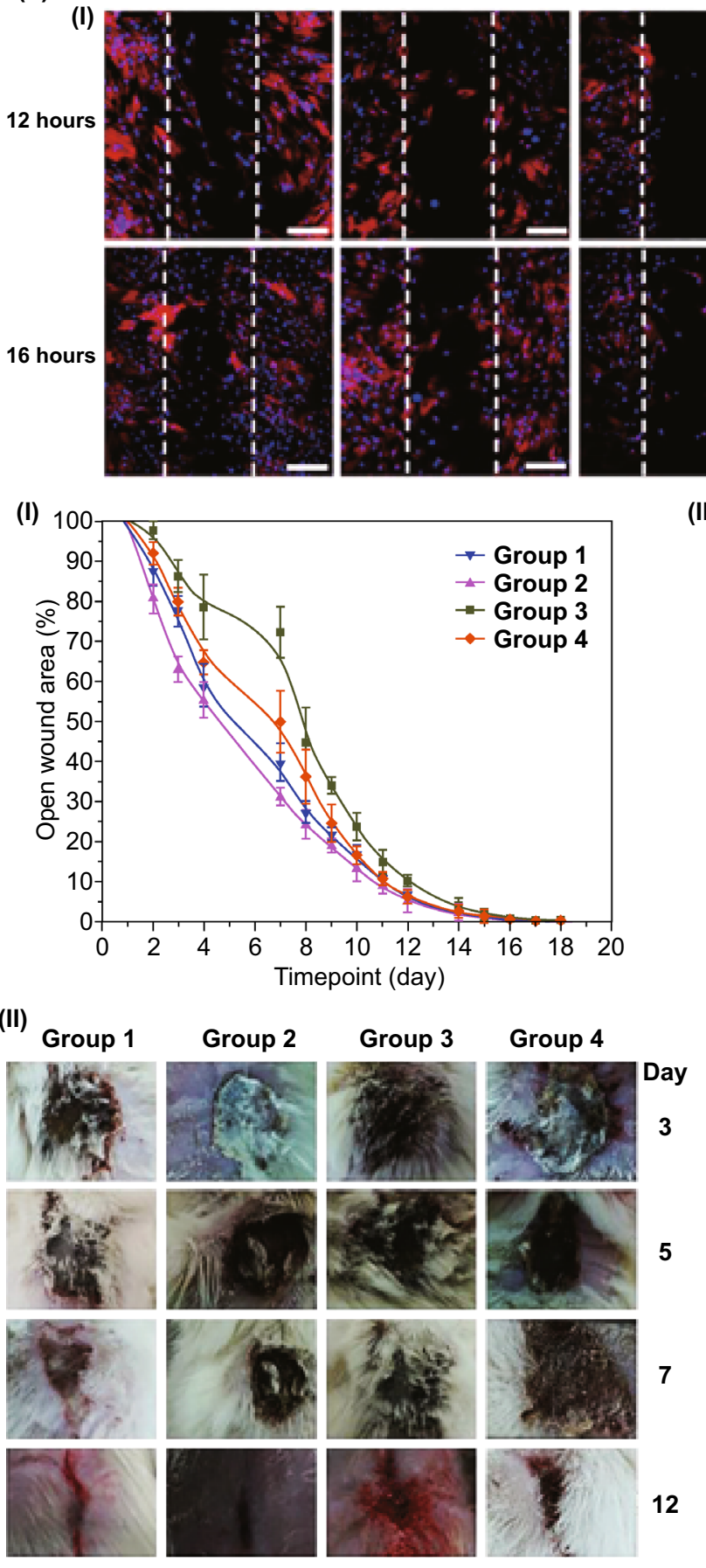

$108 \mathrm{~nm}$
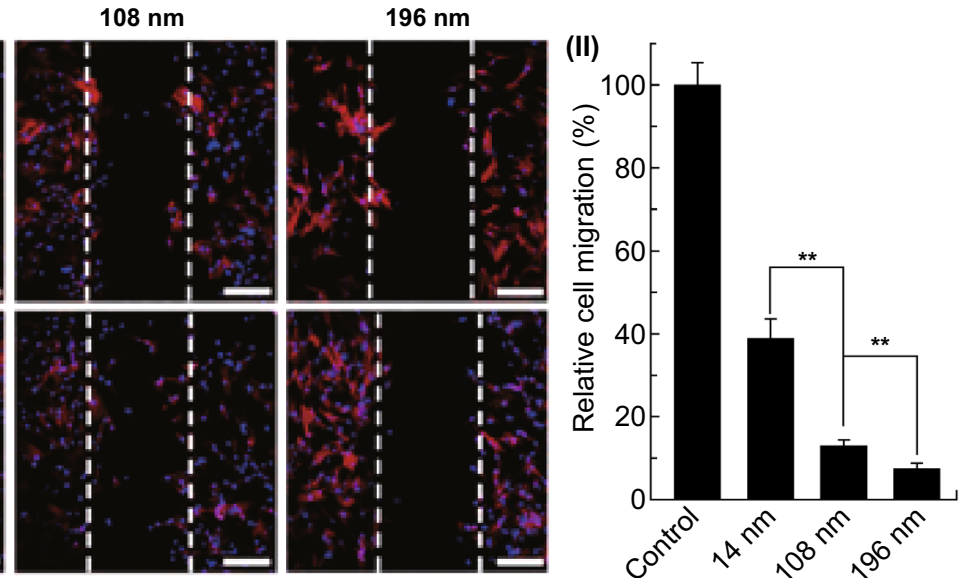

(III)
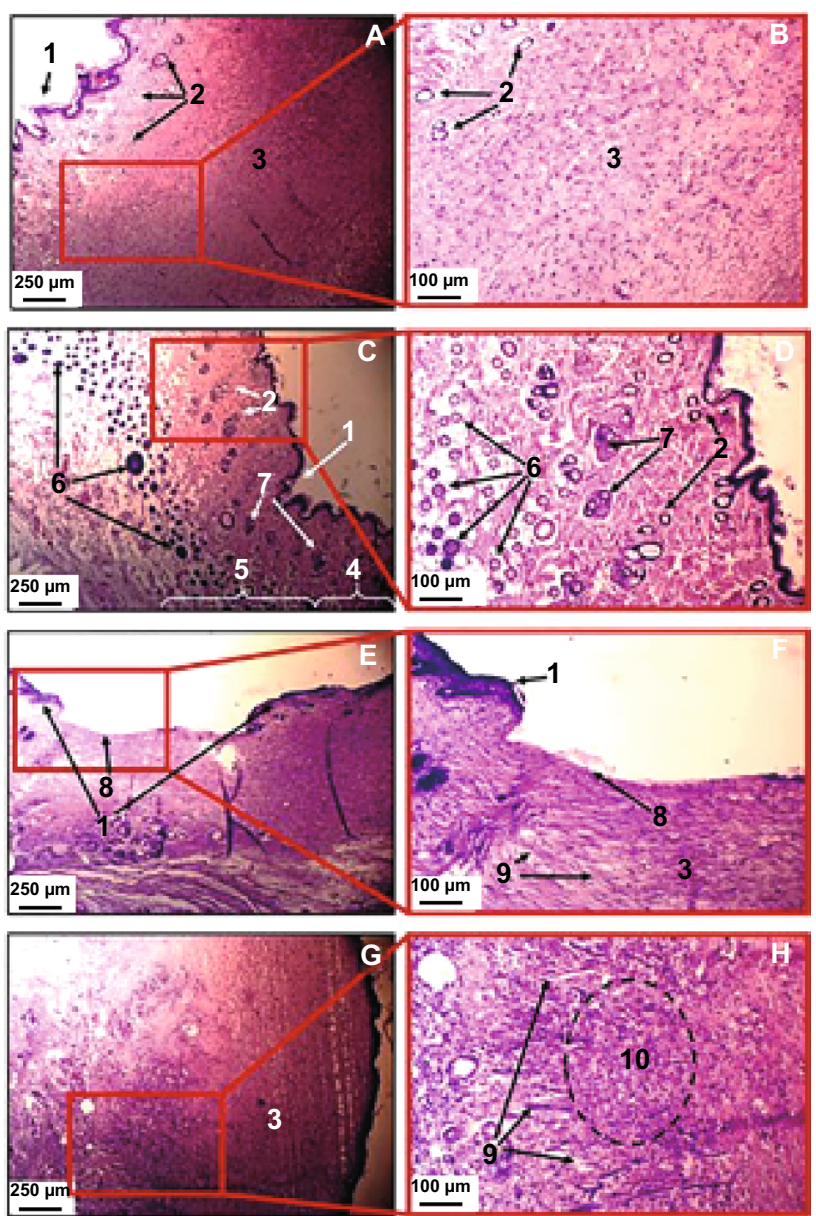

Fig. 10 a Cellular migration of mesenchymal stem cells incubated with different sized $\mathrm{TiO}_{2}$ particles. Scale bars show $100 \mu \mathrm{m}$. Adapted from Ref. [208] with permission from the Dove Press Ltd. b The wound-healing process (I) macroscopically analyzed over the course of 19 days, (II) the representative wounds through the healing process for each group, and (III) the optical images of the healed skin from group 1 (A and B), group $2(\mathrm{C}$ and $\mathrm{D})$, group $3(\mathrm{E}$ and $\mathrm{F})$, and group $4(\mathrm{G}$ and $\mathrm{H})$. Numbers indicate tissue structural elements: 1 -epidermis; 2 -sweat glands; 3 scar; 4-derma; 5-hypodermis; 6-hair follicles; 7—sebaceous glands; 8—de-epithelialized scar tissue; 9—scar vessels; 10—inflammatory infiltration in the scar. Adapted from Ref. [214] with permission from the Springer Nature 
vascularization and increased fibrosis hypodermis) have been investigated for rats in the group 3 without the treatment. However, a daily base treatment using $\mathrm{TiO}_{2}$ nanoparticles for rats in group 4 brought obvious wound-healing effects by thickening epithelium layer, reducing dermal thickness, as well as increasing the formation of new blood vessels and base materials [214].

Nevertheless, either bone and wound infections or dental abscesses are highly likely because of possible contamination of implants and systemic diseases; infections can be minimized by the physical adsorption of anti-inflammatory drugs or silver nanoparticles onto $\mathrm{TiO}_{2} \mathrm{NSs}$ [140, 215]. Moreover, it has been proved that antimicrobial activity of $\mathrm{TiO}_{2}$ nanomaterials eliminates infections and accelerates the proliferation of cells in the wound area compared to other materials [216-219]. For example, a mat composed of silk fibroin nanofibrous and $\mathrm{TiO}_{2}$ nanoparticles has been developed not only to improve the adhesion and proliferation of fibroblasts, but also trigger an antibacterial activity against Escherichia coli under UV light irradiation [40]. In another study, electrospun polyurethane membranes with $\mathrm{TiO}_{2}$ nanomaterials assembled in situ have exhibited an antibacterial effect in fighting Pseudomonas aeruginosa and Staphylococcus aureus and then caused a promoted adhesion of fibroblasts [220]. A quick UV light irradiation can activate bacteriostatic features in $\mathrm{TiO}_{2}$ nanomaterials and accelerate the wound-healing process [221]. $\mathrm{TiO}_{2}$ films with crystalline phases (anatase and a mixture of anatase and rutile) can produce higher amounts of ROS and biofilm reduction (composed of Streptococcus sanguinis, Actinomyces naeslundii, and Fusobacterium nucleatum) after the UV light activation compared to pure rutile $\mathrm{TiO}_{2}$ films [39]. Among metallic nanomaterials, silver nanomaterials are one of the well-known anti-infective agents used for wound dressing, but their resistance to silver is an emerging issue impairing the wound-healing process [222, 223]. Hence, a composition of $\mathrm{TiO}_{2}$ nanomaterials and antimicrobial polymers can improve the wound-healing process, because the antimicrobial activity of $\mathrm{TiO}_{2}$ nanomaterials under UV light irradiation can be harnessed against heavy-metalresistant bacteria.

\section{Conclusions and Future Perspectives}

$\mathrm{TiO}_{2}$ is a promising biomaterial for decoding a wide variety of limitations present in nanomedicine, and also thanks to its easy fabrication, post-fabrication, and biocompatibility. This review focused on the theranostic properties of $\mathrm{TiO}_{2}$ nanomaterials developed for a variety of unique and limited applications in nanomedicine. A broad range of $\mathrm{TiO}_{2}$ nanomaterials have been fabricated with high precision and post-fabricated with adjustable physiochemical properties. Biocompatible $\mathrm{TiO}_{2}$ nanomaterials are unique due to a wide range of features (i.e., a tunable geometry, dimension, porosity, as well as quantum effect, its photoactivity and well-established surface chemistry) that generate less toxic biological responses. There has also been substantial progress in fabrication and post-fabrication of $\mathrm{TiO}_{2}$ nanomaterials to obtain the best performance for different biomedical applications in vivo. However, to realize their theranostic potential and predict clinical outcomes, there are critical limitations and challenges that need to be addressed.

Many promising studies show the successful development of $\mathrm{TiO}_{2} \mathrm{NSs}$ for therapies in vitro and in vivo; however, their translation into a clinical setting remains unexplored mainly due to long-term biocompatibility uncertainties. $\mathrm{TiO}_{2}$ nanomaterials are not biodegradable, and it is crucial to focus on procedures to accelerate their clearance after the therapies. Preclinical studies show that administered NSs can be diminished from organs for a period of 1 week to 1 month after the treatment without harm; however, the removal process in these cases proved to be size, shape, and dosage dependent [157, 224]. Therefore, an elaborated design of $\mathrm{TiO}_{2}$ nanomaterials based on biological microenvironments and responses is still needed to minimize long-term cytotoxicity and accelerate the clearance process.

Recently, significant advances have also been made with respect to sensitivity, specificity, and reproducibility, thus furthering real-time, wearable, and implantable $\mathrm{TiO}_{2}$ nanomaterial-based biosensors. Nevertheless, many challenges, including false detection from complex biological fluids, still remain and must be overcome for practical and clinical purposes. In doing so, the long-term stability of such bio-detectors has to be improved, biofouling diminished and supersensitive receptors integrated regardless of other interfering biomolecules.

Clinical-use implants based on orthopedic $\mathrm{TiO}_{2}$ nanomaterials, offering significant osseointegration and greatly imitating the strength of bone structure, are well known. However, cellular responses to nanoscale $\mathrm{TiO}_{2}$ biomaterials used to directly or indirectly support the cellular differentiation and proliferation are ambiguous due to an unknown 
long-term biocompatibility. A multicomplex nanohybrid system composed of smart biocompatible polymers and $\mathrm{TiO}_{2}$ NSs still needs to be developed to successfully regenerate and repair tissues, hereby extending human life. Our knowledge of the clinical potential of $\mathrm{TiO}_{2}$ nanomaterials in biomedical applications is extremely limited, and ongoing, comprehensive, and multidisciplinary studies are required to adjust the inherent properties of $\mathrm{TiO}_{2}$ nanomaterials.

All things considered, most of the studies as a proof of principle have demonstrated that $\mathrm{TiO}_{2}$ nanomaterials have the potential to overcome challenges in certain aspects associated with nanomedicine. An elaborated design of multifunctional $\mathrm{TiO}_{2}$ nanomaterials based on biological microenvironments and responses may improve the limited theranostic efficacy. Thus, further preclinical studies of functionalized $\mathrm{TiO}_{2} \mathrm{NSs}$ still need to be taken into account in order to improve biological responses and to diminish side effects before these nanomaterials can be translated into clinical settings.

Acknowledgements This work was supported by the Alexander von Humboldt Foundation (MHK) and European Union Horizon 2020 program Phys2BioMed, EU H2020-MSCA-ITN-2018 (WHG). We thank Mr. Paul Gahman (MA) and Ms. Celia Marshall (MA) for proofreading the manuscript.

Open Access This article is licensed under a Creative Commons Attribution 4.0 International License, which permits use, sharing, adaptation, distribution and reproduction in any medium or format, as long as you give appropriate credit to the original author(s) and the source, provide a link to the Creative Commons licence, and indicate if changes were made. The images or other third party material in this article are included in the article's Creative Commons licence, unless indicated otherwise in a credit line to the material. If material is not included in the article's Creative Commons licence and your intended use is not permitted by statutory regulation or exceeds the permitted use, you will need to obtain permission directly from the copyright holder. To view a copy of this licence, visit http://creativecommons.org/licenses/by/4.0/.

\section{References}

1. P. Nyamukamba, O. Okoh, H. Mungondori, R. Taziwa, S. Zinya, in Synthetic Methods for Titanium Dioxide Nanoparticles: A Review (BoD-Books on Demand; 2018), pp. 151. https://doi.org/10.5772/intechopen.75425

2. X. Wang, Z. Li, J. Shi, Y. Yu, One-dimensional titanium dioxide nanomaterials: nanowires, nanorods, and nanobelts. Chem. Rev. 114, 9346-9384 (2014). https://doi.org/10.1021/ cr400633s
3. R. Verma, J. Gangwar, A.K. Srivastava, Multiphase $\mathrm{TiO}_{2}$ nanostructures: a review of efficient synthesis, growth mechanism, probing capabilities, and applications in bio-safety and health. RSC Adv. 7, 44199-44224 (2017). https://doi. org/10.1039/c7ra06925a

4. Q. Li, X. Wang, X. Lu, H. Tian, H. Jiang et al., The incorporation of daunorubicin in cancer cells through the use of titanium dioxide whiskers. Biomaterials 30, 4708-4715 (2009). https://doi.org/10.1016/j.biomaterials.2009.05.015

5. P. Xu, R. Wang, J. Ouyang, B. Chen, A new strategy for $\mathrm{TiO}_{2}$ whiskers mediated multi-mode cancer treatment. Nanoscale Res. Lett. 10, 94 (2015). https://doi.org/10.1186/s1167 1-015-0796-4

6. S.-S. Song, B.-Y. Xia, J. Chen, J. Yang, X. Shen et al., Two dimensional $\mathrm{TiO}_{2}$ nanosheets: in vivo toxicity investigation. RSC Adv. 4, 42598-42603 (2014). https://doi.org/10.1039/ C4RA05953K

7. Y. He, J. Wan, Y. Yang, P. Yuan, C. Yang, Z. Wang, L. Zhang, Multifunctional polypyrrole-coated mesoporous $\mathrm{TiO}_{2}$ nanocomposites for photothermal, sonodynamic, and chemotherapeutic treatments and dual-modal ultrasound/photoacoustic imaging of tumors. Adv. Healthcare Mater. 8, 1801254 (2019). https://doi.org/10.1002/adhm.201801254

8. T. Wang, H. Jiang, L. Wan, Q. Zhao, T. Jiang, B. Wang, S. Wang, Potential application of functional porous $\mathrm{TiO}_{2}$ nanoparticles in light-controlled drug release and targeted drug delivery. Acta Biomater. 13, 354-363 (2015). https://doi. org/10.1016/j.actbio.2014.11.010

9. S.P. Adhikari, H.R. Pant, H.M. Mousa, J. Lee, H.J. Kim, C.H. Park, C.S. Kim, Synthesis of high porous electrospun hollow $\mathrm{TiO}_{2}$ nanofibers for bone tissue engineering application. Ind. Eng. Chem. Res. 35, 75-82 (2016). https://doi.org/10.1016/j. jiec.2015.12.004

10. M.H. Kafshgari, A. Mazare, M. Distaso, W.H. Goldmann, W. Peukert, B. Fabry, P. Schmuki, Intracellular drug delivery with anodic titanium dioxide nanotubes and nanocylinders. ACS Appl. Mater. Interfaces 11, 14980-14985 (2019). https ://doi.org/10.1021/acsami.9b01211

11. N.P. Truong, M.R. Whittaker, C.W. Mak, T.P. Davis, The importance of nanoparticle shape in cancer drug delivery. Expert Opin. Drug Deliv. 12, 129-142 (2015). https://doi. org/10.1517/17425247.2014.950564

12. S. Wang, W. Ren, J. Wang, Z. Jiang, M. Saeed, L. Zhang, A. $\mathrm{Li}, \mathrm{A}$. Wu, Black $\mathrm{TiO}_{2}$-based nanoprobes for T1-weighted MRI-guided photothermal therapy in CD133 high expressed pancreatic cancer stem-like cells. Biomater. Sci. 6, 22092218 (2018). https://doi.org/10.1039/C8BM00454D

13. M. Saeed, M.Z. Iqbal, W. Ren, Y. Xia, W.S. Khan, A. Wu, Tunable fabrication of new theranostic $\mathrm{Fe}_{3} \mathrm{O}_{4}$-black $\mathrm{TiO}_{2}$ nanocomposites: dual wavelength stimulated synergistic imaging-guided phototherapy in cancer. J. Mater. Chem. B 7, 210-223 (2019). https://doi.org/10.1039/C8TB02704H

14. H. Chanseok, K. Jungwoo, L. Jungkeun, Z. Hongmei, H. Soonsun, L. Donheang, L. Chongmu, Photothermal therapy using $\mathrm{TiO}_{2}$ nanotubes in combination with near-infrared laser. 
J. Cancer Ther. 1, 52-58 (2010). https://doi.org/10.4236/ jct.2010.12009

15. H.K. Patra, R. Imani, J.R. Jangamreddy, M. Pazoki, A. Iglič, A.P.F. Turner, A. Tiwari, On/off-switchable anti-neoplastic nanoarchitecture. Sci. Rep. 5, 14571 (2015). https://doi. org/10.1038/srep14571

16. C.M. Sayes, R. Wahi, P.A. Kurian, Y. Liu, J.L. West, K.D. Ausman, D.B. Warheit, V.L. Colvin, Correlating nanoscale titania structure with toxicity: a cytotoxicity and inflammatory response study with human dermal fibroblasts and human lung epithelial cells. Toxicol. Sci. 92, 174-185 (2006). https://doi.org/10.1093/toxsci/kfj197

17. Y.Y. Song, F. Schmidt-Stein, S. Bauer, P. Schmuki, Amphiphilic $\mathrm{TiO}_{2}$ nanotube arrays: an actively controllable drug delivery system. J. Am. Chem. Soc. 131, 4230-4232 (2009). https://doi.org/10.1021/ja810130h

18. F. Schmidt-Stein, R. Hahn, J.F. Gnichwitz, Y.Y. Song, N.K. Shrestha, A. Hirsch, P. Schmuki, X-ray induced photocatalysis on $\mathrm{TiO}_{2}$ and $\mathrm{TiO}_{2}$ nanotubes: degradation of organics and drug release. Electrochem. Commun. 11, 2077-2080 (2009). https://doi.org/10.1016/j.elecom.2009.08.036

19. M. Hasanzadeh Kafshgari, N.H. Voelcker, F.J. Harding, in Porous Silicon Nanoparticles for Applications in Nano-medicine (Academic Press, Oxford, 2019), pp. 211-226. https:// doi.org/10.1016/B978-0-12-803581-8.10463-1

20. E. Galata, E.A. Georgakopoulou, M.E. Kassalia, N. Papadopoulou-Fermeli, E.A. Pavlatou, Development of smart composites based on doped- $\mathrm{TiO}_{2}$ nanoparticles with visible light anticancer properties. Materials 12, 2589 (2019). https ://doi.org/10.3390/ma12162589

21. M. Hasanzadeh Kafshgari, D. Kah, A. Mazare, N.T. Nguyen, M. Distaso et al., Anodic titanium dioxide nanotubes for magnetically guided therapeutic delivery. Sci. Rep. 9, 13439 (2019). https://doi.org/10.1038/s41598-01949513-2

22. H. Zheng, H. Yi, W. Lin, H. Dai, Z. Hong, Y. Lin, X. Li, A dual-amplified electrochemiluminescence immunosensor constructed on dual-roles of rutile $\mathrm{TiO}_{2}$ mesocrystals for ultrasensitive zearalenone detection. Electrochim. Acta 260, 847-854 (2018). https://doi.org/10.1016/j.elect acta.2017.12.054

23. C. Zhao, F.U. Rehman, Y. Yang, X. Li, D. Zhang, H. Jiang, M. Selke, X. Wang, C. Liu, Bio-imaging and photodynamic therapy with tetra sulphonatophenyl porphyrin (TSPP)- $\mathrm{TiO}_{2}$ nanowhiskers: new approaches in rheumatoid arthritis theranostics. Sci. Rep. 5, 11518 (2015). https://doi.org/10.1038/ srep11518

24. P. Yuan, D. Song, Mri tracing non-invasive $\mathrm{TiO}_{2}$-based nanoparticles activated by ultrasound for multi-mechanism therapy of prostatic cancer. Nanotechnology 29, 125101 (2018). https://doi.org/10.1088/1361-6528/aaa92a

25. H. Akasaka, N. Mukumoto, N.M. Akayama, T. Wang, R. Yada et al., Investigation of the potential of using $\mathrm{TiO}_{2}$ nanoparticles as a contrast agent in computed tomography and magnetic resonance imaging. Appl. Nanosci. (2019). https:// doi.org/10.1007/s13204-019-01098-y
26. F. Zanghelini, I.A.M. Frías, M.J.B.M. Rêgo, M.G.R. Pitta, M. Sacilloti, M.D.L. Oliveira, C.A.S. Andrade, Biosensing breast cancer cells based on a three-dimensional $\mathrm{TiO}_{2}$ nanomembrane transducer. Biosens. Bioelectron. 92, 313-320 (2017). https://doi.org/10.1016/j.bios.2016.11.006

27. M.A. Ali, K. Mondal, Y. Jiao, S. Oren, Z. Xu, A. Sharma, L. Dong, Microfluidic immuno-biochip for detection of breast cancer biomarkers using hierarchical composite of porous graphene and titanium dioxide nanofibers. ACS Appl. Mater. Interfaces 8, 20570-20582 (2016). https://doi.org/10.1021/ acsami.6b05648

28. H. Shen, J. Wang, H. Liu, Z. Li, F. Jiang, F.B. Wang, Q. Yuan, Rapid and selective detection of pathogenic bacteria in bloodstream infections with aptamer-based recognition. ACS Appl. Mater. Interfaces 8, 19371-19378 (2016). https://doi. org/10.1021/acsami.6b06671

29. C. Zhang, J.Q. Xu, Y.T. Li, L. Huang, D.W. Pang et al., Photocatalysis-induced renewable field-effect transistor for protein detection. Anal. Chem. 88, 4048-4054 (2016). https ://doi.org/10.1021/acs.analchem.6b00374

30. K.S. Mun, S.D. Alvarez, W.Y. Choi, M.J. Sailor, A stable, label-free optical interferometric biosensor based on $\mathrm{TiO}_{2}$ nanotube arrays. ACS Nano 4, 2070-2076 (2010). https:// doi.org/10.1021/nn901312f

31. Y.C. Nah, I. Paramasivam, P. Schmuki, Doped $\mathrm{TiO}_{2}$ and $\mathrm{TiO}_{2}$ nanotubes: synthesis and applications. ChemPhysChem 11, 2698-2713 (2010). https://doi.org/10.1002/cphc.201000276

32. A. Zaleska, Doped-TiO 2 : a review. Recent Pat. Eng. 2, 157164 (2008). https://doi.org/10.2174/187221208786306289

33. L. Otero-González, C. García-Saucedo, J.A. Field, R. Sierra-Álvarez, Toxicity of $\mathrm{TiO}_{2}, \mathrm{ZrO}_{2}, \mathrm{Fe}_{0}, \mathrm{Fe}_{2} \mathrm{O}_{3}$, and $\mathrm{Mn}_{2} \mathrm{O}_{3}$ nanoparticles to the yeast, saccharomyces cerevisiae. Chemosphere 93, 1201-1206 (2013). https://doi. org/10.1016/j.chemosphere.2013.06.075

34. H.L. Karlsson, P. Cronholm, J. Gustafsson, L. Möller, Copper oxide nanoparticles are highly toxic: a comparison between metal oxide nanoparticles and carbon nanotubes. Chem. Res. Toxicol. 21, 1726-1732 (2008). https://doi. org/10.1021/tx800064j

35. S. Bauer, J. Park, J. Faltenbacher, S. Berger, K. von der Mark, P. Schmuki, Size selective behavior of mesenchymal stem cells on $\mathrm{ZrO}_{2}$ and $\mathrm{TiO}_{2}$ nanotube arrays. Integr. Biol. 1, 525-532 (2009). https://doi.org/10.1039/b908196h

36. J. Park, S. Bauer, A. Pittrof, M.S. Killian, P. Schmuki, K. von der Mark, Synergistic control of mesenchymal stem cell differentiation by nanoscale surface geometry and immobilized growth factors on $\mathrm{TiO}_{2}$ nanotubes. Small $\mathbf{8}$, 98-107 (2012). https://doi.org/10.1002/smll.201100790

37. S. Nájera, M. Michel, J. Kyung-Hwan, J.N.-S. Kim, Characterization of 3D printed PLA/PCL/TiO 2 composites for cancellous bone. J. Mater. Sci. Eng. 7, 417 (2018). https:// doi.org/10.4172/2169-0022.1000417

38. X. Wang, R.A. Gittens, R. Song, R. Tannenbaum, R. Olivares-Navarrete, Z. Schwartz, H. Chen, B.D. Boyan, Effects of structural properties of electrospun $\mathrm{TiO}_{2}$ nanofiber meshes on their osteogenic potential. Acta 
Biomater. 8, 878-885 (2012). https://doi.org/10.1016/j. actbio.2011.10.023

39. H.N. Pantaroto, A.P. Ricomini-Filho, M.M. Bertolini, J.H. Dias da Silva, N.F. Azevedo Neto, C. Sukotjo, E.C. Rangel, V.A.R. Barão, Antibacterial photocatalytic activity of different crystalline $\mathrm{TiO}_{2}$ phases in oral multispecies biofilm. Dent. Mater. 34, e182-e195 (2018). https://doi.org/10.1016/j.denta 1.2018.03.011

40. W.C. Jao, M.C. Yang, C.H. Lin, C.C. Hsu, Fabrication and characterization of electrospun silk fibroin $/ \mathrm{TiO}_{2}$ nanofibrous mats for wound dressings. Polym. Adv. Technol. 23, 10661076 (2012). https://doi.org/10.1002/pat.2014

41. K. Hirakawa, in Fundamentals of Medicinal Application of Titanium Dioxide Nanoparticles (InTech, 2015), pp. 13-32. http://dx.doi.org/10.5772/61302

42. S. Çeşmeli, C. Biray Avci, Application of titanium dioxide $\left(\mathrm{TiO}_{2}\right)$ nanoparticles in cancer therapies. J. Drug Target 27, 762-766 (2019). https://doi.org/10.1080/10611 86X.2018.1527338

43. Z. Jing, D. Guo, W. Wang, S. Zhang, W. Qi, B. Ling, Comparative study of titania nanoparticles and nanotubes as antibacterial agents. Solid State Sci. 13, 1797-1803 (2011). https ://doi.org/10.1016/j.solidstatesciences.2011.07.010

44. M.H. Kafshgari, N.H. Voelcker, F.J. Harding, Applications of zero-valent silicon nanostructures in biomedicine. Nanomedicine (Lond) 10, 2553-2571 (2015). https://doi.org/10.2217/ nnm. 15.91

45. S. Bagheri, Z.A.M. Hir, A.T. Yousefi, S.B.A. Hamid, Progress on mesoporous titanium dioxide: synthesis, modification and applications. Microporous Mesoporous Mater. 218, 206-222 (2015). https://doi.org/10.1016/j.micromeso.2015.05.028

46. A.R. Gharakhlou, M.N. Sarvi, Synthesis of mesoporous nanoparticles of $\mathrm{TiO}_{2}$ from ilmenite. Mater. Res. Express 4, 025027 (2017). https://doi.org/10.1088/2053-1591/aa5bab

47. W. Guo, F. Wang, D. Ding, C. Song, C. Guo, S. Liu, $\mathrm{TiO}_{2-x}$ based nanoplatform for bimodal cancer imaging and NIRtriggered chem/photodynamic/photothermal combination therapy. Chem. Mater. 29, 9262-9274 (2017). https://doi. org/10.1021/acs.chemmater.7b03241

48. H. Peng, J. Hu, C. Hu, T. Wu, X. Tian, Microwave absorbing $\mathrm{Fe}_{3} \mathrm{O}_{4} @ \mathrm{mTiO}_{2}$ nanoparticles as an intelligent drug carrier for microwave-triggered synergistic cancer therapy. J. Nanosci. Nanotechnol. 17, 5139-5146 (2017). https://doi.org/10.1166/ jnn.2017.13809

49. X.W. Lou, L.A. Archer, A general route to nonspherical anatase $\mathrm{TiO}_{2}$ hollow colloids and magnetic multifunctional particles. Adv. Mater. 20, 1853-1858 (2008). https://doi. org/10.1002/adma.200702379

50. W. Song, L. Zhao, K. Fang, B. Chang, Y. Zhang, Biofunctionalization of titanium implant with chitosan/sirna complex through loading-controllable and time-saving cathodic electrodeposition. J. Mater. Chem. B 3, 8567-8576 (2015). https ://doi.org/10.1039/C5TB01062D

51. D. Liu, Y.G. Bi, Controllable fabrication of hollow $\mathrm{TiO}_{2}$ spheres as sustained release drug carrier. Adv. Powder
Technol. 30, 2169-2177 (2019). https://doi.org/10.1016/j. apt.2019.06.032

52. X. Wang, W. Wang, L. Yu, Y. Tang, J. Cao, Y. Chen, Sitespecific sonocatalytic tumor suppression by chemically engineered single-crystalline mesoporous titanium dioxide sonosensitizers. J. Mater. Chem. B 5, 4579-4586 (2017). https:// doi.org/10.1039/C7TB00938K

53. W. Ding, C. Song, T. Li, H. Ma, Y. Yao, C. Yao, TiO 2 nanowires as an effective sensing platform for rapid fluorescence detection of single-stranded DNA and double-stranded DNA. Talanta 199, 442-448 (2019). https://doi.org/10.1016/j.talan ta.2019.02.002

54. Z.X. Hao, W. Wang, Y. Liang, J. Fu, M. Zhu, H. Shi, S. Lei, C. Tao, Visible-light-driven charge transfer to significantly improve surface-enhanced raman scattering (SERS) activity of self-cleaning $\mathrm{TiO}_{2} / \mathrm{Au}$ nanowire arrays as highly sensitive and recyclable SERS sensor. Sens. Actuators B Chem. 279, 313-319 (2019). https://doi.org/10.1016/j.snb.2018.10.010

55. W.Q. Wu, B.X. Lei, H.S. Rao, Y.F. Xu, Y.F. Wang, C.Y. $\mathrm{Su}$, D.B. Kuang, Hydrothermal fabrication of hierarchically anatase $\mathrm{TiO}_{2}$ nanowire arrays on FTO glass for dye-sensitized solar cells. Sci. Rep. 3, 1352 (2013). https://doi.org/10.1038/ srep01352

56. T. Zhang, Z.U. Rahman, N. Wei, Y. Liu, J. Liang, D. Wang, In situ growth of single-crystal $\mathrm{TiO}_{2}$ nanorod arrays on ti substrate: controllable synthesis and photoelectro-chemical water splitting. Nano Res. 10, 1021-1032 (2017). https://doi. org/10.1007/s12274-016-1361-x

57. J. Kalb, A. Folger, E. Zimmermann, M. Gerigk, B. Trepka, C. Scheu, S. Polarz, L. Schmidt-Mende, Controlling the density of hydrothermally grown rutile $\mathrm{TiO}_{2}$ nanorods on anatase $\mathrm{TiO}_{2}$ films. Surf. Interfaces 15, 141-147 (2019). https://doi.org/10.1016/j.surfin.2019.02.010

58. Y. Wang, Y. Li, Z. Guo, W. Liu, R. Zhang, L. Chu, X.A. $\mathrm{Li}$, Ethanol addition for morphology regulation of $\mathrm{TiO}_{2}$ nanorod arrays towards efficient hole-conductor-free perovskite solar cells. Funct. Mater. Lett. 11, 1850080 (2018). https://doi.org/10.1142/S1793604718500807

59. N. Wongkaew, Nanofiber-integrated miniaturized systems: an intelligent platform for cancer diagnosis. Anal. Bioanal. Chem. 411, 4251-4264 (2019). https://doi.org/10.1007/ s00216-019-01589-5

60. A. Haider, S. Haider, I.K. Kang, A comprehensive review summarizing the effect of electrospinning parameters and potential applications of nanofibers in biomedical and biotechnology. Arab. J. Chem. 11, 1165-1188 (2015). https:// doi.org/10.1016/j.arabjc.2015.11.015

61. S. Mirmohammad Sadeghi, M. Vaezi, A. Kazemzadeh, R. Jamjah, Morphology enhancement of $\mathrm{TiO}_{2} / \mathrm{PVP}$ composite nanofibers based on solution viscosity and processing parameters of electrospinning method. J. Appl. Polym. 135, 46337 (2018). https://doi.org/10.1002/app.46337

62. P. Aghasiloo, M. Yousefzadeh, M. Latifi, R. Jose, Highly porous $\mathrm{TiO}_{2}$ nanofibers by humid-electrospinning with enhanced photocatalytic properties. J. Alloys Compd. 
790, 257-265 (2019). https://doi.org/10.1016/j.jallc om.2019.03.175

63. G.L. Li, G.H. Wang, J.M. Hong, Synthesis and characterization of rutile $\mathrm{TiO}_{2}$ nanowhiskers. J. Mater. Res. Technol. 14, 3346-3354 (1999). https://doi.org/10.1557/ JMR.1999.0453

64. Y.L. Pang, S. Lim, H.C. Ong, W.T. Chong, A critical review on the recent progress of synthesizing techniques and fabrication of $\mathrm{TiO}_{2}$-based nanotubes photocatalysts. Appl. Catal. A 481, 127-142 (2014). https://doi.org/10.1016/j.apcat a.2014.05.007

65. S. Kumar, P. Bhushan, S. Bhattacharya, in Fabrication of Nanostructures with Bottom-up Approach and Their Utility in Diagnostics, Therapeutics, and Others (Springer, 2018), pp. 167-198. https://doi.org/10.1007/978-981-10-7751-7_8

66. L. Zhang, X. Liao, A. Fok, C. Ning, P. Ng, Y. Wang, Effect of crystalline phase changes in titania $\left(\mathrm{TiO}_{2}\right)$ nanotube coatings on platelet adhesion and activation. Mater. Sci. Eng. C 82, 91-101 (2018). https://doi.org/10.1016/j.msec.2017.08.024

67. N. Liu, X. Chen, J. Zhang, J.W. Schwank, A review on $\mathrm{TiO}_{2}$-based nanotubes synthesized via hydrothermal method: formation mechanism, structure modification, and photocatalytic applications. Catal. Today 225, 34-51 (2014). https:// doi.org/10.1016/j.cattod.2013.10.090

68. M. Zulfiqar, S. Chowdhury, A.A. Omar, Hydrothermal synthesis of multiwalled $\mathrm{TiO}_{2}$ nanotubes and its photocatalytic activities for orange ii removal. Sep. Sci. Technol. 53, 14121422 (2018). https://doi.org/10.1080/01496395.2018.14440 50

69. M. Ge, C. Cao, J. Huang, S. Li, Z. Chen, K.Q. Zhang, S. Al-Deyab, Y. Lai, A review of one-dimensional $\mathrm{TiO}_{2}$ nanostructured materials for environmental and energy applications. J. Mater. Chem. A 4, 6772-6801 (2016). https://doi. org/10.1039/C5TA09323F

70. A. Kazufumi, T.S. Suzuki, E. Nakamura, A. Hiroya, Y. Suzuki, Aao-template assisted synthesis and size control of one-dimensional $\mathrm{TiO}_{2}$ nanomaterials. J. Ceram. Soc. Jpn. 121, 915-918 (2013). https://doi.org/10.2109/jcersj2.121.915

71. H.R. Jafry, M.V. Liga, Q. Li, A.R. Barron, Single walled carbon nanotubes (SWNTs) as templates for the growth of $\mathrm{TiO}_{2}$ : the effect of silicon in coverage and the positive and negative synergies for the photocatalytic degradation of congo red dye. New J. Chem. 35, 400-406 (2011). https://doi.org/10.1039/ C0NJ00604A

72. Z. Ma, J. Gao, X. Wu, Y. Xie, H. Yuan, Y. Shi, Preparation of well-aligned $\mathrm{TiO}_{2}$ nanotubes with high length-diameter aspect ratio by anodic oxidation method. J. Nanosci. Nanotechnol. 18, 5810-5816 (2018). https://doi.org/10.1166/ jnn.2018.15397

73. Y. Fu, A. Mo, A review on the electrochemically self-organized titania nanotube arrays: synthesis, modifications, and biomedical applications. Nanoscale Res. Lett. 13, 187 (2018). https://doi.org/10.1186/s11671-018-2597-z

74. K. Lee, A. Mazare, P. Schmuki, One-dimensional titanium dioxide nanomaterials: nanotubes. Chem. Rev. 114, 93859454 (2014). https://doi.org/10.1021/cr500061m
75. G. Liu, K. Wang, N. Hoivik, H. Jakobsen, Progress on freestanding and flow-through $\mathrm{TiO}_{2}$ nanotube membranes. Sol. Energy Mater. Sol. Cells 98, 24-38 (2012). https://doi. org/10.1016/j.solmat.2011.11.004

76. W.M. Seong, D.H. Kim, I.J. Park, G.D. Park, K. Kang, S. Lee, K.S. Hong, Roughness of ti substrates for control of the preferred orientation of $\mathrm{TiO}_{2}$ nanotube arrays as a new orientation factor. J. Phys. Chem. C 119, 13297-13305 (2015). https://doi.org/10.1021/acs.jpcc.5b02371

77. J.H. Lim, J. Choi, Titanium oxide nanowires originating from anodically grown nanotubes: the bamboo-splitting model. Small 3, 1504-1507 (2007). https://doi.org/10.1002/ smll.200700114

78. Z. Xing, X. Zong, T. Butburee, J. Pan, Y. Bai, L. Wang, Nanohybrid materials of titania nanosheets and plasmonic gold nanoparticles for effective hydrogen evolution. Appl. Catal. A 521, 96-103 (2016). https://doi.org/10.1016/j.apcat a.2016.01.014

79. X. Han, Q. Kuang, M. Jin, Z. Xie, L. Zheng, Synthesis of titania nanosheets with a high percentage of exposed (001) facets and related photocatalytic properties. J. Am. Chem. Soc. 131, 3152 (2009). https://doi.org/10.1021/ja8092373

80. X. Gan, X. Gao, J. Qiu, P. He, X. Li, X. Xiao, TiO 2 nanorodderived synthesis of upstanding hexagonal kassite nanosheet arrays: an intermediate route to novel nanoporous $\mathrm{TiO}_{2}$ nanosheet arrays. Cryst. Growth Des. 12, 289-296 (2012). https://doi.org/10.1021/cg2010612

81. Y. Yu, P. Zhang, L. Guo, Z. Chen, Q. Wu, Y. Ding, W. Zheng, Y. Cao, The design of $\mathrm{TiO}_{2}$ nanostructures (nanoparticle, nanotube, and nanosheet) and their photocatalytic activity. J. Phys. Chem. C 118, 12727-12733 (2014). https://doi. org/10.1021/jp500252g

82. J. Zhang, Z. Zhu, Y. Tang, K. Müllen, X. Feng, Titania nanosheet-mediated construction of a two-dimensional titania/cadmium sulfide heterostructure for high hydrogen evolution activity. Adv. Mater. 26, 734-738 (2014). https://doi. org/10.1002/adma.201303571

83. T. Ban, T. Nakagawa, Y. Ohya, Bottom-up synthesis of titanate nanosheets in aqueous sols and their morphology change by the addition of organic ligands and dialysis. Cryst. Growth Des. 15, 1801-1807 (2015). https://doi.org/10.1021/cg501 $852 \mathrm{a}$

84. S. Zhang, H. Li, S. Wang, Y. Liu, H. Chen, Z. Lu, Bacteriaassisted synthesis of nanosheets-assembled $\mathrm{TiO}_{2}$ hierarchical architectures for constructing $\mathrm{TiO}_{2}$-based composites for photocatalytic and electrocatalytic application. ACS Appl. Mater. Interfaces 11, 37004-37012 (2019). https://doi.org/10.1021/ acsami.9b15282

85. C. Uboldi, P. Urbán, D. Gilliland, E. Bajak, E. Valsami-Jones, J. Ponti, F. Rossi, Role of the crystalline form of titanium dioxide nanoparticles: rutile, and not anatase, induces toxic effects in balb/3T3 mouse fibroblasts. Toxicol. In Vitro 31, 137-145 (2016). https://doi.org/10.1016/j.tiv.2015.11.005

86. S. Sugapriya, R. Sriram, S. Lakshmi, Effect of annealing on $\mathrm{TiO}_{2}$ nanoparticles. Optik 124, 4971-4975 (2013). https:// doi.org/10.1016/j.ijleo.2013.03.040 
87. A. Hamlekhan, A. Butt, S. Patel, D. Royhman, C. Takoudis et al., Fabrication of anti-aging $\mathrm{TiO}_{2}$ nanotubes on biomedical ti alloys. PLoS ONE 9, e96213 (2014). https://doi. org/10.1371/journal.pone.0096213

88. M. Osada, S. Yoguchi, M. Itose, B.W. Li, Y. Ebina et al., Controlled doping of semiconducting titania nanosheets for tailored spinelectronic materials. Nanoscale 6, 14227-14236 (2014). https://doi.org/10.1039/C4NR04465G

89. A. Stavrinadis, G. Konstantatos, Strategies for controlled electronic doping of colloidal quantum dot solids. ChemPhysChem 17, 632-644 (2015). https://doi.org/10.1002/ cphc. 201500834

90. F. Dong, H. Wang, Z. Wu, One-step "green" synthetic approach for mesoporous c-doped titanium dioxide with efficient visible light photocatalytic activity. J. Phys. Chem. C 113, 16717-16723 (2009). https://doi.org/10.1021/jp904 9654

91. Z.G.M. Azzawi, T.I. Hamad, S.A. Kadhim, G.A.H. Naji, Osseointegration evaluation of laser-deposited titanium dioxide nanoparticles on commercially pure titanium dental implants. J. Mater. Sci. Mater. Med. 29, 96 (2018). https:// doi.org/10.1007/s10856-018-6097-6

92. Z.D. Gao, Y. Qu, T. Li, N.K. Shrestha, Y.Y. Song, Development of amperometric glucose biosensor based on prussian blue functionlized $\mathrm{TiO}_{2}$ nanotube arrays. Sci. Rep. 4, 6891 (2014). https://doi.org/10.1038/srep06891

93. T.C. Damato, C.C. de Oliveira, R.A. Ando, P.H. Camargo, A facile approach to $\mathrm{TiO}_{2}$ colloidal spheres decorated with Au nanoparticles displaying well-defined sizes and uniform dispersion. Langmuir 29, 1642-1649 (2013). https://doi. org/10.1021/la3045219

94. A. Bauer, K. Lee, C. Song, Y. Xie, J. Zhang, R. Hui, Pt nanoparticles deposited on $\mathrm{TiO}_{2}$ based nanofibers: electrochemical stability and oxygen reduction activity. J. Power Sources 195, 3105-3110 (2010). https://doi.org/10.1016/j.jpows our.2009.11.107

95. N.T. Nguyen, M. Altomare, J. Yoo, P. Schmuki, Efficient photocatalytic $\mathrm{H}_{2}$ evolution: controlled dewetting-dealloying to fabricate site-selective high-activity nanoporous Au particles on highly ordered $\mathrm{TiO}_{2}$ nanotube arrays. Adv. Mater. 27, 3208-3215 (2015). https://doi.org/10.1002/adma.20150 0742

96. M.S. Killian, P. Schmuki, Influence of bioactive linker molecules on protein adsorption. Surf. Interface Anal. 46, 193197 (2014). https://doi.org/10.1002/sia.5497

97. M.H. Kafshgari, M. Alnakhli, B. Delalat, S. Apostolou, F. Harding et al., Small interfering RNA delivery by polyethylenimine-functionalised porous silicon nanoparticles. Biomater. Sci. 3, 1555-1565 (2015). https://doi.org/10.1039/ C5BM00204D

98. J. Salonen, M. Kaasalainen, O.-P. Rauhala, L. Lassila, M. Hakamies et al., Thermal carbonization of porous silicon: the current status and recent applications. ECS Trans. 69, 167-176 (2015). https://doi.org/10.1149/06902.0167ecst

99. G. Wang, H. Wang, Y. Ling, Y. Tang, X. Yang et al., Hydrogen-treated $\mathrm{TiO}_{2}$ nanowire arrays for photoelectrochemical water splitting. Nano Lett. 11, 3026-3033 (2011). https://doi. org/10.1021/nl201766h

100. Y. Wang, S. Duan, Z. Tian, Y. Shen, M. Xie, X. Guo, X. Guo, Fabrication of $\mathrm{TiO}_{2} @$ carbon core-shell nanosheets for advanced lithium-ion batteries with excellent cyclability. J. Mater. Chem. A 5, 6047-6051 (2017). https://doi. org/10.1039/C6TA11187D

101. G. Loget, J.E. Yoo, A. Mazare, L. Wang, P. Schmuki, Highly controlled coating of biomimetic polydopamine in $\mathrm{TiO}_{2}$ nanotubes. Electrochem. Commun. 52, 41-44 (2015). https ://doi.org/10.1016/j.elecom.2015.01.011

102. V.K.H. Bui, D. Park, Y.C. Lee, Chitosan combined with ZnO, $\mathrm{TiO}_{2}$ and $\mathrm{Ag}$ nanoparticles for antimicrobial wound healing applications: a mini review of the research trends. Polymers 9, 21 (2017). https://doi.org/10.3390/polym9010021

103. S. Rahim, M.S. Ghamsari, S. Radiman, Surface modification of titanium oxide nanocrystals with PEG. Sci. Iran. 19, 948-953 (2012). https://doi.org/10.1016/j.scient.2012.03.009

104. A. Márquez, T. Berger, A. Feinle, N. Hüsing, M. Himly, A. Duschl, O. Diwald, Bovine serum albumin adsorption on $\mathrm{TiO}_{2}$ colloids: the effect of particle agglomeration and surface composition. Langmuir 33, 2551-2558 (2017). https:// doi.org/10.1021/acs.langmuir.6b03785

105. G.T. Hermanson, Bioconjugate Techniques, 3rd edn (Academic Press, 2013), pp. 1200. https://doi.org/10.1016/C2009 $-0-64240-9$

106. J. Shu, Z. Han, H. Cui, Highly chemiluminescent $\mathrm{TiO}_{2} /$ tetra(4-carboxyphenyl)porphyrin/n-(4-aminobutyl)-n-ethylisoluminol nanoluminophores for detection of heart disease biomarker copeptin based on chemiluminescence resonance energy transfer. Anal. Bioanal. Chem. 411, 4175-4183 (2019). https://doi.org/10.1007/s00216-019-01821-2

107. K. Brown, T. Thurn, L. Xin, W. Liu, R. Bazak et al., Intracellular in situ labeling of $\mathrm{TiO}_{2}$ nanoparticles for fluorescence microscopy detection. Nano Res. 11, 464-476 (2018). https://doi.org/10.1007/s12274-017-1654-8

108. N. Zhang, Y. Deng, Q. Tai, B. Cheng, L. Zhao et al., Electrospun $\mathrm{TiO}_{2}$ nanofiber-based cell capture assay for detecting circulating tumor cells from colorectal and gastric cancer patients. Adv. Mater. 24, 2756-2760 (2012). https://doi. org/10.1002/adma.201200155

109. L. He, C. Mao, M. Brasino, A. Harguindey, W. Park, A.P. Goodwin, J.N. Cha, $\mathrm{TiO}_{2}$-capped gold nanorods for plasmon-enhanced production of reactive oxygen species and photothermal delivery of chemotherapeutic agents. ACS Appl. Mater. Interfaces 10, 27965-27971 (2018). https:// doi.org/10.1021/acsami.8b08868

110. N. Mustafaoglu, T. Kiziltepe, B. Bilgicer, Site-specific conjugation of an antibody on a gold nanoparticle surface for one-step diagnosis of prostate specific antigen with dynamic light scattering. Nanoscale 9, 8684-8694 (2017). https://doi.org/10.1039/c7nr03096g

111. C.H. Lai, S. Choon Lim, L.C. Wu, C.F. Wang, W.S. Tsai, H.C. Wu, Y.C. Chang, Site-specific antibody modification and immobilization on a microfluidic chip to promote the capture of circulating tumor cells and microemboli. Chem. 
Commun. 53, 4152-4155 (2017). https://doi.org/10.1039/ C7CC00247E

112. R. Toy, K. Roy, Engineering nanoparticles to overcome barriers to immunotherapy. Bioeng. Transl. Med. 1, 47-62 (2016). https://doi.org/10.1002/btm2.10005

113. M.H. Kafshgari, F.J. Harding, N.H. Voelcker, Insights into cellular uptake of nanoparticles. Curr. Drug Deliv. 12, 63-77 (2015). https://doi.org/10.2174/156720181166614 0821110631

114. K.T. Thurn, H. Arora, T. Paunesku, A. Wu, E.M.B. Brown, C. Doty, J. Kremer, G. Woloschak, Endocytosis of titanium dioxide nanoparticles in prostate cancer PC-3M cells. Nanomedicine NBM 7, 123-130 (2011). https://doi. org/10.1016/j.nano.2010.09.004

115. E.L.S. da Rosa, Kinetic effects of $\mathrm{TiO}_{2}$ fine particles and nanoparticles aggregates on the nanomechanical properties of human neutrophils assessed by force spectroscopy. BMC Biophys. 6, 11 (2013). https://doi. org/10.1186/2046-1682-6-11

116. K. McNear, Y. Huang, C. Yang, Understanding cellular internalization pathways of silicon nanowires. J. Nanobiotechnol. 15, 17 (2017). https://doi.org/10.1186/s12951-017-0250-0

117. Y. Wang, K. Sui, J. Fang, C. Yao, L. Yuan, Q. Wu, M. Wu, Cytotoxicity evaluation and subcellular location of titanium dioxide nanotubes. Appl. Biochem. Biotechnol. 171, 15681577 (2013). https://doi.org/10.1007/s12010-013-0447-0

118. J. Zhang, X. Cai, Y. Zhang, X. Li, W. Li et al., Imaging cellular uptake and intracellular distribution of $\mathrm{TiO}_{2}$ nanoparticles. Anal. Methods 5, 6611-6616 (2013). https://doi.org/10.1039/ C3AY41121D

119. M. Biola-Clier, D. Beal, S. Caillat, S. Libert, L. Armand et al., Comparison of the DNA damage response in BEAS$2 \mathrm{~b}$ and A549 cells exposed to titanium dioxide nanoparticles. Mutagenesis 32, 161-172 (2017). https://doi.org/10.1093/ mutage/gew055

120. K.N. Yu, S.H. Chang, S.J. Park, J. Lim, J. Lee, T.J. Yoon, J.S. Kim, M.H. Cho, Titanium dioxide nanoparticles induce endoplasmic reticulum stress-mediated autophagic cell death via mitochondria-associated endoplasmic reticulum membrane disruption in normal lung cells. PLoS ONE 10, e0131208 (2015). https://doi.org/10.1371/journal.pone.0131208

121. B. Trouiller, R. Reliene, A. Westbrook, P. Solaimani, R.H. Schiestl, Titanium dioxide nanoparticles induce DNA damage and genetic instability in vivo in mice. Cancer Res. 69, 8784-8789 (2009). https://doi.org/10.1158/0008-5472. CAN-09-2496

122. A. Magrez, L. Horvth, R. Smajda, V. Salicio, N. Pasquier, L. Forro, B. Schwaller, Cellular toxicity of $\mathrm{TiO}_{2}$-based nanofilaments. ACS Nano 3, 2274-2280 (2009). https://doi. org/10.1021/nn9002067

123. R. Allen, The cytotoxic and genotoxic potential of titanium dioxide $\left(\mathrm{TiO}_{2}\right)$ nanoparticles on human sh-sy5y neuronal cells in vitro. Plymouth Stud. Sci. 9, 5-28 (2016)

124. C.W. Chen, J.H. Huang, T.C. Lai, Y.H. Jan, M. Hsiao, C.H. Chen, Y.K. Hwu, R.S. Liu, Evaluation of the intracellular uptake and cytotoxicity effect of $\mathrm{TiO}_{2}$ nanostructures for various human oral and lung cells under dark conditions. Toxicol. Res. 5, 303-311 (2016). https://doi.org/10.1039/ c5tx00312a

125. M.S. Mohamed, A. Torabi, M. Paulose, D.S. Kumar, O.K. Varghese, Anodically grown titania nanotube induced cytotoxicity has genotoxic origins. Sci. Rep. 7, 41844 (2017). https://doi.org/10.1038/srep41844

126. L. Li, X. Mu, L. Ye, Y. Ze, F. Hong, Suppression of testosterone production by nanoparticulate $\mathrm{TiO}_{2}$ is associated with ERK1/2-PKA-PKC signaling pathways in rat primary cultured leydig cells. Int. J. Nanomed. 13, 5909-5924 (2018). https://doi.org/10.2147/IJN.S175608

127. M. Allegri, M.G. Bianchi, M. Chiu, J. Varet, A.L. Costa et al., Shape-related toxicity of titanium dioxide nanofibres. PLoS ONE 11, e0151365 (2016). https://doi.org/10.1371/journ al.pone. 0151365

128. E.J. Park, G.H. Lee, H.W. Shim, J.H. Kim, M.H. Cho, D.W. $\mathrm{Kim}$, Comparison of toxicity of different nanorod-type $\mathrm{TiO}_{2}$ polymorphs in vivo and in vitro. J. Appl. Toxicol. 34, 357366 (2014). https://doi.org/10.1002/jat.2932

129. F. Fenyvesi, Z. Kónya, Z. Rázga, M. Vecsernyés, P. Kása, K. Pintye-Hódi, I. Bácskay, Investigation of the cytotoxic effects of titanate nanotubes on Caco-2 cells. AAPS PharmSciTech 15, 858-861 (2014). https://doi.org/10.1208/s1224 9-014-0115-x

130. H. Zheng, L.J. Mortensen, S. Ravichandran, K. Bentley, L.A. DeLouise, Effect of nanoparticle surface coating on cell toxicity and mitochondria uptake. J. Biomed. Nanotechnol. 13, 155-166 (2017). https://doi.org/10.1166/jbn.2017.2337

131. E.J. Park, G.H. Lee, C. Yoon, M.S. Kang, S.N. Kim, M.H. Cho, J.H. Kim, D.W. Kim, Time-dependent bioaccumulation of distinct rod-type $\mathrm{TiO} 2$ nanoparticles: comparison by crystalline phase. J. Appl. Toxicol. 34, 1265-1270 (2014). https://doi.org/10.1002/jat.3006

132. L.K. Braydich-Stolle, N.M. Schaeublin, R.C. Murdock, J. Jiang, P. Biswas, J.J. Schlager, S.M. Hussain, Crystal structure mediates mode of cell death in $\mathrm{TiO}_{2}$ nanotoxicity. J. Nanopart. Res. 11, 1361-1374 (2009). https://doi.org/10.1007/ s11051-008-9523-8

133. É. de Melo Reis, A.A.A. de Rezende, P.F. de Oliveira, H.D. Nicolella, D.C. Tavares et al., Evaluation of titanium dioxide nanocrystal-induced genotoxicity by the cytokinesisblock micronucleus assay and the drosophila wing spot test. Food Chem. Toxicol. 96, 309-319 (2016). https://doi. org/10.1016/j.fct.2016.08.023

134. Q. Sun, K. Kanehira, A. Taniguchi, Low doses of $\mathrm{TiO}_{2}$-polyethylene glycol nanoparticles stimulate proliferation of hepatocyte cells. Sci. Technol. Adv. Mater. 17, 669676 (2016). https://doi.org/10.1080/14686996.2016.1239499

135. R. Tedja, The impact of titanium dioxide nanoparticles on human lung cell lines in vitro. Chemical Sciences Engineering, Faculty of Engineering, The University of New South Wales (2012). http://handle.unsw.edu.au/1959.4/52987

136. R. Tedja, A.H. Soeriyadi, M.R. Whittaker, M. Lim, C. Marquis, C. Boyer, T.P. Davis, R. Amal, Effect of $\mathrm{TiO}_{2}$ nanoparticle surface functionalization on protein adsorption, cellular 
uptake and cytotoxicity: the attachment of PEG comb polymers using catalytic chain transfer and thiol-ene chemistry. Polym. Chem. 3, 2743-2751 (2012). https://doi.org/10.1039/ C2PY20450A

137. M.A. Alvarez Lemus, H. Monroy, T. Lopez, E.N. de la Cruz Hernández, R. López-González, Effect of surface modification on the bioactivity of sol-gel $\mathrm{TiO}_{2}$-based nanomaterials. J. Chem. Technol. Biotechnol. 91, 2148-2155 (2016). https ://doi.org/10.1002/jctb.4915

138. H. Shi, R. Magaye, V. Castranova, J. Zhao, Titanium dioxide nanoparticles: a review of current toxicological data. Part. Fibre Toxicol. 10, 15 (2013). https://doi. org/10.1186/1743-8977-10-15

139. J. Mao, L. Wang, Z. Qian, M. Tu, Uptake and cytotoxicity of $\mathrm{Ce}(\mathrm{IV})$ doped $\mathrm{TiO}_{2}$ nanoparticles in human hepatocyte cell line L02. J. Nanomater. 2010, 910434 (2010). https://doi. org/10.1155/2010/910434

140. K.C. Popat, M. Eltgroth, T.J. LaTempa, C.A. Grimes, T.A. Desai, Decreased staphylococcus epidermis adhesion and increased osteoblast functionality on antibiotic-loaded titania nanotubes. Biomaterials 28, 4880-4888 (2007). https://doi. org/10.1016/j.biomaterials.2007.07.037

141. K.S. Brammer, C.J. Frandsen, S. Jin, $\mathrm{TiO}_{2}$ nanotubes for bone regeneration. Trends Biotechnol. 30, 315-322 (2012). https ://doi.org/10.1016/j.tibtech.2012.02.005

142. A. Tan, B. Pingguan-Murphy, R. Ahmad, S. Akbar, Review of titania nanotubes: fabrication and cellular response. Ceram. Int. 38, 4421-4435 (2012). https://doi.org/10.1016/j.ceram int.2012.03.002

143. K.S. Brammer, S. Oh, C.J. Cobb, L.M. Bjursten, H. van der Heyde, S. Jin, Improved bone-forming functionality on diameter-controlled $\mathrm{TiO}_{2}$ nanotube surface. Acta Biomater. 5, 3215-3223 (2009). https://doi.org/10.1016/j.actbi o.2009.05.008

144. W. Lü, N. Wang, P. Gao, C. Li, H. Zhao, Z. Zhang, Effects of anodic titanium dioxide nanotubes of different diameters on macrophage secretion and expression of cytokines and chemokines. Cell Prolif. 48, 95-104 (2015). https://doi. org/10.1111/cpr.12149

145. P. Neacsu, A. Mazare, P. Schmuki, A. Cimpean, Attenuation of the macrophage inflammatory activity by $\mathrm{TiO}_{2}$ nanotubes via inhibition of MAPK and NF- $\mathrm{BB}$ pathways. Int. J. Nanomed. 10, 6455 (2015). https://doi.org/10.2147/ IJN.S92019

146. E. Fabian, R. Landsiedel, L. Ma-Hock, K. Wiench, W. Wohlleben, B. Van Ravenzwaay, Tissue distribution and toxicity of intravenously administered titanium dioxide nanoparticles in rats. Arch. Toxicol. 82, 151-157 (2008). https://doi.org/10.1007/s00204-007-0253-y

147. J. Chen, X. Dong, J. Zhao, G. Tang, In vivo acute toxicity of titanium dioxide nanoparticles to mice after intraperitioneal injection. J. Appl. Toxicol. 29, 330-337 (2009). https://doi. org/10.1002/jat.1414

148. J. Wang, Y. Fan, Lung injury induced by $\mathrm{TiO}_{2}$ nanoparticles depends on their structural features: size, shape, crystal phases, and surface coating. Int. J. Mol. Sci. 15,
22258-22278 (2014). https://doi.org/10.3390/ijms151222 258

149. H. Kan, Z. Wu, S.H. Young, T.H. Chen, J.L. Cumpston, F. Chen, M.L. Kashon, V. Castranova, Pulmonary exposure of rats to ultrafine titanium dioxide enhances cardiac protein phosphorylation and substance $\mathrm{p}$ synthesis in nodose ganglia. Nanotoxicology 6, 736-745 (2012). https://doi. org/10.3109/17435390.2011.611915

150. Q. Sun, D. Tan, Y. Ze, X. Sang, X. Liu et al., Pulmotoxicological effects caused by long-term titanium dioxide nanoparticles exposure in mice. J. Hazard. Mater. 235, 47-53 (2012). https://doi.org/10.1016/j.jhazmat.2012.05.072

151. T. Tang, Z. Zhang, X. Zhu, Toxic effects of $\mathrm{TiO}_{2} \mathrm{NPs}$ on zebrafish. Int. J. Environ. Res. Public Health 16, 523 (2019). https://doi.org/10.3390/ijerph16040523

152. N. Li, Y. Duan, M. Hong, L. Zheng, M. Fei et al., Spleen injury and apoptotic pathway in mice caused by titanium dioxide nanoparticules. Toxicol. Lett. 195, 161-168 (2010). https://doi.org/10.1016/j.toxlet.2010.03.1116

153. L. Ma, J. Liu, N. Li, J. Wang, Y. Duan et al., Oxidative stress in the brain of mice caused by translocated nanoparticulate $\mathrm{TiO}_{2}$ delivered to the abdominal cavity. Biomaterials 31, 99-105 (2010). https://doi.org/10.1016/j.biomateria 1s.2009.09.028

154. A. Cetinkaya, E.B. Kurutas, M.A. Buyukbese, B. Kantarceken, E. Bulbuloglu, Levels of malondialdehyde and superoxide dismutase in subclinical hyperthyroidism. Mediat. Inflamm. 2005, 57-59 (2005). https://doi. org/10.1155/MI.2005.57

155. S. Li, H.Y. Tan, N. Wang, Z.J. Zhang, L. Lao, C.W. Wong, Y. Feng, The role of oxidative stress and antioxidants in liver diseases. Int. J. Mol. Sci. 16, 26087-26124 (2015). https://doi.org/10.3390/ijms161125942

156. A. Nemmar, K. Melghit, B.H. Ali, The acute proinflammatory and prothrombotic effects of pulmonary exposure to rutile $\mathrm{TiO}_{2}$ nanorods in rats. Exp. Biol. Med. 233, 610-619 (2008). https://doi.org/10.3181/0706-RM-165

157. D. Elgrabli, R. Beaudouin, N. Jbilou, M. Floriani, A. Pery, F. Rogerieux, G. Lacroix, Biodistribution and clearance of $\mathrm{TiO}_{2}$ nanoparticles in rats after intravenous injection. PLoS ONE 10, e0124490 (2015). https://doi.org/10.1371/journ al.pone.0124490

158. J.K. Patra, G. Das, L.F. Fraceto, E.V.R. Campos, M.D.P. Rodriguez-Torres et al., Nano based drug delivery systems: recent developments and future prospects. J. Nanobiotechnol. 16, 71 (2018). https://doi.org/10.1186/s1295 1-018-0392-8

159. M.C. Liu, B. Liu, X.Y. Sun, H.C. Lin, J.Z. Lu et al., Core/ shell structured $\mathrm{Fe}_{3} \mathrm{O}_{4} @ \mathrm{TiO}_{2}$-DNM nanospheres as multifunctional anticancer platform: chemotherapy and photodynamic therapy research. J. Nanosci. Nanotechnol. 18, 44454456 (2018). https://doi.org/10.1166/jnn.2018.15338

160. Y.Y. Song, P. Roy, I. Paramasivam, P. Schmuki, Voltageinduced payload release and wettability control on $\mathrm{TiO}_{2}$ and $\mathrm{TiO}_{2}$ nanotubes. Angew. Chem. Int. Ed. 49, 351-354 (2010). https://doi.org/10.1002/anie.200905111 
161. F.F. Wang, Y. Li, H.C. Liu, A study on PLGA sustained release icariin/titanium dioxide nanotube composite coating. Eur. Rev. Med. Pharmacol. 23, 911-917 (2019). https://doi. org/10.26355/eurrev_201902_16974

162. G.G. Genchi, Y. Cao, T.A. Desai, in $\mathrm{TiO}_{2}$ Nanotube Arrays as Smart Platforms for Biomedical Applications (Elsevier, 2018), pp. 143-157. https://doi.org/10.1016/B978-0-12814156-4.00010-0

163. M. SinnáAw, A multi-drug delivery system with sequential release using titania nanotube arrays. Chem. Commun. 48, 3348-3350 (2012). https://doi.org/10.1039/C2CC17690D

164. F. Ge, M. Yu, C. Yu, J. Lin, W. Weng, K. Cheng, H. Wang, Improved RHBMP-2 function on mbg incorporated $\mathrm{TiO}_{2}$ nanorod films. Colloids Surf. B: Biointerfaces 150, 153-158 (2017). https://doi.org/10.1016/j.colsurfb.2016.11.030

165. S. Samadi, M. Moradkhani, H. Beheshti, M. Irani, M. Aliabadi, Fabrication of chitosan/poly(lactic acid)/graphene oxide/ $\mathrm{TiO}_{2}$ composite nanofibrous scaffolds for sustained delivery of doxorubicin and treatment of lung cancer. Int. J. Biol. Macromol. 110, 416-424 (2018). https://doi.org/10.1016/j.ijbio mac.2017.08.048

166. X. Wang, D. Zhang, Q. Xiang et al., Review of water-assisted crystallization for $\mathrm{TiO}_{2}$ nanotubes. Nano-Micro Lett. 10, 77 (2018). https://doi.org/10.1007/s40820-018-0230-4

167. E. Liu, Y. Zhou, Z. Liu, J. Li, D. Zhang, J. Chen, Z. Cai, Cisplatin loaded hyaluronic acid modified $\mathrm{TiO}_{2}$ nanoparticles for neoadjuvant chemotherapy of ovarian cancer. J. Nanomater. 16, 275 (2015). https://doi.org/10.1155/2015/390358

168. F.F. Cheng, P. Sun, W.W. Xiong, Y. Zhang, Q. Zhang, W. Yao, Y. Cao, L. Zhang, Multifunctional titanium phosphate nanoparticles for site-specific drug delivery and real-time therapeutic efficacy evaluation. Analyst 144, 3103-3110 (2019). https://doi.org/10.1039/c8an02450b

169. Y. Du, W. Ren, Y. Li, Q. Zhang, L. Zeng, C. Chi, A. Wu, J. Tian, The enhanced chemotherapeutic effects of doxorubicin loaded PEG coated $\mathrm{TiO}_{2}$ nanocarriers in an orthotopic breast tumor bearing mouse model. J. Mater. Chem. B 3, 1518-1528 (2015). https://doi.org/10.1039/C4TB01781A

170. T. Zheng, W. Wang, F. Wu, M. Zhang, J. Shen, Y. Sun, Zwitterionic polymer-gated $\mathrm{Au} @ \mathrm{TiO}_{2}$ core-shell nanoparticles for imaging-guided combined cancer therapy. Theranostics 9, 5035-5048 (2019). https://doi.org/10.7150/thno.35418

171. V.V. Mody, A. Cox, S. Shah, A. Singh, W. Bevins, H. Parihar, Magnetic nanoparticle drug delivery systems for targeting tumor. Appl. Nanosci. 4, 385-392 (2014). https://doi. org/10.1007/s13204-013-0216-y

172. L. Zeng, W. Ren, L. Xiang, J. Zheng, B. Chen, A. Wu, Multifunctional $\mathrm{Fe}_{3} \mathrm{O}_{4}-\mathrm{TiO}_{2}$ nanocomposites for magnetic resonance imaging and potential photodynamic therapy. Nanoscale 5, 2107-2113 (2013). https://doi.org/10.1039/ C3NR33978E

173. N.K. Shrestha, J.M. Macak, F. Schmidt-Stein, R. Hahn, C.T. Mierke, B. Fabry, P. Schmuki, Magnetically guided titania nanotubes for site-selective photocatalysis and drug release. Angew. Chem. Int. Ed. 48, 969-972 (2009). https://doi. org/10.1002/anie.200804429
174. J. Wu, Y. Liu, W. Li, C. Wang, Y. Li et al., Magnetically guided survivin-sirna delivery and simultaneous dual-modal imaging visualization based on $\mathrm{Fe}_{3} \mathrm{O}_{4} @ \mathrm{mTiO}_{2}$ nanospheres for breast cancer. J. Mater. Chem. B 2, 7756-7764 (2014). https://doi.org/10.1039/C4TB01264J

175. Q. Yu, J. Sun, X. Zhu, L. Qiu, M. Xu, S. Liu, J. Ouyang, J. Liu, Mesoporous titanium dioxide nanocarrier with magnetic-targeting and high loading efficiency for dual-modal imaging and photodynamic therapy. J. Mater. Chem. B 5, 6081-6096 (2017). https://doi.org/10.1039/C7TB01035D

176. B.P. Chelobanov, M.N. Repkova, S.I. Baiborodin, E.I. Ryabchikova, D.A. Stetsenko, Nuclear delivery of oligonucleotides via nanocomposites based on $\mathrm{TiO}_{2}$ nanoparticles and polylysine. Mol. Biother. 51, 695-704 (2017). https://doi. org/10.1134/S0026893317050065

177. X. Zhang, Z. Zhang, G. Shen, J. Zhao, Enhanced osteogenic activity and anti-inflammatory properties of lenti-BMP-2loaded $\mathrm{TiO}_{2}$ nanotube layers fabricated by lyophilization following trehalose addition. Int. J. Nanomed. 11, 429-439 (2016). https://doi.org/10.2147/IJN.S93177

178. H. Schneckenburger, Laser-assisted optoporation of cells and tissues-a mini-review. Biomed. Opt. Express 10, 2883-2888 (2019). https://doi.org/10.1364/BOE.10.002883

179. A.M. Wilson, J. Mazzaferri, E.R. Bergeron, S. Patskovsky, P. Marcoux-Valiquette, S. Costantino, P. Sapieha, M. Meunier, In vivo laser-mediated retinal ganglion cell optoporation using Kv1. 1 conjugated gold nanoparticles. Nano Lett. 18, 6981-6988 (2018). https://doi.org/10.1021/acs.nanol ett.8b02896

180. L. Gao, R. Liu, F. Gao, Y. Wang, X. Jiang, X. Gao, Plasmon-mediated generation of reactive oxygen species from near-infrared light excited gold nanocages for photodynamic therapy in vitro. ACS Nano 8, 7260-7271 (2014). https://doi. org/10.1021/nn502325j

181. G. Ou, Z. Li, D. Li, L. Cheng, Z. Liu, H. Wu, Photothermal therapy by using titanium oxide nanoparticles. Nano Res. 9, 1236-1243 (2016). https://doi.org/10.1007/s1227 4-016-1019-8

182. Z. Shah, S. Nazir, K. Mazhar, R. Abbasi, I.M. Samokhvalov, PEGylated doped- and undoped- $\mathrm{TiO}_{2}$ nanoparticles for photodynamic therapy of cancers. Photodiagnosis Photodyn. Ther. 27, 173-183 (2019). https://doi.org/10.1016/j.pdpdt 2019.05.019

183. D. Rebleanu, C. Gaidau, G. Voicu, C.A. Constantinescu, C. Mansilla Sánchez, T.C. Rojas, S. Carvalho, M. Calin, The impact of photocatalytic $\mathrm{Ag} / \mathrm{TiO}_{2}$ and $\mathrm{Ag} / \mathrm{n}-\mathrm{TiO}_{2}$ nanoparticles on human keratinocytes and epithelial lung cells. Toxicology 416, 30-43 (2019). https://doi.org/10.1016/j. tox.2019.01.013

184. J.L. Chen, H. Zhang, X.Q. Huang, H.Y. Wan, J. Li et al., Antiangiogenesis-combined photothermal therapy in the second near-infrared window at laser powers below the skin tolerance threshold. Nano-Micro Lett. 11, 93 (2019). https:// doi.org/10.1007/s40820-019-0327-4

185. D.G. You, V. Deepagan, W. Um, S. Jeon, S. Son et al., Rosgenerating $\mathrm{TiO}_{2}$ nanoparticles for non-invasive sonodynamic 
therapy of cancer. Sci. Rep. 6, 23200 (2016). https://doi. org/10.1038/srep23200

186. Y. Cao, T. Wu, W. Dai, H. Dong, X. Zhang, $\mathrm{TiO}_{2}$ nanosheets with Au nanocrystals decorated edge for mitochondria-targeting enhanced sonodynamic therapy. Chem. Mater. 31, 91059114 (2019). https://doi.org/10.1021/acs.chemmater.9b03430

187. Z. Yu, W. Pan, N. Li, B. Tang, A nuclear targeted dual-photosensitizer for drug-resistant cancer therapy with nir activated multiple ROS. Chem. Sci. 7, 4237-4244 (2016). https://doi. org/10.1039/C6SC00737F

188. E. Rozhkova, I. Ulasov, S. Nandi, L. Zhang, T. Rajh, M. Lesniak, Development and evaluation of $\mathrm{TiO}_{2}$-nanoparticles for gene therapy of brain tumors. Mol. Ther. 16, S321 (2008). https://doi.org/10.1016/S1525-0016(16)40264-9

189. Z.F. Yin, L. Wu, H.G. Yang, Y.H. Su, Recent progress in biomedical applications of titanium dioxide. Phys. Chem. Chem. Phys. 15, 4844-4858 (2013). https://doi.org/10.1039/C3CP4 $3938 \mathrm{~K}$

190. S. Wintzheimer, E. Genin, L. Vellutini, G. Le Bourdon, M. Kessler, S. Hackenberg, S. Dembski, K. Heuzé, Functionalisation of $\mathrm{TiO}_{2}$ nanoparticles with a fluorescent organosilane: a synergy enabling their visualisation in biological cells and an enhanced photocatalytic activity. Colloids Surf. B: Biointerfaces 181, 1019-1025 (2019). https://doi.org/10.1016/j. colsurfb.2019.05.060

191. T. Kawai, Y. Kishimoto, K. Kifune, Photoluminescence studies of nitrogen-doped $\mathrm{TiO}_{2}$ powders prepared by annealing with urea. Philos. Mag. 92, 4088-4097 (2012). https://doi. org/10.1080/14786435.2012.7044231

192. J.S. Roy, T.P. Majumder, R. Dabrowski, Photoluminescence behavior of $\mathrm{TiO}_{2}$ nanoparticles doped with liquid crystals. J. Mol. Struct. 1098, 351-354 (2015). https://doi. org/10.1016/j.molstruc.2015.06.028

193. W.G. Kreyling, U. Holzwarth, N. Haberl, J. Kozempel, A. Wenk et al., Quantitative biokinetics of titanium dioxide nanoparticles after intratracheal instillation in rats: part 3. Nanotoxicology 11, 454-464 (2017). https://doi. org/10.1080/17435390.2017.1306894

194. J. Estelrich, M.J. Sánchez-Martín, M.A. Busquets, Nanoparticles in magnetic resonance imaging: from simple to dual contrast agents. Int. J. Nanomed. 10, 1727-1741 (2015). https://doi.org/10.2147/IJN.S76501

195. T.P. Dasari Shareena, D. McShan, A.K. Dasmahapatra, P.B. Tchounwou, A review on graphene-based nanomaterials in biomedical applications and risks in environment and health. Nano-Micro Lett. 10, 53 (2018). https://doi. org/10.1007/s40820-018-0206-4

196. X. Wang, H. Zhang, H. Jing, L. Cui, Highly efficient labeling of human lung cancer cells using cationic polyL-lysine-assisted magnetic iron oxide nanoparticles. NanoMicro Lett. 7, 374-384 (2015). https://doi.org/10.1007/ s40820-015-0053-5

197. F. Yalçıner, E. Çevik, M. Şenel, A. Baykal, Development of an amperometric hydrogen peroxide biosensor based on the immobilization of horseradish peroxidase onto nickel ferrite nanoparticle-chitosan composite. Nano-Micro Lett. 3, 91-98 (2011). https://doi.org/10.1007/BF03353657

198. S.J. Sadeghi, in Amperometric Biosensors (Springer Berlin Heidelberg; Berlin, Heidelberg, 2013), pp. 61-67. https:// doi.org/10.1007/978-3-642-16712-6_713

199. J. Wang, G. Xu, X. Zhang, J. Lv, X. Zhang, Z. Zheng, Y. $\mathrm{Wu}$, Electrochemical performance and biosensor application of $\mathrm{TiO}_{2}$ nanotube arrays with mesoporous structures constructed by chemical etching. Dalton Trans. 44, 76627672 (2015). https://doi.org/10.1039/C5DT00678C

200. J. Li, X. Li, Q. Zhao, Z. Jiang, M. Tadé, S. Wang, S. Liu, Polydopamine-assisted decoration of $\mathrm{TiO}_{2}$ nanotube arrays with enzyme to construct a novel photoelectrochemical sensing platform. Sens. Actuators B: Chem. 255, 133-139 (2018). https://doi.org/10.1016/j.snb.2017.06.168

201. R. Wu, G.C. Fan, L.P. Jiang, J.J. Zhu, Peptide-based photoelectrochemical cytosensor using a hollow-TiO $2 / \mathrm{EG} /$ $\mathrm{ZnIn}_{2} \mathrm{~S}_{4}$ cosensitized structure for ultrasensitive detection of early apoptotic cells and drug evaluation. ACS Appl. Mater. Interfaces 10, 4429-4438 (2018). https://doi. org/10.1021/acsami.7b16054

202. Y. Wang, G. Zhao, Y. Zhang, B. Du, Q. Wei, Ultrasensitive photoelectrochemical immunosensor based on $\mathrm{Cu}$-doped $\mathrm{TiO}_{2}$ and carbon nitride for detection of carcinoembryonic antigen. Carbon 146, 276-283 (2019). https://doi. org/10.1016/j.carbon.2019.02.008

203. C.C. Lin, Y.M. Chu, H.C. Chang, In situ encapsulation of antibody on $\mathrm{TiO}_{2}$ nanowire immunosensor via electro-polymerization of polypyrrole propylic acid. Sens. Actuators B: Chem. 187, 533-539 (2013). https://doi. org/10.1016/j.snb.2013.03.045

204. R. Wang, C. Ruan, D. Kanayeva, K. Lassiter, Y. Li, $\mathrm{TiO}_{2}$ nanowire bundle microelectrode based impedance immunosensor for rapid and sensitive detection of listeria monocytogenes. Nano Lett. 8, 2625-2631 (2008). https://doi. org/10.1021/n1080366q

205. W. Li, R. Li, B. Huang, Z. Wang, Y. Sun et al., $\mathrm{TiO}_{2}$ nanopillar arrays coated with gelatin film for efficient capture and undamaged release of circulating tumor cells. Nanotechnology 30, 335101 (2019). https://doi.org/10.1088/1361-6528/ ab176c

206. M. Rasoulianboroujeni, F. Fahimipour, P. Shah, K. Khoshroo, M. Tahriri et al., Development of 3D-printed PLGA/TiO nanocomposite scaffolds for bone tissue engineering applications. Mater. Sci. Eng. C 96, 105-113 (2019). https://doi. org/10.1016/j.msec.2018.10.077

207. M. Vercellino, G. Ceccarelli, F. Cristofaro, M. Balli, F. Bertoglio et al., Nanostructured $\mathrm{TiO}_{2}$ surfaces promote human bone marrow mesenchymal stem cells differentiation to osteoblasts. Nanomaterials 6, 124 (2016). https://doi.org/10.3390/ nano6070124

208. Y. Hou, K. Cai, J. Li, X. Chen, M. Lai, Y. Hu, Z. Luo, X. Ding, D. Xu, Effects of titanium nanoparticles on adhesion, migration, proliferation, and differentiation of mesenchymal stem cells. Int. J. Nanomed. 8, 3619 (2013). https://doi. org/10.2147/IJN.S38992 
209. K. Li, T. Yan, Y. Xue, L. Guo, L. Zhang, Y. Han, Intrinsically ferromagnetic $\mathrm{Fe}$-doped $\mathrm{TiO}_{2}$ coatings on titanium for accelerating osteoblast response in vitro. J. Mater. Chem. B 6, 5756-5767 (2018). https://doi.org/10.1039/C8TB01414K

210. A. Ma, H. Shang, Y. Song, B. Chen, Y. You et al., Icariinfunctionalized coating on $\mathrm{TiO}_{2}$ nanotubes surface to improve osteoblast activity in vitro and osteogenesis ability in vivo. Coatings 9, 327 (2019). https://doi.org/10.3390/coatings90 50327

211. S. Babitha, M. Annamalai, M.M. Dykas, S. Saha, K. Poddar et al., Fabrication of a biomimetic zeinpda nanofibrous scaffold impregnated with BMP-2 peptide conjugated $\mathrm{TiO}_{2}$ nanoparticle for bone tissue engineering. J. Tissue Eng. Regen. Med. 12, 991-1001 (2018). https://doi.org/10.1002/ term. 2563

212. H. Zhu, T. Yan, X. Cai, X. Xu, Characterization and property of a bone sialoprotein fragment coated $\mathrm{TiO}_{2}$ nanotube. J. Biomater. Tissue Eng. 8, 632-639 (2018). https://doi. org/10.1166/jbt.2018.1791

213. M. Chen, Y. Hu, M. Li, M. Chen, X. Shen et al., Regulation of osteoblast differentiation by osteocytes cultured on sclerostin antibody conjugated $\mathrm{TiO}_{2}$ nanotube array. Colloids Surf. B: Biointerfaces 175, 663-670 (2019). https://doi.org/10.1016/j. colsurfb.2018.12.023

214. G.A. Seisenbaeva, K. Fromell, V.V. Vinogradov, A.N. Terekhov, A.V. Pakhomov et al., Dispersion of $\mathrm{TiO}_{2}$ nanoparticles improves burn wound healing and tissue regeneration through specific interaction with blood serum proteins. Sci. Rep. 7, 15448 (2017). https://doi.org/10.1038/s41598-017-15792-w

215. L. Zhao, H. Wang, K. Huo, L. Cui, W. Zhang et al., Antibacterial nano-structured titania coating incorporated with silver nanoparticles. Biomaterials 32, 5706-5716 (2011). https:// doi.org/10.1016/j.biomaterials.2011.04.040

216. T. Limongi, L. Tirinato, F. Pagliari, A. Giugni, M. Allione, G. Perozziello, P. Candeloro, E. Di Fabrizio, Fabrication and applications of micro/nanostructured devices for tissue engineering. Nano-Micro Lett. 9, 1 (2016). https://doi. org/10.1007/s40820-016-0103-7
217. I. Unalan, S. Endlein, B. Slavik, A. Buettner, W.H. Goldmann, R. Detsch, A.R. Boccaccini, Evaluation of electrospun poly( $\varepsilon$-caprolactone)/gelatin nanofiber mats containing clove essential oil for antibacterial wound dressing. Pharmaceutics 11, 570 (2019). https://doi.org/10.3390/pharmaceutics11 110570

218. A. Lapa, M. Cresswell, I. Campbell, P. Jackson, W.H. Goldmann et al., $\mathrm{Ga}$ and $\mathrm{Ce}$ ion-doped phosphate glass fibres with antibacterial properties and their composite for wound healing applications. J. Mater. Chem. B 7, 6981-6993 (2019). https://doi.org/10.1039/C9TB00820A

219. I. Unalan, B. Slavik, A. Buettner, W.H. Goldmann, G. Frank, A.R. Boccaccini, Physical and antibacterial properties of peppermint essential oil loaded poly ( $\varepsilon$-caprolactone) (PCL) electrospun fiber mats for wound healing. Front. Bioeng. Biotechnol. 7, 346 (2019). https://doi.org/10.3389/fbioe 2019.00346

220. L. Yan, S. Si, Y. Chen, T. Yuan, H. Fan, Y. Yao, Q. Zhang, Electrospun in situ hybrid polyurethane/nano- $\mathrm{TiO}_{2}$ as wound dressings. Fibers Polym. 12, 207 (2011). https://doi. org/10.1007/s12221-011-0207-0

221. O. Galkina, Functional hybrid bionanomaterials based on titanium dioxide and cellulose, possessing antibacterial and drug delivery properties. Swedish University of Agricultural Sciences (2015). https://pub.epsilon.slu.se/12222/1/galki na_o_150518.pdf

222. S.L. Percival, P.G. Bowler, D. Russell, Bacterial resistance to silver in wound care. J. Hosp. Infect. 60, 1-7 (2005). https ://doi.org/10.1016/j.jhin.2004.11.014

223. F.E. Ciraldo, K. Schnepf, W.H. Goldmann, A.R. Boccaccini, Development and characterization of bioactive glass containing composite coatings with ion releasing function for antibiotic-free antibacterial surgical sutures. Materials 12, 423 (2019). https://doi.org/10.3390/ma12030423

224. V.H. Grassian, P.T. O'Shaughnessy, A. Adamcakova-Dodd, J.M. Pettibone, P.S. Thorne, Inhalation exposure study of titanium dioxide nanoparticles with a primary particle size of 2-5 nm. Environ. Health Perspect. 115, 397-402 (2007). https://doi.org/10.1289/ehp.9469 